\title{
Mass spectrometric investigation of metallothionein and ionic liquids using electrospray ion source coupled with quadrupole ion trap mass analyzer
}

Yuchen Lu

West Virginia University

Follow this and additional works at: https://researchrepository.wvu.edu/etd

\section{Recommended Citation}

Lu, Yuchen, "Mass spectrometric investigation of metallothionein and ionic liquids using electrospray ion source coupled with quadrupole ion trap mass analyzer" (2006). Graduate Theses, Dissertations, and Problem Reports. 4245.

https://researchrepository.wvu.edu/etd/4245

This Dissertation is protected by copyright and/or related rights. It has been brought to you by the The Research Repository @ WVU with permission from the rights-holder(s). You are free to use this Dissertation in any way that is permitted by the copyright and related rights legislation that applies to your use. For other uses you must obtain permission from the rights-holder(s) directly, unless additional rights are indicated by a Creative Commons license in the record and/ or on the work itself. This Dissertation has been accepted for inclusion in WVU Graduate Theses, Dissertations, and Problem Reports collection by an authorized administrator of The Research Repository @ WVU.

For more information, please contact researchrepository@mail.wvu.edu. 


\title{
Mass Spectrometric Investigation of Metallothionein and Ionic Liquids Using Electrospray Ion Source Coupled with Quadrupole Ion Trap Mass Analyzer
}

\author{
Yuchen Lu \\ Dissertation submitted to the Eberly College of Arts and Sciences \\ at West Virginia University \\ in partial fulfillment of the requirements for the degree of
}

Doctor of Philosophy

in

Chemistry

Fred L. King, Ph. D., Chair

Ronald B. Smart, Ph. D.

Aaron Timperman, Ph. D.

Bjorn Soderberg, Ph. D.

Patrick S. Callery, Ph. D.

C. Eugene Bennett Department of Chemistry

Morgantown, West Virginia

2006

Keywords: Electrospray Ionization, Quadrupole ion trap, Metallothionein, Ionic liquids.

Copy Right 2006 Yuchen Lu 


\section{ABSTRACT \\ Mass Spectrometric Investigation of Metallothionein and Ionic Liquids Using Electrospray Ion Source Coupled with Quadrupole Ion Trap Mass Analyzer}

Yuchen Lu

Electrospray is a well-developed ionization technique for transferring intact dissolved molecules from liquid into the gas-phase through a capillary emitter. As a 'soft' ionization method, intact molecules are transformed and are ready for mass identification and structure characterization. Quadrupole ion traps are versatile mass analyzers and are well-known for the capability to perform tandem mass scans by which the structural information can be obtained.

Collision-induced dissociation (CID) is applicable used in quadrupole ion trap to produce fragment ions. Metal-protein bond dissociation properties were studied by the tandem mass spectrometry. Binding properties of metal ions and ligand groups on peptide chains were studied. The chelating reagent EDTA was used to confirm the production of the free metal ions formed in the CID process by capturing them and forming complex ions which were detectable by the ion trap mass analyzer based on their large $m / z$ values.

Negative ion mode electrospray mass spectrometric studies of undiluted ionic liquid reveal the influence of water on the observed gas-phase population. Anions observed in addition to the pre-existing hexafluorophosphate anion result from a series of reactions initiated by hydrolysis of hexafluorophosphate. The mass spectral response shows a quantitative logarithmic relationship between signal intensities and the amount of water present, against which the water content could be rapidly assessed.

Positive ion mode electrospray mass spectrometric analysis of room temperature ionic liquids shows fragmentation of dialkylimidazolium cations resulting from alkyl elimination reactions that yield an $N$-methylimidazolium cation and a neutral alkene. This unimolecular dissociation reaction requires the formation of a cyclic transition state involving a proton on the leaving alkyl chain. The same process was observed in low 
energy collision-induced dissociation reactions of the isolated precursor ion in tandem mass spectrometry experiments.

The measurement of difference between the gas-phase ion intensity and the concentration of the solution provides an interesting approach to mass-analysis of the dissolved analytes in undiluted ionic liquids. Electrospray behavior of solution of neutral ferrocene and ferrocenium salt dissolved in ionic liquids is studied. 
To My Parents, Zongkai Lu \& Fuqin Wang

My Wife, Rong Hu

Baby Girl, Belle (Dou Dou)

With love 


\section{CONTENTS LISTING}

Title Page

$\begin{array}{ll}\text { Abstract } & \text { ii }\end{array}$

Dedication $\quad$ iv

Contents Listing $\quad$ V

Acknowledgement xii

Chapter 1. Introduction

1.1 Electrospray Ionization 1

1.2 Quadrupole Ion Trap Mass Analyzer 5

$\begin{array}{lll}1.3 & \text { Zinc-Metallothionein } & 10\end{array}$

1.4 Room Temperature Ionic Liquids 13

$\begin{array}{lll}1.5 & \text { References } & 15\end{array}$

Chapter 2. Mass Spectroemetric Study of Zinc-Metallothionein Binding Properties

2.1 Introduction $\quad 20$

2.2 Experimental Section 24

2.3 Results and Discussion $\quad 27$

2.4 Conclusion $\quad 47$ 
Chapter 3. A Zinc-Methallothionein Dimer Intermediate Found in Tandem Mass Spectrometry

3.1 Introduction

3.2 Experimental Section

Chapter 4. Electrochemically-Induced Reactions of Hexafluorophosphate Anions with Water in Negative Ion Electrospray Ionization Mass Spectrometry of Undiluted Ionic Liquids

4.1 Introduction

4.2 Experimental Section

4.3 Results and Discussion

4.4 Conclusion

4.5 References

Chapter 5. Elimination in Electrospray Ionization Mass Spectrometry of Imidazolium Based Ionic Liquids 
5.1 Introduction

Chapter 6. Detection of Ferrocene and Their salts Dissolved in Undiluted Ionic Liquids by Positive Ion Electrospray Mass Spectrometry

6.1 Introduction

6.2 Experimental Section

6.3 Results and Discussion

6.4 Conclusion 


\section{LIST OF FIGURES}

Figure

2.1 The full MS spectrum of the metallothionein molecule ions $\left(\mathrm{Zn}_{7}\right.$ $\mathrm{MT})^{4+}$ at buffer $\mathrm{pH} 8.0$.

2.2 The full MS spectrum of the pre-acidified metallothionein $\alpha$-cluster ions $\left(\mathrm{Zn}_{4}-\mathrm{MT}\right)^{4+}$ at buffer $\mathrm{pH}$ 7.0.

2.3 The MS/MS spectrum of the metallothionein molecule ions ( $\mathrm{Zn}_{7}-$ $\mathrm{MT})^{4+}$ at buffer $\mathrm{pH} 8.0$.

2.4 The MS/MS spectrum of the metallothionein molecule ions ( $\mathrm{Zn}_{6}$ MT-Zn-MT- $\left.\mathrm{Zn}_{6}\right)^{8+}$ at buffer $\mathrm{pH}$ 8.0.

2.5 The curves of intensities of the metallothionein species with different number of zinc vs. the relative collision energies at buffer $\mathrm{pH} 8.0$ were plotted. The parent ion was the metallothionein molecule ions $\left(\mathrm{Zn}_{7}-\mathrm{MT}\right)^{4+}$.

2.6 The curves of intensities of the metallothionein species with different number of zinc vs. the relative collision energies at buffer $\mathrm{pH} 7.7$ were plotted. The parent ion was the metallothionein molecule ions $\left(\mathrm{Zn}_{7}-\mathrm{MT}\right)^{4+}$.

2.7 The curves of intensities of the metallothionein species with different number of zinc vs. the relative collision energies at buffer $\mathrm{pH} 7.0$ were plotted. The parent ion was the metallothionein $\alpha-$ cluster ions $\left(\mathrm{Zn}_{4}-\mathrm{MT}\right)^{4+}$.

3.1 Electrospray mass spectrum of EDTA in solution of methanol at concentration of $10^{-6} \mathrm{M}$.

3.2 Mass spectra of EDTA freshly mixed with Zn-MT.

3.3 In-source CID MS on solution of EDTA and Zn-MT

3.4 CID MS of mixture of EDTA and Zn-MT shows the dimer of metallothionein formed.

4.1 Negative ion ES-MS of $\mathrm{BMIM}^{+} \mathrm{PF}_{6}{ }^{-}$at a) $3.0 \mathrm{kV}$, b) $3.7 \mathrm{kV}$, and c) $5.0 \mathrm{kV}$, each normalized to (a). Water content and flow rate were held constant at $0.24 \%(\mathrm{w} / \mathrm{w})$ and $0.3 \mu \mathrm{l} / \mathrm{min}$, respectively. 
4.2 Negative ion ES-MS of $\mathrm{BMIM}^{+} \mathrm{PF}_{6}{ }^{-}$spiked with $\mathrm{NH}_{4} \mathrm{OH}$ with $\left[\mathrm{OH}^{-}\right]$at a) $\left.0 \%(\mathrm{w} / \mathrm{w}), \mathrm{b}\right) 0.05 \%(\mathrm{w} / \mathrm{w})$, and c) $0.16 \%(\mathrm{w} / \mathrm{w})$, each normalized to (a). Water content, electrospray voltage, and flow rate were held constant at $2.03 \%(\mathrm{w} / \mathrm{w}), 3.7 \mathrm{KV}$, and $0.3 \mu \mathrm{l} / \mathrm{min}$, respectively.

4.3 Negative ion ES-MS of $\mathrm{BMIM}^{+} \mathrm{PF}_{6}{ }^{-}$at various flow rates, a) 5 $\mu \mathrm{l} / \mathrm{min}$, b) $3 \mu \mathrm{l} / \mathrm{min}$, and c) $0.3 \mu \mathrm{l} / \mathrm{min}$, each normalized to (a). Water content and electrospray voltage were held constant at 3.43 $\%(\mathrm{w} / \mathrm{w})$ and $5.0 \mathrm{kV}$, respectively.

4.4 Negative ion ES-MS of $\mathrm{BMIM}^{+} \mathrm{PF}_{6}{ }^{-}$at various water contents, a) $1.16 \%(\mathrm{w} / \mathrm{w}), \mathrm{b}) 2.56 \%(\mathrm{w} / \mathrm{w})$, and c) $3.43 \%(\mathrm{w} / \mathrm{w})$, each normalized to (a). Flow rate and electrospray voltage were held constant at $0.3 \mu \mathrm{l} / \mathrm{min}$ and $5.0 \mathrm{kV}$, respectively.

4.5 Relationship between extent of $\mathrm{PF}_{6}{ }^{-} / \mathrm{H}_{2} \mathrm{O}$ reaction and water content for $\mathrm{BMIM}^{+} \mathrm{PF}_{6}{ }^{-} \mathrm{ES}-\mathrm{MS}$ at $3.6 \mathrm{kV}$ and $4.6 \mathrm{kV}$ and at flow rate of 0.3 $\mu / \mathrm{min}$. The response of the fluorophosphates were weighted for mole equivalents of water required and the sum was normalized to the total ion current in each scan.

5.1 Positive ion ES/MS of dialkylimidazolium cation a) 1-hexyl-3methyl-imidazolium, b) 1-butyl-3-methyl-imidazolium, c) 1-ethyl3-methyl-imidazolium, and d) 1, 3-dimethyl-imidazolium.

5.2 Collision-induced dissociation mass spectra of $\mathrm{MMIM}^{+}$(upper) and $\mathrm{BMIM}^{+}$(bottom) at the same applied resonance excitation potentials.

6.1 Scheme of the set-up of the electrospray source with upstream ground current measurement. Two picoammeters $A_{1}$ and $A_{2}$ were used to record the electrospary currents. $\mathrm{R}$ is of an array of resistors. $\mathrm{P}$ is of injection pump. $\mathrm{HV}$ is of high voltage power supply. Picoammeter A2 is attached to the ion transfer tubing on the mass spectrometer.

6.2 Positive ion ESI-MS of undiluted $\mathrm{BMIM}^{+} \mathrm{BF}_{4}{ }^{-}$solution at spray voltage of $4.0 \mathrm{kV}$, injection flow rate of $3.0 \mu \mathrm{l} / \mathrm{min}$, and upstream grounding resistance of $10 \mathrm{G}$. Tthe measured total electrospray current is $1.2 \mu \mathrm{A}$. (a) ESI-MS of $\mathrm{Fc}^{+} \mathrm{BF}_{4}^{-}$(b) ESI-MS of ferrocene. (c) ESI-MS of $\mathrm{Fc}^{+}$in $\mathrm{BMIM}^{+} \mathrm{PF}_{6}^{-}$. 
6.3 Plots of total ion current (TIC) against the injection flow rate. Three curves are ploted at a) $4.99 \mu \mathrm{A}$, b) $1.62 \mu \mathrm{A}$, c) $1.20 \mu \mathrm{A}$.

6.4 Plots of ferrocenium ion current against the total current. Three curves are ploted at a) $0.5 \mu / \mathrm{min}$, b) $3 \mu / \mathrm{min}$, c) $5 \mu / \mathrm{min}$. 


\section{LIST OF TABLES}

2.1 The list of data shown in pictures of ions involved in experiments.

$3.1 \mathrm{~m} / \mathrm{z}$ value of EDTA in ESI-MS

3.2 list of fragment ions and their molecular weights.

6.1 Measured currents are listed 


\section{Acknowledgement}

I am indebted to my supervisor Dr Fred L. King and his professional guidance leading me into a marvelous world of science. Without his encouragement, I could have not taken over the challenge to work through my academic program. I would like to take this opportunity to thank Dr Douglas C. Duckworth, my mentor in the Chemical and Isotopic Mass Spectrometry (CIMS) group at Oak Ridge National Laboratory for his generous direction on my research experience.

I am grateful to my committee members: Dr Patrick S. Callery, Dr Ronald B. Smart, Dr Aaron Timperman, and Dr Bjorn Soderberg for their knowledge and help.

I am also thankful to the King group at West Virginia University and the CIMS group for creating such a supportive and friendly working environment. Special thanks should also be attributed to Dr Cris Lewis, Rosa Lewis, Dr Carol M. Babyak, Dr Glen P. Jackson, and Dr Lei Li for their professional and personal assistances. 
I wish to acknowledge financial support from the Eberly College of Arts and Sciences and the C. Eugene Bennett Department of Chemistry at West Virginia University. The research done in ORNL is sponsored by the Division of Chemical Sciences, Office of Basic Energy Sciences, U.S. Department of Energy, under contract No. DE-AC05-00OR22725 with Oak Ridge National Laboratory, managed and operated by UT-Battelle, LLC.

Foremost, I want to thank the support from my family. My parents have given me their endless love and encouragement. My wife deserves all I can say for her unselfish contribution to my life. I'd also like to thank my baby girl for her gorgeous smile and her cry. Without their love I would not be where I am today. 
This page was intended to be leaved as blank. 


\section{Chapter 1 . Introduction}

\subsection{Electrospray Ionization}

\subsubsection{A Historic Outlook}

In the early 1970's, research in areas such as organic chemistry, biophysics, and pharmacology was in need of a mass spectrometric technique that would afford the analysis of large, thermally labile molecules whose vaporization and ionization could not be achieved with the available electron ionization or chemical ionization sources. As a result of this need, methods such as fast atom bombardment [1], laser desorption [2], and plasma desorption [3], were developed to extend the utility of mass spectrometry to low volatility species. In some cases, however, the energy introduced into the compound via these techniques to achieve their transfer into gas phase resulted in localized energy densities sufficient to yield unwanted fragmentation. The problem remained until a 'soft' ionization method, electrospray ionization, was introduced by Fenn [4]. Electrospray 
ionization (ESI) achieves volatilization of intact molecular ions for relatively nonvolatile species with little if any internal energy introduction into the analyte. Via this method, fragile and hydrophilic molecules, especially polypeptides, could be transferred readily into the gas phase intact from the aqueous environment. An added benefit was that ESI endowed ions with a wide range of charge states, from single charged alkali metal ions to multi-charged bioorganic macromolecules with masses greater than or equal to 100,000 Da. The extensive charging of the latter species affords the implementation of low range mass analyzers in their characterization. Throughout the past 15 years of development, ESI has emerged as the premier ionization source for biological mass spectrometry.

\subsubsection{Fundamentals of Electrospray Ionization}

Generally, an electrolytic solution containing the analyte is injected into a capillary emitter. A spray voltage is applied to the electrolytic solution through either a metal capillary emitter or a conductive wire where a silicon capillary emitter was involved. In the latter case, the conductive wire is integrated into the capillary. The counter electrode, a metal plate with an orifice or embedded capillary, serves as the ion sampling orifice for the mass analyzer and is set about $2 \mathrm{~cm}$ away from the emitter tip. The strong electric field formed between the emitter and the counter electrode penetrates the solution and 
attracts oppositely charged ions until field free conditions are established inside the solution. For simplicity, this discussion will focus on positive mode electrospray ionization. Positive ions concentrate on the surface layer of solution at the emitter tip. As the electronic repulsion between the ions approaches the surface tension of the solution, the solvated ions pull the solution toward the counter electrode forming a so-called Taylor cone [4b]. As the charge repulsion increases, owing to the imposed electric field, the surface tension is exceeded and fine droplets carrying net positive charges evaporate from the Taylor cone tip. At this point the spray droplets are desolvated to yield intact molecular ions. Two mechanisms have been proposed for this desolvation, the charged residue mechanism [4c] and the ion evaporation mechanism [4d].

\section{a) Charged Residue Mechanism}

The charged residue mechanism is akin to the process by which inkjet printers operate. Electrospray of volatile solutions can be explained straightforwardly based on this mechanism. As the charged droplets pass through the air, evaporation of the solvent causes the further shrinkage of the droplets, resulting in higher charge densities. With this increasing charge density, the electronic repulsion eventually exceeds the Rayleigh 
stability limit [5], and the droplet undergoes fission. The repeating cycle of the solvent evaporation and droplet fission processes finally yields the desolvated gas-phase ions.

\section{b) Ion Evaporation Mechanism}

The ion evaporation mechanism is not completely distinct from the charged residue mechanism because it also depends on electronic repulsion. Iribane and Thomson, as well as other workers, $[6,7,8,9,10,11,12]$ based this explanation for electrospray ionization on transition state theory. The required free energy of activation represents the noncovalent bindings of analyte ions with solvent, e.g. electrostatic attraction between the emitted ions and the polarizable solvent. The repulsion of ions by the other charges in the droplet is the driving force for their evaporation. Once the activation energy barriers are overcome, ions are emitted directly into the gas phase from the surface of these charged fine droplets. A derived equation predicts the relation of the emission rates of ions with their free energies of activation. The advantage of this method is that it provides a theoretical explanation within the framework of classic electrostatics and thermodynamics. Those species with high surface activities [13] or those emitted from non-volatile solution [14] are likely to escape from the solvent in this way. 


\subsection{Quadrupole Ion Trap Mass Analyzer}

Invented in early the 1950's, the quadrupole ion trap mass spectrometer (ITMS) typically consists of three hyperbolic electrodes. Two are identical endcaps working as entrance and exit orifices and the third is a ring electrode. In the beginning, the difficulty in machining perfect hyperbolic surfaces restricted the development and performance of the instruments and limited their usage in chemical analysis. In the 1980's, this easy-to-use, inexpensive, baseball-sized mass analyzer became commercially available. As a mass analyzer it offers flexibility and sensitivity for the characterization of complex mixtures of inorganic, small organic and biomolecules.

\subsubsection{Basics of Quadrupole Ion Trap}

The ion trap is composed of a ring electrode sandwiched between the two endcaps. Externally generated gas-phase ions are introduced into the trap through the inlet in the entrance endcap and are trapped through action of all three electrodes. Various types of voltages applied to these electrodes result in the formation of a trapping potential cavity. A fundamental RF signal, of constant frequency but with a ramping amplitude, 
combined with a DC signal applied on the ring electrode produce a 3D quadrupolar potential field within the trap. This field traps the ions in a stable oscillating trajectory. The stability depends on the ion's mass-to-charge ratio, $\mathrm{m} / \mathrm{z}$, the size of the trap field, as well as the frequency and the amplitude of the fundamental RF potential applied to the ring electrode. A dimensionless parameter $q_{Z}$ is calculated from these values and determines the stabilities of the ions.

$$
q_{z}=4 e V / m r^{2} w^{2}
$$

For a single ion, the value of $q_{Z}$ can only vary with the RF amplitude due to the fixed physical size of the trap and the fixed frequency of the RF signal. In this case, ion trapping and ejection will be achieved by varying the RF amplitude.

A physical 'cooling' of the ions to improve their stability is achieved by introducing about 1 mtorr of helium into the trap. The helium 'damping gas' reduces the ion kinetic energy and efficiently contains the ion trajectory in the center of the trap. [15] This helps to improve the mass resolution of the resulting mass spectra because ions with single mass-over-charge values are ejected more efficiently in an ion packet formed in a tighter trajectory than those in a diffuse ion cloud. 
Ion trap mass analysis was first achieved by operation in the so-called 'mass-selective stability' mode which is analogous to the operation of a quadrupole mass filter. [16] In this mode, the amplitudes of the RF and DC voltages applied to the ring electrode are ramped at a constant $\mathrm{RF} / \mathrm{DC}$ ratio to allow stability, hence storage, of a single (increasing) $\mathrm{m} / \mathrm{z}$ value in the ion trap. The real power of ion trap mass spectrometry was not realized until the development of the 'mass-selective instability' operation mode. [18] The fundamental difference from the 'stability' mode of operation is that during the performance of mass analysis, all ions created by an ion source in a given time window are trapped simultaneously and then sequentially ejected out to the detector, unlike the mass-selective stability mode where only one value of $\mathrm{m} / \mathrm{z}$ at a time was stored and ejected. This 'instability’ mode extends usage of ion trap mass analyzers because it can work with both continuous and pulsed ion sources.

For ion detection, the potential applied on the ring electrode is ramped to axially excite the ion motions resulting in ejection of the ions through the exit endcap. The sequential ejection in order of increasing $\mathrm{m} / \mathrm{z}$ produces the mass spectrum. However, simply increasing the RF potential runs up to a limit at which electrical breakdown occurs in the trap. This limits the upper end of the mass range over which the ion trap mass analyzer can operate. This problem was resolved by introducing axial modulation operation mode. 
In this mode a supplementary ac potential is applied to the endcaps. This results in excitation of the trapped ions if its frequency matches the secular frequency of those ions. Increasing the amplitude of the supplementary potential, higher kinetic energy will be introduced into ions by resonance excitation until those ions become instable. This instability will lead to the ejection of ions. When the amplitude of the supplementary potential is too low to cause excitation ejection, the ions gaining extra kinetic energy collide with helium damping gas and then fragment randomly. Such fragmentation is generally referred to as collision induced dissociation (CID). Through the use of CID it becomes possible to examine the structure of macromolecules utilizing the quadrupole ion trap mass analyzer.

\subsubsection{Multi-stage MS for Structural Study}

The modern ability to selectively trap, excite, and eject mass selected ions makes the ion trap especially suited to perform $\mathrm{MS}^{\mathrm{n}}$ experiments for structural elucidation. The process begins by selectively isolating ions with a particular $m / z$ in the trap while ejecting all other ions. Fragmentation of this isolated precursor ion can then be induced by CID experiments, as described above. The isolation and fragmentation steps can be repeated multiple times, only limited by the trapping efficiency of the instrument. 
The technique provides a probe for primary protein structure through the dissociation of peptide bonds and mass analysis of the resulting fragments. By introducing a smaller amount of energy, the relatively weak bond between the metal and ligand group can be broken while the peptide backbone is retained intact. It is possible to isolate intermediate ions that have resulted from fragmentation and to analyze these daughter ions in a controlled fashion during tandem MS scans. 


\subsection{Zinc-Metallothionein}

Metallolthionein (MT) is a family of small polypeptides containing 61-68 amino acids with an unusually high concentration of cysteine (30\%). Cysteine contains a thiol group (SH) that has the ability to react with a number of metals including zinc, mercury, copper and cadmium. MTs are thought to function as intracellular distributors and mediators of copper and zinc, as well as playing a major role in heavy metal detoxification. $[18,19$, $20,21]$.

By binding and releasing zinc, metallothioneins (MTs) regulate its level within the body. Zinc, in turn, is a key element for the activation and binding of certain transcription factors through its participation in zinc fingers. Metallothionein also transports zinc ions (signals) from one part of the cell to another. When zinc enters a cell, it can be picked up by thionein which thus becomes "metallothionein" and carried to another part of the cell where it is released to another organelle or protein. In this way the thioneinmetallothionein becomes a key component of the zinc signaling system in cells. This system is particularly important in the brain, where zinc signaling is prominent both between and within nerve cells. 
Metallothionein (MT) detoxifies mercury and heavy metals by binding to the metal before it can cause harm. It forms subcellular inclusions or crystals which act jointly to consolidate and enclose excess metals. These inclusions then accumulate within tissues or skeletal structure over time. [22, 23, 24, 25, 26, 27]

Electrospray ionization, ESI, coupled with an ion trap mass spectrometer, ITMS, was used to study the zinc-thiolate complex binding properties in metallothionein zinc salt $\left(\mathrm{Zn}_{7}-\mathrm{MT}\right)$. Tandem MS was performed to study the interaction between the $\mathrm{Zn}$ and peptide. Internal energies required to induce dissociation of the complex of $\mathrm{Zn}$ (II) with peptide were evaluated. The protein conformation in solution influences the overall charge state observed in electrospray ionization mass spectra. The charge state of the most abundant species observed in ESI-ITMS is found to decrease with decreases in $\mathrm{pH}$ of the buffer. Whereas the MT can be unfolded by demetallization, the unfolded system accepted more charges. The MT dimer was formed by combining a $\mathrm{Zn}_{\mathrm{m}}-\mathrm{MT}$ ion and a $\mathrm{Zn}_{\mathrm{m}-1}-\mathrm{MT}$ ion through an intermolecular zinc-thiolate bridge. The change in CID behavior showed the influence of the three-dimensional conformational structure on the CID reaction. The unfolded peptide ions received the collision energy and quickly relaxed by the sequential release of the zinc ions. The folded system could accumulate the energy at a relatively lower collision energy level until one or more of the zinc ions 
released simultaneously because it was unable to efficiently release the energy received by collision. 


\subsection{Room Temperature Ionic Liquids}

Composed entirely of organic cations and inorganic complex anions, room temperature ionic liquids (ILs) have attracted tremendous attention as novel solvents. The most commonly investigated cations are $N, N$-dialkylimidazolium, $N$-alkylpyridinium, and tetra-alkyl-ammonium. Common anions are tetrafluoroborate $\left(\mathrm{BF}_{4}{ }^{-}\right)$, hexafluorophosphate $\left(\mathrm{PF}_{6}^{-}\right)$, bis[(trifluoromethyl)sulfonate $]$amide $\left(\mathrm{TF}_{2} \mathrm{~N}^{-}\right)$, and trifluoroethanoate $\left(\mathrm{CF}_{3} \mathrm{CO}_{2}^{-}\right)$. These salts display unique properties in addition to being liquid at room temperature. These include negligible vapor pressure, wide electrochemical window, and high ionic conductivity. As an alternative to aqueous or organic solvents, ILs are thought to hold much promise for green chemistry applications.

ILs are effective solvents for both organic and inorganic materials. Another unique feature is the ability to solvate very different types of species in one medium to enable reactions that would not be possible in traditional solvent systems. Currently, IL's are being developed for applications such as polymer synthesis [28, 29, 30], catalysis [31, 32], electrochemical reactions [33]. The fact that ionic liquids are immiscible with a number of aqueous or organic solvents but exhibit good solubility with for a range of 
chemical species makes them an interesting inert extraction phase.[34] Because of their low volatility coupled with their excellent solvent ability, ILs are a good vacuum compatible matrix for matrix-assisted laser desorption/ionization. [35, 36, 37, 38, 39] 


\subsection{References}

1. Barber, M.; Bordoli, R. S.; Elliot, G. J.; Sedgwick, R. D.; Tyler, A. N. Anal. Chem., 1982, 54, 645A.

2. Karas, M.; Bachmann, D.; Hillenkamp, F. Anal. Chem. 1985, 57, 2935.

3. Hilf, E. R. Int. Journal of Mass Spectrometry and Ion Processes, 1993, 126, 25.

4. (a) Fenn, J. B.; Mann, M.; Meng, C. K.; Wong, S. F.; Whitehouse, C. M. Science, 1989, 246, 64. (b) Dole, M. Mack, L. L.; Hines, R. L.; Mobley, R. C.; Ferguson, L. D. Alice, M. B.; J. chem.. Phys. 1968, 49, 2240. (c) Iribarne, J. V.; Thomson, B. A.; J. Chem. Phy. 1976, 64, 2287. (d) Taylor, G. I.; Proc. R. Soc. London A 1964, 280, 383.

5. $\quad$ Lord Rayleigh, Philas. Mag. 1882, 14, 184.

6. Fenn, J. B.; Mann, M.; Meng, C. K.; Wong, S. F.; Witehouse, C. M. Science, 1989, 246, 64.

7. Iribarne, J. V.; Thomson, B. A.; J. Chem. Phy. 1976, 64, 2287.

8. Thomson, B. A.; Iribarne, J. V.; J. Chem. Phy. 1979, 71, 4451. 
9. Ikonomou, m. g.; Blades, A. T.; Kebarle, P. Anal. Chem. 1991, 63. 1989.

10. Hiraoka, K. Rapid Commun. Mass Spectrom. 1992. 6. 463.

11. Sakairi, M.; Yergey, A. L.; Siu, KWM; LeBlanc, JCY; Guevremont R.; Berman, RS Anal Sci 1991, 7, 199.

12. Rafaelli, A.; Bruns, AP Rapid Commun. Mass Spectrom. 1991, 5, 269.

13. Fenn, JB; J Am Soc. Mass Spectrom. 1993, 4, 524.

14. Romero-Sanz, I; Bocanegra, R; Fernandel de la Mora, J; Gamero-Castaño, M. J of Appl. Phys. 2003, 94, 3599.

15. Louris, J.N., Cooks, R.G., Syka, J.E.P., Kelley., P.E., Stafford, G.C., Jr. and Todd, J.F.J. Analytical Chemistry 1987, 59, 1677-1685

16. Dehmelt, H. Physica Scripta 1995, T59, 87 -92.

17. Stafford, G.C., Jr., Kelley, P.E., Syka, J.E.P., Reynolds, W.E. and Todd, J.F.J. (1984) International Journal of Mass Spectrometry and Ion Processes 1984, 60, 85-98

18. Arseniev, A.; Schultze, P.; Worgotter, E.; Braun, W.; Wagner, G.; Vašák, M.; Kagi, J. H. R.; Wuthrich, K. J. Mol. Biol. 1988, 214, 637-657. 
19. Robbins, A. H.; McRee, D. E.; Williamson, M.; Collett, S. A.; Xuong, N.

H.; Furey, W. F.; Wang, B. C.; Stout, C. D. J. Mol. Biol. 1991, 221, 12691293.

20. Kagi, J. H. R.; Schaffer, A. Biochemistry 1988, 27, 8509-8515.

21. Zangger, K.; Shen, G.; Oz, G.; Otvos, J. D.; Armitage, I. M. Biochem. J. 2001, 359, 353-360.

22. Hathout, Y.; Fabris, D.; Fenselau, C. Int. J. Mass Spectrom. 2001, 204, 1-6.

23. Krizek, B. A.; Merkle, D. L.; Berg, J. M. Inorg. Chem. 1993, 32, 937-940.

24. Yu, X.; Wojciechowski, M.; Fenselau, C. Anal. Chem. 1993, 65, 1355-1359.

25. Zaia, J.; Fabris, D.; Wei, D.; Karpel, R. L.; Fenselau, C. Protein Science 1998, 7, 2398-2404.

26. Fabris, D.; Zaia, J.; Hathout, Y.; Fenselau, C. J. Am. Chem. Soc. 1996, 118, 12242-12243.

27. Loo, J. A. Mass spectrum. Rev. 1997, 16, 1-23.

28. H. Zhang, K. Hong and J. W. Mays, Macromolecules 2002, 35, 5738.

29. C. Guerrero-Sanchez, S. Ulrich, Polymer Preprints (American Chemical Society, Division of Polymer Chemistry 2004, 45, 321. 
30. M. J. Muldoon, C. M. Gordon, Journal of Polymer Science, Part A: Polymer Chemistry 2004, 42, 3865.

31. Z. Fei, D. Zhao, R. Scoelliti and P. J. Dyson, Organometallics 2004, 23, 1622.

32. X. Mu, J. Meng, Z. Li, Y. Kou, Journal of the American Chemical Society 2005, 127, 9694.

33. U. Schröder, J. Wadhawan, R. Compton, F. Marken, P. A. Z. Suarez, C. S. Consorti, R. F. de Souza and J. Dupont, New J. Chem.2000, 24, 1009.

34. S. Dai, Y. Ju and C. Barnes, J. Chem. Soc. Dalton Trans. 1999, 8, 1201.

35. L. S. Santos, R. Haddad, N. F. Höehr, R. A. Pilli and M. N. Eberlin, Anal. Chem. 2004, 76, 2144.

36. Y. Li, M. L. Gross, F. Hsu, Journal of the American Society for Mass Spectrometry 2005, 16, 679.

37. M. abet-Moghaddam,R. Krueger,E. Heinzle, A. Tholey, Journal of Mass Spectrometry 2004, 39, 1494.

38. M. Mank, B. Stahl, G. Boehm, Analytical Chemistry 2004, 76, 2938.

39. S. Carda-Broch, A. Berthod, D. W. Armstrong, Rapid Communications in Mass Spectrometry : RCM 2003, 17, 553. 
40. D. W. Armstrong, L. K. Zhang, L. He, M. L. Gross, Analytical Chemistry 2001, 73, 3679. 


\section{Chapter 2 Mass Spectrometric Study of Zinc- metallothionein Binding Properties}

\subsection{Introduction}

Metallothioneins (MTs) with a characterized molecular weight of 6000-7000 Da. are present in many animals and plants. They contain 60 to 68 amino acid residues, among them 20 Cysteine groups. These specific amino acid residue groups bind up to seven equivalents of bivalent metal ions such as $\mathrm{Zn}^{2+}, \mathrm{Cd}^{2+}$, and/or $\mathrm{Cu}^{2+}$. In the studies of the three-dimensional structure of metallothionein, a two-domain model has been accepted based on NMR [1] and X-ray crystallography [2] results. The carboxyl terminal domain contains eleven cysteine thiolate groups with which four bivalent ions bind to form a four-metal cluster, $\mathrm{M}_{4} \mathrm{~S}_{11}$, named as $\alpha$-domain. The letters $\mathrm{M}$ and $\mathrm{S}$ stand for metal ion and thiolate group in Cysteine residue respectively. The $\beta$-domain, $\mathrm{M}_{3} \mathrm{~S}_{9}$, is a three-metal .cluster in which nine cysteine thiols and three ions form the amino terminal domain of 
MT. The evenly sized and nearly circular $\alpha$ - and $\beta$-domains have diameters of $15-20 \AA$ [3].

It has been shown that all of seven tetrahedral complexes of divalent metals with thiol groups are required for proper folding of this protein [3]. The MTs hold the respective metal-thiolate complexes as several mineral centers around which peptide chains are wrapped. The three-dimensional structure of metallothionein was affected by the metalthiolate binding. The mechanism of ligand binding to the specific ions is fundamental to our understanding of their biological function as well as poly-peptide synthesis.

Metal binding in MTs has a high thermodynamic, but low kinetic stability [4]. It is very tight, but the metal elements are labile for metal exchange with other proteins. The Fenselau group published research about stoichiometry in zinc ion transfer between different zinc finger peptides [5] showing that zinc ions were transferred extensively. The affinity constants for the metallo-peptide are in the range of $k a=10^{11} \mathrm{M}^{-1}$ [6]. It has been proposed that the transportation of zinc ions between the metallothioneins occurs in protein/protein complexes by way of ligand substitution. This mechanism allows for the existence of intermediates in which the two MTs share one zinc ion. Therefore, the 
dissociation constants published for the metallopeptide are the result of the dissociation of a few zinc ions.

It was impossible to isolate the intermediate that lost one metal ion from the fully metallated MT molecule and to measure the energy exchanged during that single step of release of the metal species. Therefore, two assumptions were made, that the binding energy of each metal-thiolate complex was the same and that changes in conformation structure caused by loss of the metal "core" did not affect the binding properties of the rest of the complex. To study the binding property in more detail, an alternative method is needed to isolate the intermediates with different numbers of coordinated metals and to obtain measurements of energy exchange during each step of dissociation from its parent.

Electrospray ionization, ESI, is a soft ionization method by which gas phase ions can be extracted from solution intact. ESI-MS was first utilized to study metallothionein in 1993 [7]. Since then, it has been used to monitor the metal ion flux between MT and their modified version [8], to study the internal structure of the MT zinc coordination center [9], and to investigate various non-covalently bound protein complexes [10]. 
Collision induced dissociation (CID) allows for the introduction of controlled amounts of energy into an analyte ion. This is widely employed in tandem mass spectrometry (MS/MS) of proteins when peptide bonds with different binding energy are induced to fragment by varying the CID energy. Mass analysis of the resulting fragments provides primary structural information regarding the protein. It is also practical in CID-MS to introduce a smaller amount of energy into the metalloprotein complex sufficient to break the relatively weak bond between the metal and ligand group while retaining the peptide backbone intact. This should permit the use of ESI-ITMS to probe the controlled release of metals from metallothioneins and characterize the intermediate products.

Experiments were performed in which tandem mass spectrometry was employed to study the binding properties of zinc ions with their ligand groups on the peptide chains. CID was used to achieve required activation energies in the dissociation reaction of every equivalent metal ion. Internal energies required inducing dissociation of the complex and the energy released in the complexation of $\mathrm{Zn}$ (II) with the peptides were evaluated. An estimation of the influence of the change in a three-dimensional conformation structure on the dissociation of zinc-thiolate complex was developed through these studies. 


\subsection{Experimental}

ESI-ITMS experiments were performed using a quadrupole ion trap mass spectrometer $\left(\mathrm{LCQ}^{\circledR}\right.$, Thermo-Finnigan, San Jose, CA). Sample was introduced using direct infusion through a $250 \mu$ syringe (Hamilton, Reno, NV) syringe. $\mathrm{LCQ}^{\mathrm{TM}}$ software was used for mass spectra deconvolution and molecular mass calculations. A pH meter, (Model AP5, Fisher Scientific, Fairlawn, NJ) equipped with a glass pH/ATC electrode was employed for the $\mathrm{pH}$ measurements.

Metallothionein zinc salt $\left(\mathrm{Zn}_{7}-\mathrm{MT}\right)$ from rabbit liver was used as purchased (SigmaAldrich Chemical, St. Louis, MI) without further purification. Ammonium bicarbonate $\left(\mathrm{NH}_{4} \mathrm{HCO}_{3}\right.$, F.W. 79.06) (Fisher Scientific, Fairlawn, NJ) was used to adjust the pH value of the sample solution. High purity helium served as the collision gas in the ion trap.

A stock solution of $\mathrm{Zn}_{7}-\mathrm{MT}$ was prepared by dissolving $0.2 \mathrm{mg}$ of the Metallothionein-II zinc salt in $2.00 \mathrm{~mL}$ of deionized water. This solution was stored in the refrigerator at 3 ${ }^{\circ} \mathrm{C}$. Working solutions of $\mathrm{Zn}_{7}-\mathrm{MT}$ were prepared daily by dilution of the stock solution yielding final concentrations of $5 \sim 10 \mu \mathrm{M}$ in an $\mathrm{NH}_{4} \mathrm{HCO}_{3}$ buffer solution. The $\mathrm{pH}$ of 
the resulting solution was varied for the experiments described below. A stock solution of $\mathrm{Zn}_{4}-\mathrm{MT}$ was prepared by pre-acidification of the $\mathrm{Zn}_{7}-\mathrm{MT}$ stock solution in an acetic acid buffer at $\mathrm{pH}$ 3.5. The working solutions of $\mathrm{Zn}_{4}-\mathrm{MT}$ were made by dilution of this solution in the same $\mathrm{NH}_{4} \mathrm{HCO}_{3}$ buffer mentioned above.

The metallothionein zinc salt solution was introduced into the ESI assembly by direct infusion at a flow rate of $2 \mu / \mathrm{min}$. ESI operating conditions were as follows: ion spray voltage $=4.2 \mathrm{kV}$, heated capillary temperature $=150{ }^{\circ} \mathrm{C}$ and heated capillary voltage $=$ 21.00 V respectively. Nitrogen was employed as a sheath gas to help nebulize the sample solution into a fine mist as the sample solution exited the ESI nozzle. Ions were transferred to the ion trap through the quadrupole gate during the ion accumulation period.

Following an ion accumulation period of $5 \sim 8 \mathrm{~s}$, protonated metallothionein ions were isolated while a relatively broad ion isolation window (i.e. several mass-to-charge ratio units) was employed to avoid collisional activation of the parent ion by off-resonance power absorption during the isolation step $[11,12]$. After a cooling period, target ions with negligible kinetic energy were left in the ion trap for the CID step. 
Analyte ions in the mass analyzer are accelerated to obtain sufficient kinetic energy so that when they collide with the helium damping gas, they undergo dissociation to yield product ions. The kinetic energy of the ion when it interacted with He was expressed in terms of percent relative collision energy (RCE \%). RCE ranging from $0 \%$ to $100 \%$ is proportional to $0 \mathrm{~V}$ to $5 \mathrm{~V}$ peak-to-peak potential applied onto the endcaps. Product ion spectra were recorded as a function of the RCE \%. The value window of the RCE \% was carefully chosen to assure that the collision induced dissociation of the zinc-sulfhydryl bond was the only reaction during the dissociation steps. 


\subsection{Results and discussion}

\subsubsection{ESI-MS of metallothionein zinc salt.}

Figure 2.1 shows a typical ESI mass spectrum obtained from the rabbit $\mathrm{Zn}_{7}-\mathrm{MT}$ at $\mathrm{pH}$ 7.7. The average molecular weight of $\mathrm{Zn}_{7}-\mathrm{MT}$ based on the mass spectral data is 6560.4 . The calculated result is 6561.1 . The major peak at $m / z 1640.1$ was of the molecular ion with the charge of $4+$. No peak with a charge state of $5+, m / z 1311.2$, or greater, was observed. This is likely due to the weakly basic or neutral buffer used in our experiments. In studies of $\mathrm{Zn}_{7}-\mathrm{MT}$ at $\mathrm{pH} 4$ [7], Yu, et al observed the most abundant ESIMS peak corresponding with a charge of $6+$. The same group [13] also found that ions with a charge of 5+ were the dominant species observed in ESI-MS when a higher $\mathrm{pH}$ of 7.4 was involved. The shifts in the charge state distribution were attributed to a conformational unfolding that results from the breaking of interactions that maintain the tertiary structure of the protein. The unfolded protein exposes basic functional groups, which are hindered in the original state, to the solvent for protonation. The conclusion that a protein's conformation in solution influences the charge state distribution observed in ESI-MS is consistent with a number of studies [14]. 


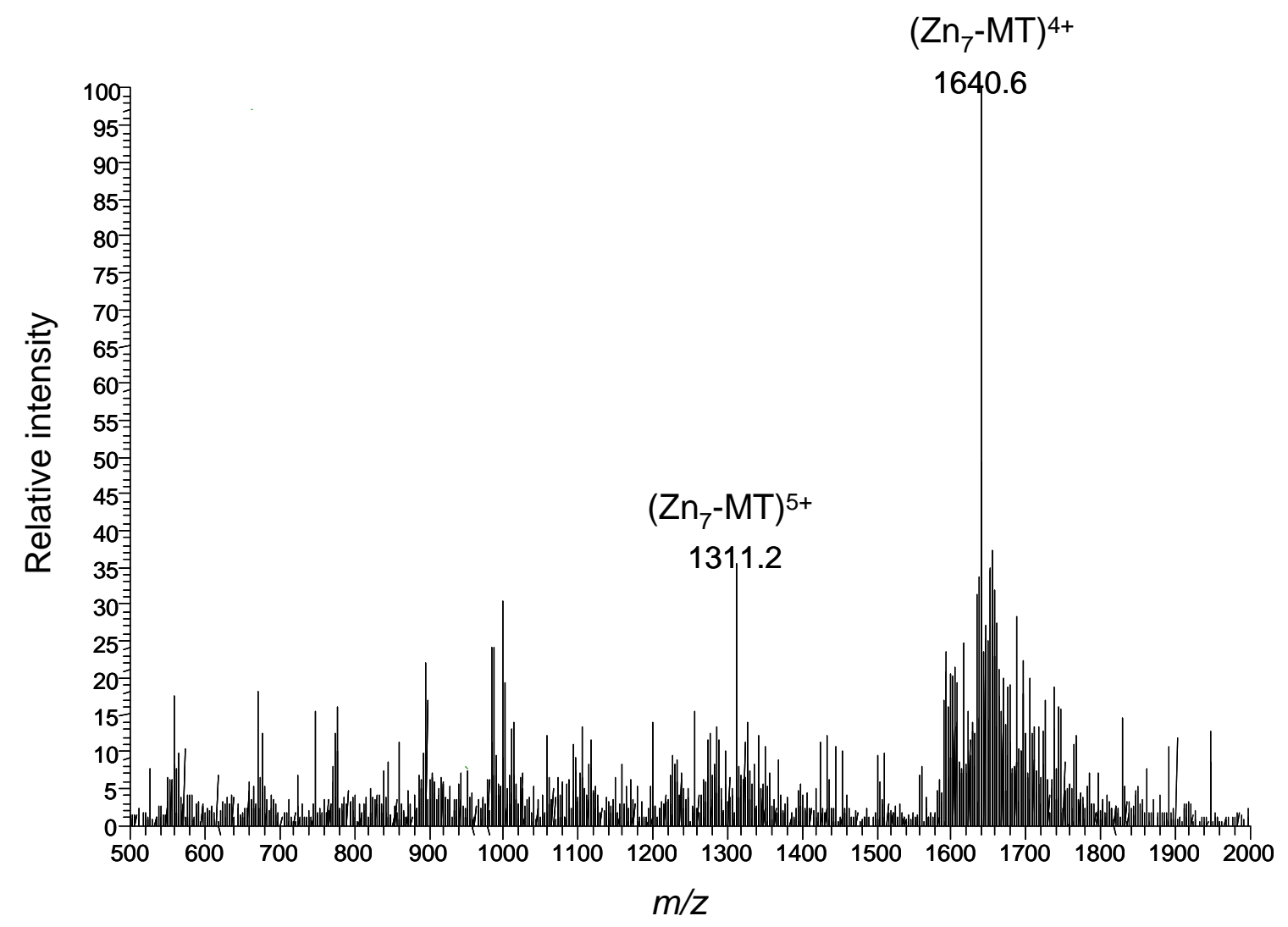

Figure 2.1 The full MS spectrum of the metallothionein molecule ions $\left(\mathrm{Zn}_{7^{-}}\right.$ $\mathrm{MT}^{4+}$ at buffer $\mathrm{pH}$ 8.0. 
The stability of the zinc metallothionein complex was known to be dependent on the solution $\mathrm{pH}$, with complete demetallation of $\mathrm{Zn}^{2+}$ occurring below $\mathrm{pH} 3$ [15]. Therefore, neutral and basic buffers were carefully chosen in order to retain the zinc ions and the integrity of the complex during the electrospray ionization process. As shown in Figure 2.1, the conclusion that the possibility of fragmentation of zinc-thiolate bonds or peptide bonds can be excluded in ESI-MS absent CID is reasonable as the intact protein ions were the major observed species. The spectrum affords no evidence that the metallothionein peptide backbone undergoes fragmentation or that metal ions were released from the complex.

The work done by Kagi and Hunziker indicated a considerable difference in thermodynamic stability between $\alpha$ and $\beta$ clusters in metallothionein [16]. The three zinc ions in the $\beta$-domain are lost first when the buffer $\mathrm{pH}$ is changed significantly or when energy is put into the polypeptide. The spectrum shown in Figure 2.2 was obtained from a solution of the MT at $\mathrm{pH}$ 7.0. The sample was neutralized and diluted from stock solution being pre-acidified in aqueous buffer at $\mathrm{pH} 3.5$. The peak at $\mathrm{m} / \mathrm{z} 1592.6$ corresponds to a MT species of $\mathrm{Zn}_{4}-\mathrm{MT}$ with a charge of $4+$, and the most abundant peak 
at $m / z, 1273.4$ belongs to the same species at a charge state of $5+$. The peak at $\mathrm{m} / \mathrm{z} 1639.2$ is close to the $m / z, 1640.1$ corresponding to the molecular ion of $\mathrm{Zn}_{7}-\mathrm{MT}$ with a charge of 4+ and its intensity is low compared to that of $\mathrm{Zn}_{4}-\mathrm{MT}$ with 4+ charges.

The zinc-thiolate clusters play a very important role in determining the structure of the metallothionein zinc complex. The metal-thiolate clusters work as "folding centers" around which the polypeptide chains are folded. This means that the $\mathrm{Zn}_{7}-\mathrm{MT}$ will lose part of its original conformation if any of the seven zinc ions is removed or any of the zinc-thiolate tertiary complexes are destroyed. In other words, the MT is folded when it is metallated and it can be unfolded by demetallation [7]. In comparison with fully

metallated MT, $\mathrm{Zn}_{4}$-MT appeared to be unfolded, exposing more basic sites with which protons could bind. Therefore, the charge state distribution could shift to a lower $\mathrm{m} / \mathrm{z}$, higher charge state, as the MT lost more "folding centers". As shown in Figure 2.1-2, the most abundant charge state observed in ESI-MS increased from 4+ for $\mathrm{Zn}_{7}-\mathrm{MT}$ to 5+ for $\mathrm{Zn}_{4}-\mathrm{MT}$ 


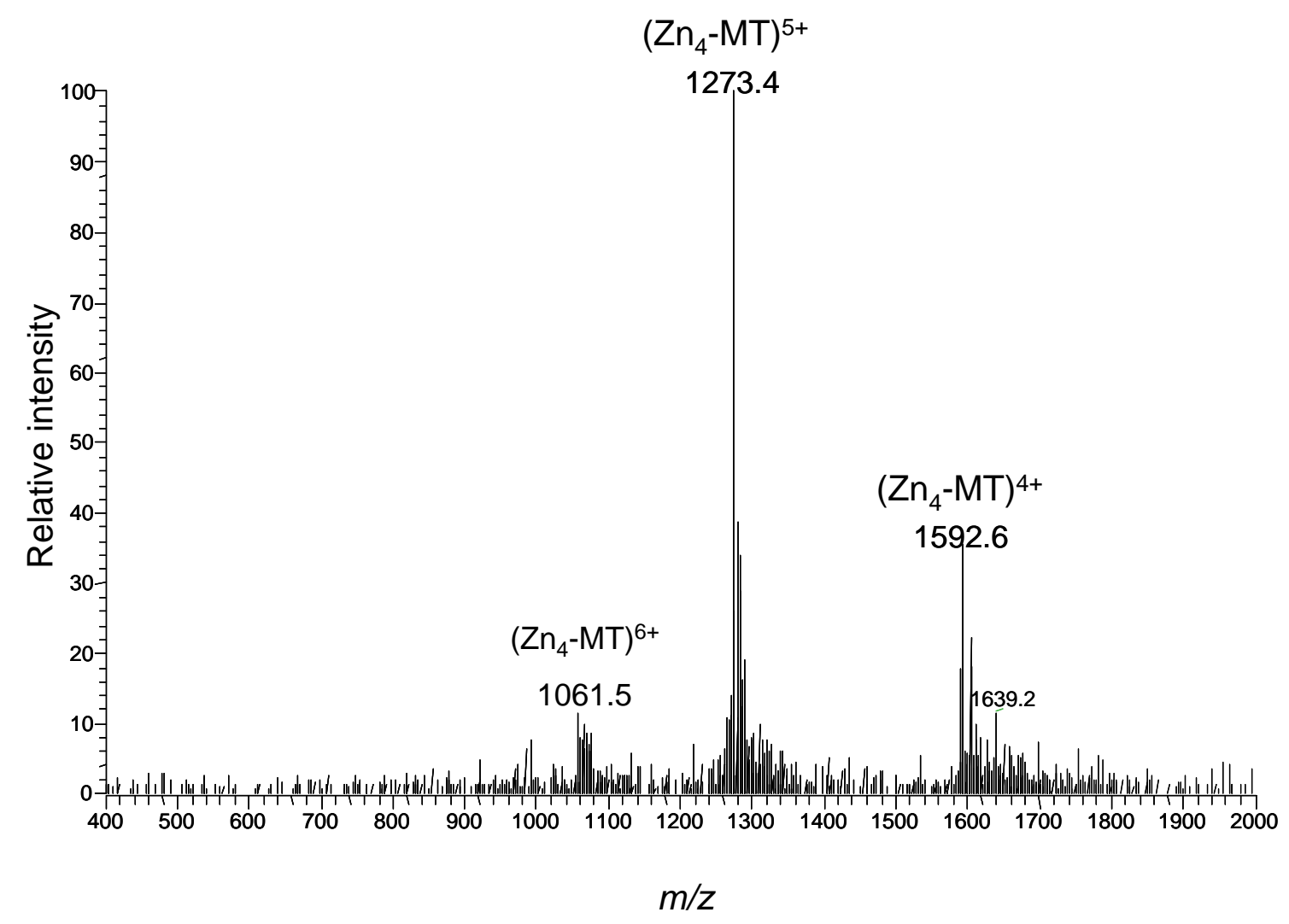

Figure 2.2. The full MS spectrum of the pre-acidified metallothionein $\alpha$ cluster ions $\left(\mathrm{Zn}_{4}-\mathrm{MT}\right)^{4+}$ at buffer $\mathrm{pH}$ 7.0. 


\subsubsection{Tandem Mass Spectrometry of metallothionein zinc salts}

Several ions, such as $\left(\mathrm{Zn}_{4}-\mathrm{MT}\right){ }^{4+},\left(\mathrm{Zn}_{4}-\mathrm{MT}\right){ }^{5+}$, and $\left(\mathrm{Zn}_{7}-\mathrm{MT}\right){ }^{4+}$, were chosen as the parent ions to be examined in MS/MS experiments. The differences in the zinc-thiolate binding properties between $\alpha$ and $\beta$ clusters were differentiated by study of the MS/MS spectra of $\mathrm{Zn}_{4}-\mathrm{MT}$ and $\mathrm{Zn}_{7}-\mathrm{MT}$ because the zinc species in the $\beta$-cluster were lost during the pre-acidification procedure to yield the $\mathrm{Zn}_{4}$-MT species. Different buffer $\mathrm{pH}$ values were employed to compare the influences of polypeptide conformation on MS/MS spectra. A series of spectra was obtained for a range of relative collision energies to provide data indicative of the energetics of zinc binding. 


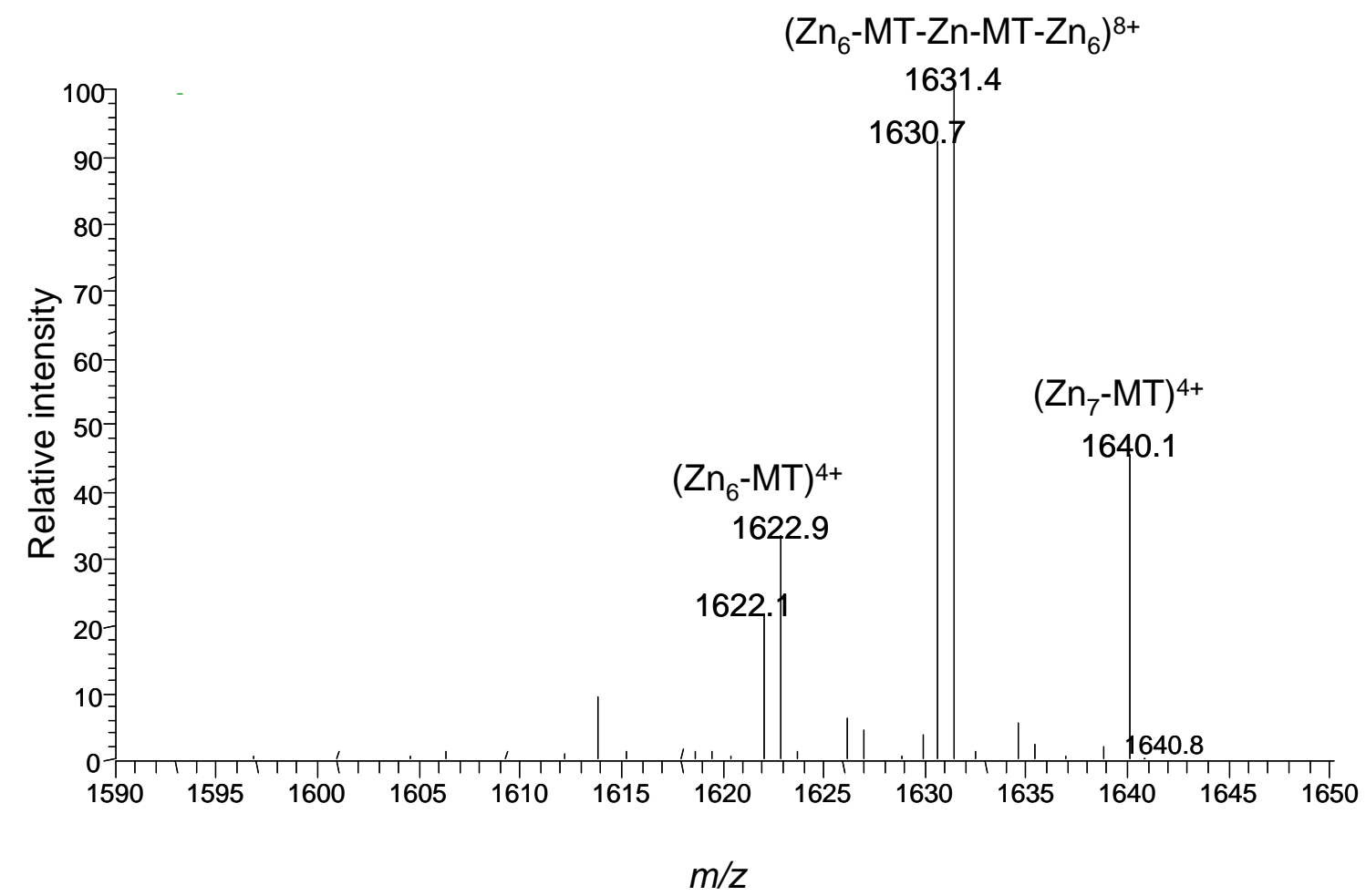

Figure 2.3. The MS/MS spectrum of the metallothionein molecule ions $\left(\mathrm{Zn}_{7}-\mathrm{MT}\right)^{4+}$ at buffer $\mathrm{pH}$ 8.0.

The published mechanism for zinc loss $[15,17]$ allows for an intermediate, that is, a metallothionein dimer consisting of two MT molecules linked through an intermolecular 
zinc-thiolate bridge. During collision induced dissociation experiments, MT dimers were observed when increasing collision energy was applied to the parent ions, as shown in Figure 2.3. The peak at $m / z 1631.4$ corresponds to the MT dimer in which thirteen zinc ions and two metallothionein peptide chains were involved, and the peak at $\mathrm{m} / \mathrm{z}, 1622.9$ corresponds to the single $\mathrm{Zn}_{6}-\mathrm{MT}$ ions with charge of $4+$. Every parent ion that underwent the CID experiments remained intact until the RCE \% increased to a threshold value of $15 \%$. After the threshold energy value, the relative collision energy was set to increase in steps of $0.5 \%$ or $1 \%$. The spectrum shown in Figure 2.3, exhibiting a peak corresponding with the MT dimer, was obtained with a relative collision energy of $19.5 \%$. With an increase in the collision energy, the amount of parent ions in the ion trap decreased and that of daughter ions, i.e. $\mathrm{Zn}_{6}-\mathrm{MT}$ ions, increased. The intermediate, MT dimer, was produced as soon as the collision energy exceeded the threshold value and its amount would reach a maximum before a drop down to zero. Meanwhile, the daughter monomer (e.g. $\mathrm{Zn}_{6}-\mathrm{MT}$ ) appeared as the product of its respective intermediate species.

In the low collision energy window, one of the $\mathrm{Zn}_{7}$-MT molecular ions lost one zinc ion and exposed the thiolate groups to one of conjugated zinc atoms in the polypeptide chains of another MT. The exposed thiolate groups could not interact with zinc ions in the same MT chain because of the rigid three-dimensional structure imposed by the other zinc- 
thiolate complexes. They could only interact with zinc ions present on separate MT ions when they came within close proximity to allow bridge bond formation. An intermolecular zinc-thiolate bridge was formed to combine a $\mathrm{Zn}_{7}-\mathrm{MT}$ ion and a $\mathrm{Zn}_{6}-\mathrm{MT}$ ion into one MT dimer ion. Another possibility for the intermolecular bond between the two monomers is that the bridge is a disulfide bond that forms between two thiolate groups from different molecules. The zinc-thiolate bridge bond was found to be the weakest interaction compared to that of the other zinc-thiolate complexes inside the MT. With increases in collision energy, the MT dimer dissociated to yield two single molecular ions that further lost the bridge zinc ion, thereby the $\mathrm{Zn}_{6}$-MT became the dominant species. 
2.3.3 Collision-Induced Dissociation of MT species

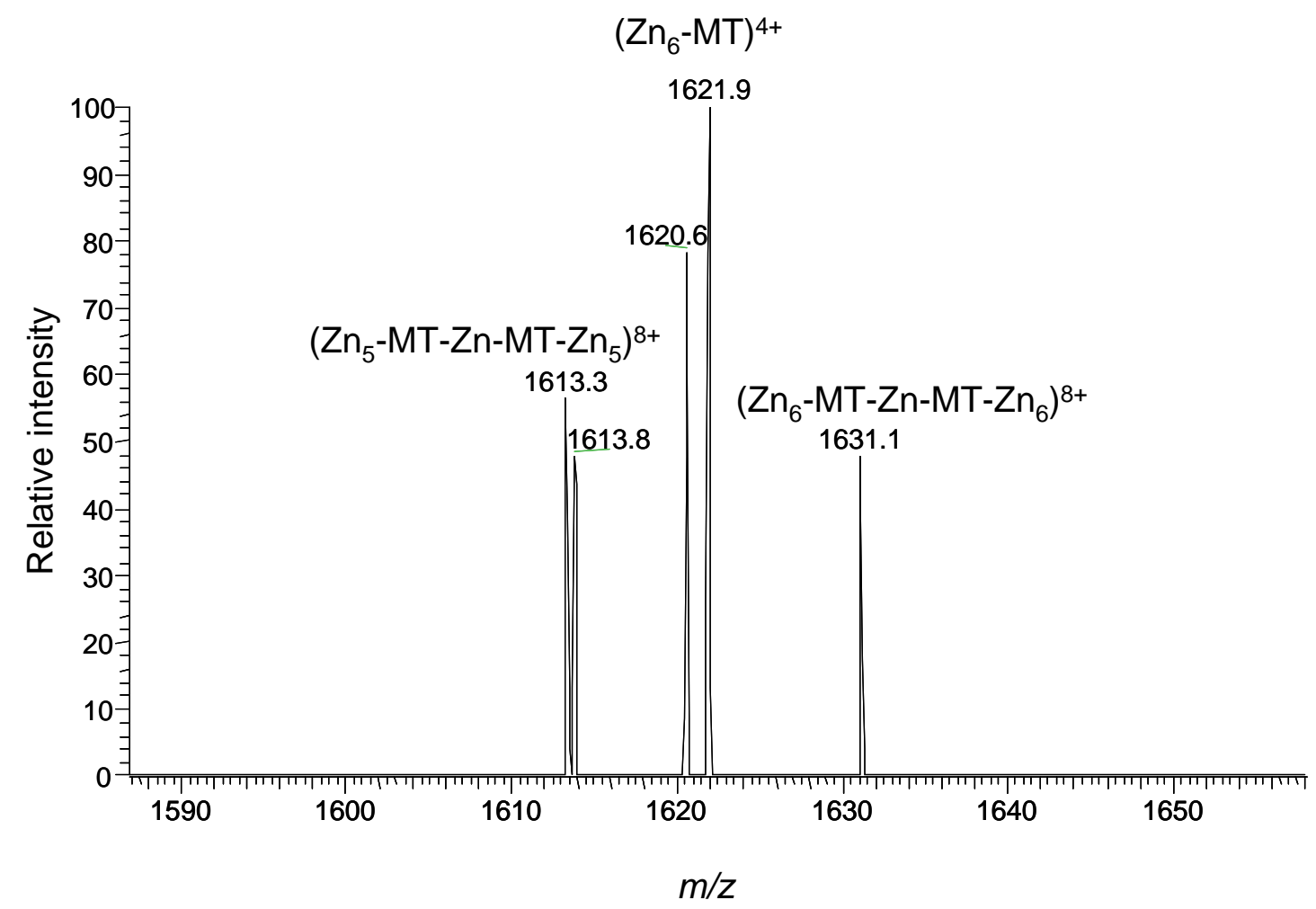

Figure 2.4. The MS/MS spectrum of the metallothionein molecule ions $\left(\mathrm{Zn}_{6}-\mathrm{MT}-\mathrm{Zn}-\mathrm{MT}-\mathrm{Zn}_{6}\right)^{8+}$ at buffer $\mathrm{pH}$ 8.0. 
To identify the intermediate as the MT dimer, the suspected ion was examined in an MS/MS/MS experiment. Mass selected $\mathrm{Zn}_{7}-\mathrm{MT}$ ions underwent $\mathrm{CID}$, losing a single zinc and yielding the intermediate. The intermediate was isolated and subjected to CID to lose zinc and dissociated to yield two single MT ions. A series of MT dimers were found during the CID process, such as $\mathrm{Zn}_{6}-\mathrm{MT} / \mathrm{Zn}_{5}-\mathrm{MT}, \mathrm{Zn}_{5}-\mathrm{MT} / \mathrm{Zn}_{4}-\mathrm{MT}$, and so on.

Several plots of peak intensities vs. the relative collision energies were used to evaluate zinc metallothionein binding properties. Because the MT dimer was made from the attachment of a MT losing one eqivelant zinc ion to their respective parent MT, it was considered that the MT losing one zinc was the sum of the target MT species and the respective MT dimer. For example, the amount of $\mathrm{Zn}_{6}-\mathrm{MT}$ species was the sum of that of both the $\mathrm{Zn}_{6}-\mathrm{MT}$ ions and the $\mathrm{Zn}_{6}-\mathrm{MT} / \mathrm{Zn}_{7}-\mathrm{MT}$ dimers shown in Figure 2.3. Up to eight curves of intensity vs. relative collision energy were plotted in one graph and several such graphs were obtained under different buffer conditions applied in ESI-MS. 


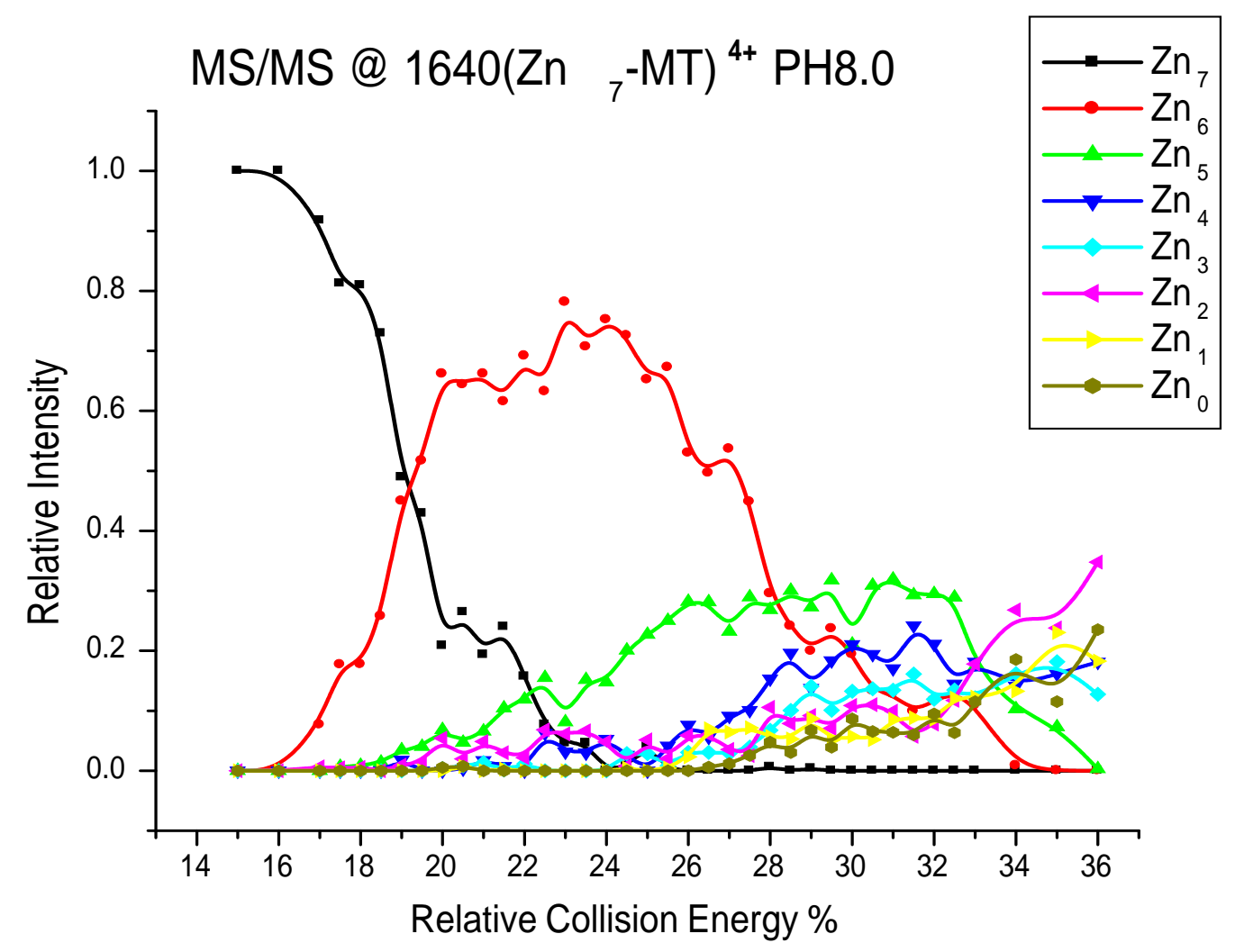

Figure 2.5 The curves of intensities of the metallothionein species with different number of zinc vs. the relative collision energies at buffer $\mathrm{pH} 8.0$ were plotted. The parent ion was the metallothionein molecule ions $\left(\mathrm{Zn}_{7}-\mathrm{MT}\right)^{4+}$. 
The graph shown in Figure 2.5 illustrates the change in the intensities as a function of collision energy for a $\mathrm{pH} 8.0$ solution. The molecular ion of $\mathrm{Zn}_{7}-\mathrm{MT}$ with $4+$ charges was isolated for CID. MS/MS spectra were scanned in steps of $0.5 \%$ relative collision energy (RCE). The peak intensities of every expected ion obtained from each MS/MS spectrum were normalized prior to plotting. The intensities of $\mathrm{Zn}_{7}-\mathrm{MT}$ ions decreased with increases in the collision energy, as that of the $\mathrm{Zn}_{6}$-MT ions increased to a plateau and then decreased. The third observable ion was the $\mathrm{Zn}_{5}-\mathrm{MT}$ which became the major species present in Figure 2.4 after the curve of $\mathrm{Zn}_{6}$-MT merged into the background. The background increased with collision energy as a multitude of minor fragment ions appeared. The intensities of $\mathrm{Zn}_{7}-\mathrm{MT}$ and $\mathrm{Zn}_{6}-\mathrm{MT}$ crossed at $19.2 \% \mathrm{RCE}$ collision energy and the $\mathrm{Zn}_{6}$-MT intensity maximized when the collision energy was $\sim 23 \% \mathrm{RCE}$. The crossing of the two curves of $\mathrm{Zn}_{6}-\mathrm{MT}$ and $\mathrm{Zn}_{5}-\mathrm{MT}$ occurred $\sim 28 \% \mathrm{RCE}$. All of the data appeared in Table 1. 
Table 2.1. The list of data shown in pictures of ions involved in experiments.

\begin{tabular}{lccccc}
\hline & $\begin{array}{c}\text { Buffer } \\
\mathrm{pH}\end{array}$ & $1^{\text {st } \text { crossing }^{\text {a }}}$ & $\begin{array}{c}\text { Top } \\
\text { intensity }\end{array}$ & $\begin{array}{c}\text { Energy } \\
\text { at top }^{\mathrm{c}}\end{array}$ & $2^{\text {nd }}$ crossing $^{\mathrm{d}}$ \\
$\left(\mathrm{Zn} \mathrm{n}_{7} \mathrm{MT}\right)^{4+}$ & 8.0 & $19.1 \pm 0.2 \%$ & $\sim 74 \%$ & $\sim 23 \%$ & $27.9 \pm 0.4 \%$ \\
$\left(\mathrm{Zn}_{7}-\mathrm{MT}\right)^{4+}$ & 7.7 & $18.3 \pm 0.1 \%$ & $\sim 94 \%$ & $\sim 22 \%$ & $27.0 \pm 0.5 \%$ \\
$\left(\mathrm{Zn}_{4}-\mathrm{MT}\right)^{4+}$ & 7.7 & $19.3 \pm 0.1 \%$ & $\sim 93 \%$ & $\sim 23 \%$ & $32.8 \pm 0.3 \%$ \\
$\left(\mathrm{Zn}_{4}-\mathrm{MT}\right)^{4+}$ & 7.0 & $19.2 \pm 0.1 \%$ & $\sim 98 \%$ & $\sim 23 \%$ & $33.3 \pm 1.1 \%$ \\
\hline
\end{tabular}

a. The collision energy corresponding to the crossing of the curves of parent ion $\left(\mathrm{Zn}_{\mathrm{m}}-\mathrm{MT}\right)$ and the daughter ion with one equivalent zinc lost $\left(\mathrm{Zn}_{\mathrm{m}-1}-\mathrm{MT}\right)$.

b. The top intensity of the daughter ion with one zinc lost $\left(\mathrm{Zn}_{\mathrm{m}-1}-\mathrm{MT}\right)$.

c. The collision energy corresponding to the top intensity of the daughter ion with one equivalent zinc lost $\left(\mathrm{Zn}_{\mathrm{m}-1}-\mathrm{MT}\right)$.

d. The collision energy corresponding to the crossing of the curves of $\left(\mathrm{Zn}_{\mathrm{m}-1}-\mathrm{MT}\right)$ and $\left(\mathrm{Zn}_{\mathrm{m}-2}-\mathrm{MT}\right)$. 


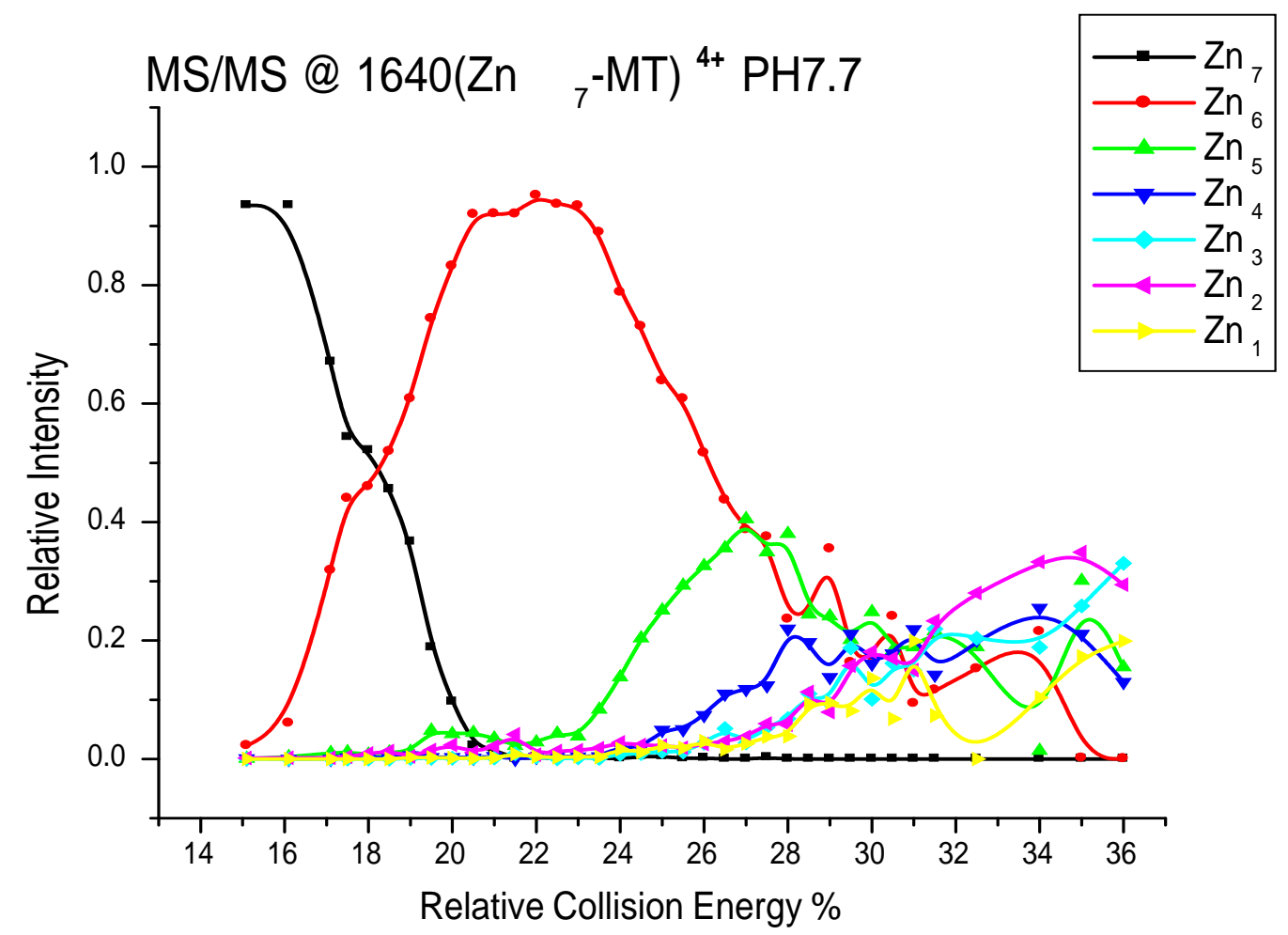

Figure 2.6 The curves of intensities of the metallothionein species with different number of zinc vs. the relative collision energies at buffer $\mathrm{pH} 7.7$ were plotted. The parent ion was the metallothionein $\alpha$-cluster ions $\left(\mathrm{Zn}_{4}-\mathrm{MT}\right)^{4+}$. 
The plot in Figure 2.6 illustrates the CID behavior of the same parent ion under the same experimental conditions except that the buffer $\mathrm{pH}$ was adjusted to 7.7. The molecular ion of $\mathrm{Zn}_{7}-\mathrm{MT}$ with 4+ charges was isolated for CID experimentation and MS/MS spectra were scanned in steps of $1 \%$ RCE. It is noted that the general behavior illustrated in Figure 2.6 is similar to that seen in Figure 2.5. The original $\mathrm{Zn}_{7}-\mathrm{MT}$ ions gradient vanished with an increase in the collision energy, while that of the $\mathrm{Zn}_{6}$-MT ions increased to a maximum and then decreased. The $\mathrm{Zn}_{5}-\mathrm{MT}$ became the major species after the $\mathrm{Zn}_{6^{-}}$ MT merged into the background. However, the crossing of the two curves of $\mathrm{Zn}_{7}-\mathrm{MT}$ and $\mathrm{Zn}_{6}-\mathrm{MT}$ intensities shifted to $18.2 \%$ RCE. Likewise, the crossing of the $\mathrm{Zn}_{6}-\mathrm{MT}$ and $\mathrm{Zn}_{5}-\mathrm{MT}$ intensities occurred at $27 \% \mathrm{RCE}$, and the $\mathrm{Zn}_{6}$-MT plateaued at $~ 22 \%$ RCE. Another difference occurred in the maximum relative intensity achieved for $\mathrm{Zn}_{6}-\mathrm{MT}$. The relative intensity of the $\mathrm{Zn}_{6}$-MT maximized at $94 \%$ in Figure 2.6 compared with $74 \%$ in Figure 2.5.

The crossing of the $\mathrm{Zn}_{7}-\mathrm{MT}$ and $\mathrm{Zn}_{6}$-MT curves shifted to lower energies as did the crossing of $\mathrm{Zn}_{5}-\mathrm{MT}$ and $\mathrm{Zn}_{6}-\mathrm{MT}$ curves. These results show that the collision energy required to break the zinc-thiolate bonds decreased with decreasing $\mathrm{pH}$. The shift in these CID breakdown curves reveals the influence of $\mathrm{pH}$ on the three-dimensional structure of the molecules. Increased acidity led to an unfolding of the peptide chains that 
encircle the zinc "center". The result of this unfolding was the more facile energy transfer into the bond between the zinc and peptide chains. Energy transfer was more efficient at lower $\mathrm{pH}$.

The seven zinc ions in metallothionein are grouped into two clusters based on their positions. Zinc ions in the $\beta$-cluster are lost first because they are less thermodynamically stable. A comparative study of the MS/MS spectra of $\alpha$ or $\beta$ clusters provides insight into differences in these zinc binding sites. In this study $\mathrm{Zn}_{4}-\mathrm{MT}$ ions with 4+ charges were generated by ESI and isolated for CID to provide information regarding the $\alpha$-cluster MT. In order to eliminate the effect of $\mathrm{pH}$ on structure and make the results comparable to those of Figure 2.6, the electrospray solution was buffered to a $\mathrm{pH}$ of 7.7. The results from MS/MS of the $\alpha$-cluster, plots of intensities of parent and daughter ions against the $\%$ RCE, appear in Figure 2.7. The curves of $\mathrm{Zn}_{4}-\mathrm{MT}$ and $\mathrm{Zn}_{3}-\mathrm{MT}$ intensities crossed at $19.3 \%$ and those of $\mathrm{Zn}_{3}-\mathrm{MT}$ and $\mathrm{Zn}_{2}-\mathrm{MT}$ intensities crossed at $33 \%$. The maximum relative intensity of the $\mathrm{Zn}_{3}-\mathrm{MT}$ species, $\sim 93 \%$, occurred at $\sim 23 \%$ RCE. Dimers of $\mathrm{Zn}_{\mathrm{m}^{-}}$ $\mathrm{MT} / \mathrm{Zn}_{\mathrm{m}-1}$-MT $(\mathrm{m}=4,3,2,1)$ were also observed in the MS/MS spectra, consistent with recombination of an ion with the equivalent daughter ion that had undergone the loss of one zinc. 


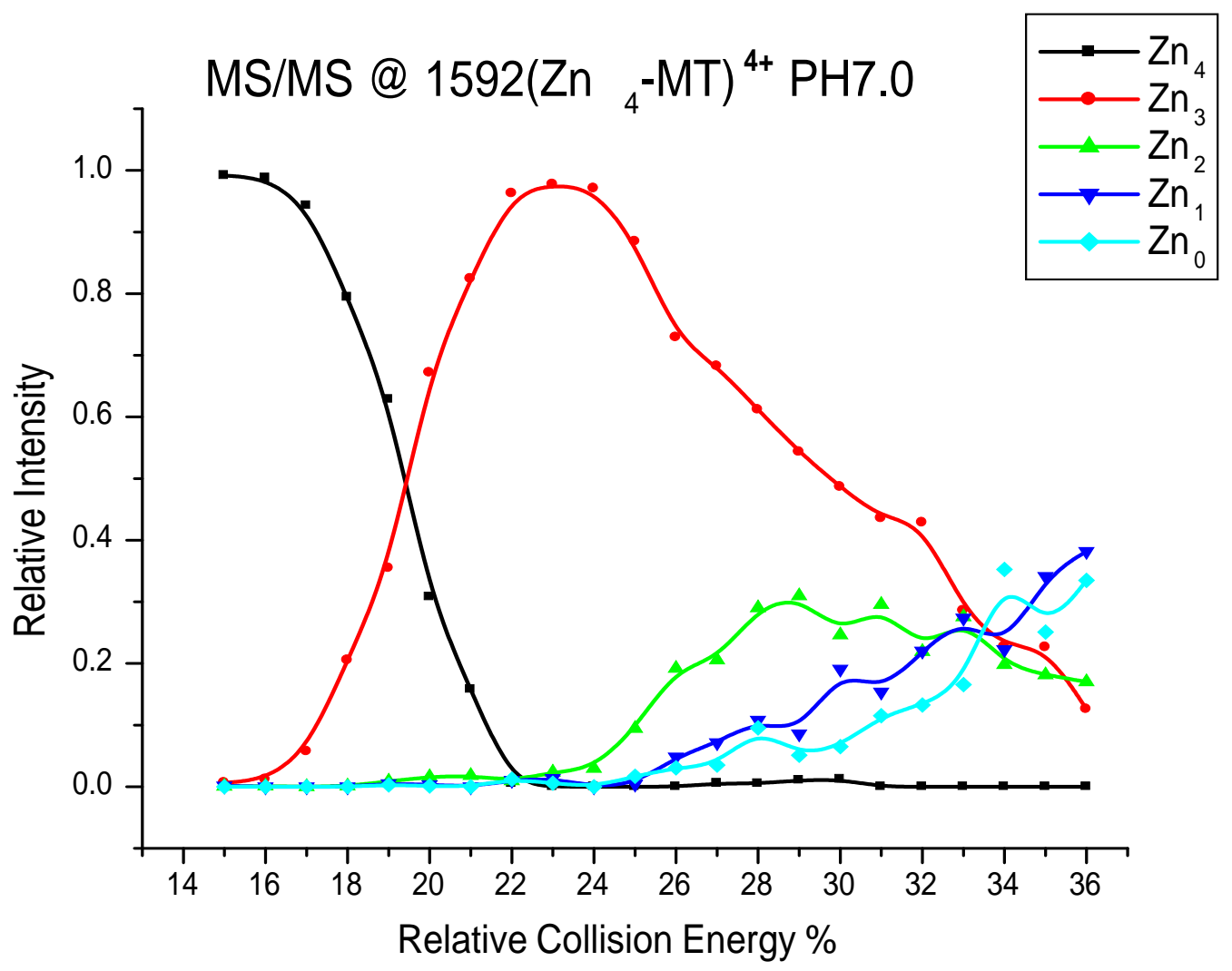

Figure 2.7 The curves of intensities of the metallothionein species with different number of zinc vs. the relative collision energies at buffer $\mathrm{pH} 7.0$ were plotted. The parent ion was the metallothionein $\alpha$-cluster ions $\left(\mathrm{Zn}_{4}-\mathrm{MT}\right)^{4+}$. 
In comparison to the results in Figure 2.6, the results in Figure 2.7 show that the ion system did not disappear into the background until higher collision energies were applied. The structure of MT appeared to be more unfolded because of the loss of $\beta$-zinc cores. The ions with only $\alpha$-cluster zinc appear to receive and release the energy through dissociation of zinc-thiolate bonds more efficiently than did the fully metallated MT species. The crossing of two curves of parent ions with the daughters where one equivalent zinc ion was lost took place at a collision energy of $19.2 \% \mathrm{RCE}$, which is almost the same as that observed in Figure 2.6. This similarity indicates a maximum for the collision energy required to remove one zinc ion. This likely is the result of the composite effect of two different mechanisms. First, the unfolded system more efficiently receives and releases energy than does the folded system leading to a shift to lower $\% \mathrm{RCE}$ for the unfolded system. Second, because the zinc in the $\alpha$-cluster is more thermodynamically stable, a greater \% RCE is required to remove the zinc from the cluster.

The differences in the CID behaviors of the same parent ions of $\mathrm{Zn}_{7}-\mathrm{MT}$ with 4+ charges were compared at different buffer $\mathrm{pH}$ values. The same experiments were repeated while the parent ions were switched to $\mathrm{Zn}_{4}$-MT with 4+ charges and two buffers used were at pH 7.7 and 7.0 respectively. The breakdown curve for $\left(\mathrm{Zn}_{4}-\mathrm{MT}\right)^{4+}$ appears in Figure 2.7. 
The corresponding data appear in Table 1. Comparison of the data from Figure 2.7 with that from Figure 2.6, confirms that the lower $\mathrm{pH}$ buffer helped to unfold the target peptide ions and therefore increase the efficiency with which ions received and released collision energy. 


\subsection{Conclusion}

ESI-MS was used to study zinc-thiolate binding properties. Collision-induced dissociation (CID) studies of the metallated metallothionein ions provided insight into the influence of three-dimension structure on the dissociation of zinc-thiolate bonds.

The protein conformation in solution influences the charge state distribution observed in electrospray mass spectra. The charge state of the most abundant peak observed in ESIMS increases as the buffer $\mathrm{pH}$ decreases. It was attributed to a conformational unfolding that results from the breaking of interactions that maintain the tertiary structure of the protein, exposing more basic sites to the solvent for protonation. The mass spectrum of the $\alpha$-cluster MT ions extracted from a pre-acidified buffer solution showed that the charge states of the dominant species increased as zincs were removed from the MT. This indicated that the MT was metallated to be folded and the unfolded system would be expected to be highly charged.

A series of intermediate, MT dimers, were produced during the CID reactions. They shared a universal form as $\left(\mathrm{Zn}_{\mathrm{m}-1}-\mathrm{MT} / \mathrm{Zn}_{\mathrm{m}-1}-\mathrm{MT}\right)^{8+}(\mathrm{m}=1,2, \ldots, 7)$. One of the $\mathrm{Zn}_{\mathrm{m}}-\mathrm{MT}$ 
molecular ions lost one zinc ion and exposed the thiolate groups to reaction with the zinc species complexed with a different MT ion to form an intermolecular zinc-thiolate bridge by which a $\mathrm{Zn}_{\mathrm{m}}-\mathrm{MT}$ ion and a $\mathrm{Zn}_{\mathrm{m}-1}-\mathrm{MT}$ ion were combined into one MT dimer ion. This was confirmed by a MS/MS/MS experiment on the resulting dimer. It was clear that when the intermediate lost another zinc, the dimer dissociated yielding two single MT ions with one fewer zinc attached to each.

Tandem MS studies revealed the influence of the three-dimensional structure. It appears that the unfolded peptide ions received the collision energy and quickly relaxed from the metastable state by the sequential release of the zinc ions. 


\subsection{References}

1. Arseniev, A.; Schultze, P.; Worgotter, E.; Braun, W.; Wagner, G.; Vašák, M.;

Kagi, J. H. R.; Wuthrich, K. J. Mol. Biol. 1988, 214, 637-657.

2. Robbins, A. H.; McRee, D. E.; Williamson, M.; Collett, S. A.; Xuong, N. H.;

Furey, W. F.; Wang, B. C.; Stout, C. D. J. Mol. Biol. 1991, 221, 1269-1293.

3. Kagi, J. H. R.; Schaffer, A. Biochemistry 1988, 27, 8509-8515.

4. Zangger, K.; Shen, G.; Oz, G.; Otvos, J. D.; Armitage, I. M. Biochem. J. 2001, $359,353-360$.

5. Hathout, Y.; Fabris, D.; Fenselau, C. Int. J. Mass Spectrom. 2001, 204, 1-6.

6. Krizek, B. A.; Merkle, D. L.; Berg, J. M. Inorg. Chem. 1993, 32, 937-940.

7. Yu, X.; Wojciechowski, M.; Fenselau, C. Anal. Chem. 1993, 65, 1355-1359.

8. Zaia, J.; Fabris, D.; Wei, D.; Karpel, R. L.; Fenselau, C. Protein Science 1998, 7, 2398-2404.

9. Fabris, D.; Zaia, J.; Hathout, Y.; Fenselau, C. J. Am. Chem. Soc. 1996, 118, $12242-12243$.

10. Loo, J. A. Mass spectrum. Rev. 1997, 16, 1-23. 
11. March, R. E.; McMahon, A. W.; Londry, F. A.; Alfred, R. L.; Todd, J. F. J.; Vedel, F. Int. J. Mass Spectrom. Ion Processes 1989, 95, 119.

12. Asano, K. G.; Goeringer, D. E.; utcher, D. J.; Mcluckey, S. A. Int. J. Mass Spectrom. 1999, 190/191, 281-293.

13. Hathout, Y.; Fabris, D.; Han, M. S.; Sowder II, R. C.; Henderson, L. E.; Fenselau, C. Drug Metabolism \& Disposition 1996, 24, 1395-1400

14. Loo, J. A.; Loo, R. R. O.; Udseth, H. R.; Edmonds, C. G.; Smith, R. D. Rapid Commun. Mass Spectrom. 1991, 5, 101-105. Kinerman, L.; Rosell, F. I.; Mauk, A. G.; Douglas, D. J. Biochemistry, 1997, 36, 6448-6454. Sogbein, O. O.; Simmons, D. A.; Konernann, L. J. Am. Soc. Mass Spectrom. 2000, 11, 312-319. Pratt, G. A. Electrospray ionization mass spectrometry for the analysis of proteins and small molecules Thesis, 2000, West Virginia University.

15. Kägi, J. H. R.; Vallee, B. L. J. Biol. Chem. 1961, 236, 2435-2442.

16. Gehrig, P. M.; You, C.; Dallinger, R.; Gruber, C.; Brouewer, M.; Kägi, J. H. R.; Hunziker, P. E. Protein Sci. 2000, 9, 395-402.

17. Frankel, A.; Bredt, D. S.; Pabo, C. O. Science, 1988, 240, 70-73. 


\section{Chapter 3 A Zinc-metallothionein Dimer Intermediate Found in Tandem Mass Spectrometry}

\subsection{Introduction}

Metallothionein (MT) was discovered in 1957 by Margashes and Vallee when a biological natural compound was identified as a cadmium-binding protein responsible for the accumulation of $\mathrm{Cd}$ in a mammalian body and also in some plants [2, 3]. In addition to cadmium, several other $\mathrm{d}^{10}$ metal ions, such as zinc, copper and mercury, were also found in this specific metalloprotein. The existence of the MT in the bio-system was very important for the realization of the biological function of these $\mathrm{d}^{10}$ metals and their transportation through the cell and organisms.

The MTs were characterized by their extremely high metal and thiol group contents. Mammalian MT has a molecular weight of 6000 7000, containing about 60 amino acid residues among which 20 are cysteine residues, contributing their thiol groups to bind 
with up to seven equivalent bivalent metal ions. These cysteine (Cys) residues repeatedly occurred in Cys-X-Cys tripeptide sequences, where $\mathrm{X}$ was an amino acid residue other than Cys. Tetrahedral coordination was suggested by NMR [4] and x-ray crystallography [5]. Two metal-thiolate clusters, named as $\alpha$ domain and $\beta$ domain, were constituted by $\mathrm{Cd}_{4} \mathrm{Cys}_{11}$ and $\mathrm{Cd}_{3} \mathrm{Cys} 9$ complexes respectively. They were allocated separately in the $\mathrm{C}$ and $\mathrm{N}$ - terminals of the peptide chain. By sharing some of the thiol ligands with adjacent metal ions, the conflict of the apparently tetrahedral geometry of the coordination with the measured stoichometry of about three thiol ligands per metal ion was reconciled completely in each domain.

Metallothionein is an important metal transportation protein. The mechanism of transferring the metal ions to their destination has been under investigation. Otovs et al. provided the evidence for the existence of MT oligomer intermediates through which the metal ions were redistributed between the different reconstituted MT molecules [6]. The oxidative dimerization was realized by formation of the monomeric and dimeric MTs [7]. In contrast to the oxidative binding mechanism, the metal bridged non-oxidative dimerization was also suggested by CD and NMR studies from the Vašák's group [8, 9]. It was suggested that additional metal ions weakly bound with monomers worked as the metal bridges and that the major structural changes occurred in the $\beta$-domains. The 
evidence of a metal- linked dimer formed within the cysteine rich protein region was provided by Frankel et al [10]. It was proposed that in a dimeric MT, two metal complexes were formed to provide two metal bridges and each of the four cysteine ligands were contributed by two monomeric units evenly. The mass spectrometric evidence for the MT dimers was provided by Fenselau's group [11]. Their research showed the necessity of the formation of transient dimers for metal ions to be redistributed and transported through the proteins.

The work in our lab described tandem mass spectrometric studies of the binding properties of zinc ions with their ligand groups on the peptide chains [12]. CollisionInduced Dissociation (CID) was used to achieve required activation energies in the dissociation reaction of each equivalent metal ion. Internal energies required to induce dissociation of the complex and the energy released in the complexation of $\mathrm{Zn}$ (II) with the peptides were evaluated. An estimation of the influence of the change in threedimension conformation structure on the dissociation of zinc-thiolate complex was developed through these studies. A dimeric intermediate was proposed to explain the presence of an intermediate product shown between the parent ions and the expected product ions during MS/MS. These dimers shared a universal form as $\left(\mathrm{Zn}_{\mathrm{m}-1^{-}}\right.$ $\left.\mathrm{MT} / \mathrm{Zn} / \mathrm{Zn}_{\mathrm{m}-1}-\mathrm{MT}\right)^{8+}(\mathrm{m}=1,2, \ldots, 7)$. After a $\mathrm{Zn}_{\mathrm{m}}-\mathrm{MT}$ molecular ion lost one zinc ion, the 
released thiolate groups were in a metastable state and were exposed to the zinc atoms bound in another MT ion. An intermolecular zinc-thiolate bridge as formed by replacing the internal metal complex with the external complex, which combined the involved monomeric MT ions into one dimeric ions. This was confirmed by a MS/MS/MS experiment on the resulting dimeric intermediates during which the $\mathrm{Zn}_{\mathrm{m}-1}-\mathrm{MT}$ ions were released and observed in the fragement mass spectra.

In this chapter, a chelating reagent was added to the MT solution and worked as a mass marker during the MS/MS experiment to identify the small fragment ions. The idea that the metal ions could be released upon CID as well as the dimeric intermediates present in the dissociation process was examined. 


\subsection{Experimental}

ESI-Tandem-MS experiments were performed using the $\mathrm{LCQ}^{\mathrm{TM}}$ quadropole ion trap instrument from Thermo-Finnigan (California, US). LCQ ${ }^{\mathrm{TM}}$ software was used for mass spectra deconvolution and molecular mass calculations. Several EPPENDORF ${ }^{\circledR}$ tip ejector pipettes (Brinkmann, Westbury, NY) with different measurement precision were involved in the preparation of the sample solution. A pH meter, Fisher Scientific Model AP5, equipped with a glass $\mathrm{pH} / \mathrm{ATC}$ electrode, was employed for the $\mathrm{pH}$ measurements and control. Direct infusion of the sample into the electrospray ionization source was realized through a $250 \mu$ Hamilton (Reno, Nevada, US) blunt needle tip syringe.

Metallothionein-II zinc salt ( $\left.\mathrm{Zn}_{7}-\mathrm{MT}\right)$ and MT-II cadmium/zinc salt $\left(\mathrm{Cd}_{5}, \mathrm{Zn}_{2}\right.$-MT) from rabbit liver were purchased from Sigma-Aldrich Chemical (St. Louis, Missouri, US), and were used without further purification. Ammonium bicarbonate $\left(\mathrm{NH}_{4} \mathrm{HCO}_{3}, \mathrm{~F}\right.$.W. 79.06) and ammonium acetic acid $\left(\mathrm{CH}_{3} \mathrm{COONH}_{4}\right.$, F.W. 77.06) purchased from Fisher Scientific (Fairlawn, NJ) were used to adjust the $\mathrm{pH}$ value of the sample solution. The EDTA(St. Louis, Missouri, US) chelating reagent was prepared as $10 \mu \mathrm{m}$ solution. The solution was degassed before storage in the refrigerator. The degassed solvent prevented oxidation 
reaction during storage. Stock solution was prepared by dissolving $0.2 \mathrm{mg}$ in $2 \mathrm{~mL}$ of degassed deionized water mixed with methanol (St. Louis, Missouri, US) (50/50, v/v) and they were kept in refrigerator of $3{ }^{\circ} \mathrm{C}$. Working solutions of $\left(\mathrm{Zn}_{7}-\mathrm{MT}\right)$ and $\left(\mathrm{Cd}_{5}, \mathrm{Zn}_{2}-\mathrm{MT}\right)$ were prepared daily by dilution of respective stock solutions to a final concentration of 5 $\sim 10 \mu \mathrm{M}$ in an $\mathrm{NH}_{4} \mathrm{HCO}_{3}$ or a $\mathrm{CH}_{3} \mathrm{COONH}_{4}$ buffer solution.

For the direct infusion conventional ESI-MS measurements, metallothionein solution was introduced into the ESI assembly at a flow rate of $2 \mu / \mathrm{min} .$. Ion spray voltage was set as $4.2 \mathrm{kV}$. Heated capillary temperature and voltage were set as $150{ }^{\circ} \mathrm{C}$ and $21.00 \mathrm{~V}$ respectively. Nitrogen gas was introduced as the inner coaxial gas into the ESI assembly at a sheath gas flow rate of 30 units, which helps to nebulize sample solution into a fine mist as the sample solution exits the ESI nozzle. Once the ions passed the heated capillary, they were transferred to the ion trap through the quadrupole gate during the ion accumulation period.

Following an ion accumulation period of $300 \sim 8000 \mathrm{~ms}$, protonated metallothionein ions were isolated using a single resonance ejection ramp. A relatively broad ion isolation window (i.e. several mass-to-charge ratio units) was employed to avoid collisional activation of the parent ion by off-resonance power absorption during the isolation step 
[13]. After a cooling period, the target ions with negligible kinetic energy were left in the ion trap ready for the CID reaction.

Collision induced dissociation (CID) was used to study the zinc-sulfhydryl bond properties. The parent ions in the mass analyzer that gain enough translational kinetic energy from the resonance excitation RF voltage applied to the endcap electrodes of the ion trap mass analyzer can collide with the helium damping gas so that the ions dissociate to product ions. Collision energy was used to estimate the kinetic energy of the ion when it interacted with $\mathrm{He}$, and was expressed in terms of percent relative collision energy (RCE \%). Product ion spectra were recorded as a function of relative collision energy (RCE \%). The values of the RCE \% were carefully chosen to assure that the collision induced dissociation of zinc-sulfhydryl bond was the only CID reaction in the ion trap. 


\subsection{Result and Discussion}

The binding of zinc in metallothionein appears to be critical to the biological function of MT's. Metal titration and NMR techniques have been applied to study the binding specificity of metal to multipeptide chains. These studies have demonstrated the different affinities of the two domains in MT to the monovalent or covalent metal ions and the availability of the facile mechanisms for the metal exchanges [14]. NMR studies showed the evidence of the dimerization of the MT resulting from the exposure to the excess metal ions $[8,9]$. A chelating reagent was used to remove the metal ions for purification of the apo-proteins [15] or for the confirmation of kinetics characterization of dimerization by checking the stability of the dimeric MT [8]. In the present MT CID experiments, EDTA was employed as an ion mass marker which was involved to bring the small fragment ions into the detection window of the mass analyzer by increasing their $m / z$ values after the combination of the fragments with EDTA ligands. EDTA was chosen as the ligand based on two points: 1) its molecular weight is much more than that of the metal found in the MT and 2) the large formation constants of EDTA with metal species favoring the stability of the complexes in CID [16]. 
During the previous CID experiments [11], an assumption that only metal ions were released in CID was made based on small differences in the mass over charge ratio between the parent and product ions. The limited detection window of the ion trap [17] accounts for the incapability of detecting the fragment with small $m / z$ values. By introducing a chelating reagent that is stable during CID, the formation of complex ions of the fragment with the ligand reagent could make the small fragment 'visible' in mass spectra because the resulting complex has an $\mathrm{m} / \mathrm{z}$ within the window of detection. 


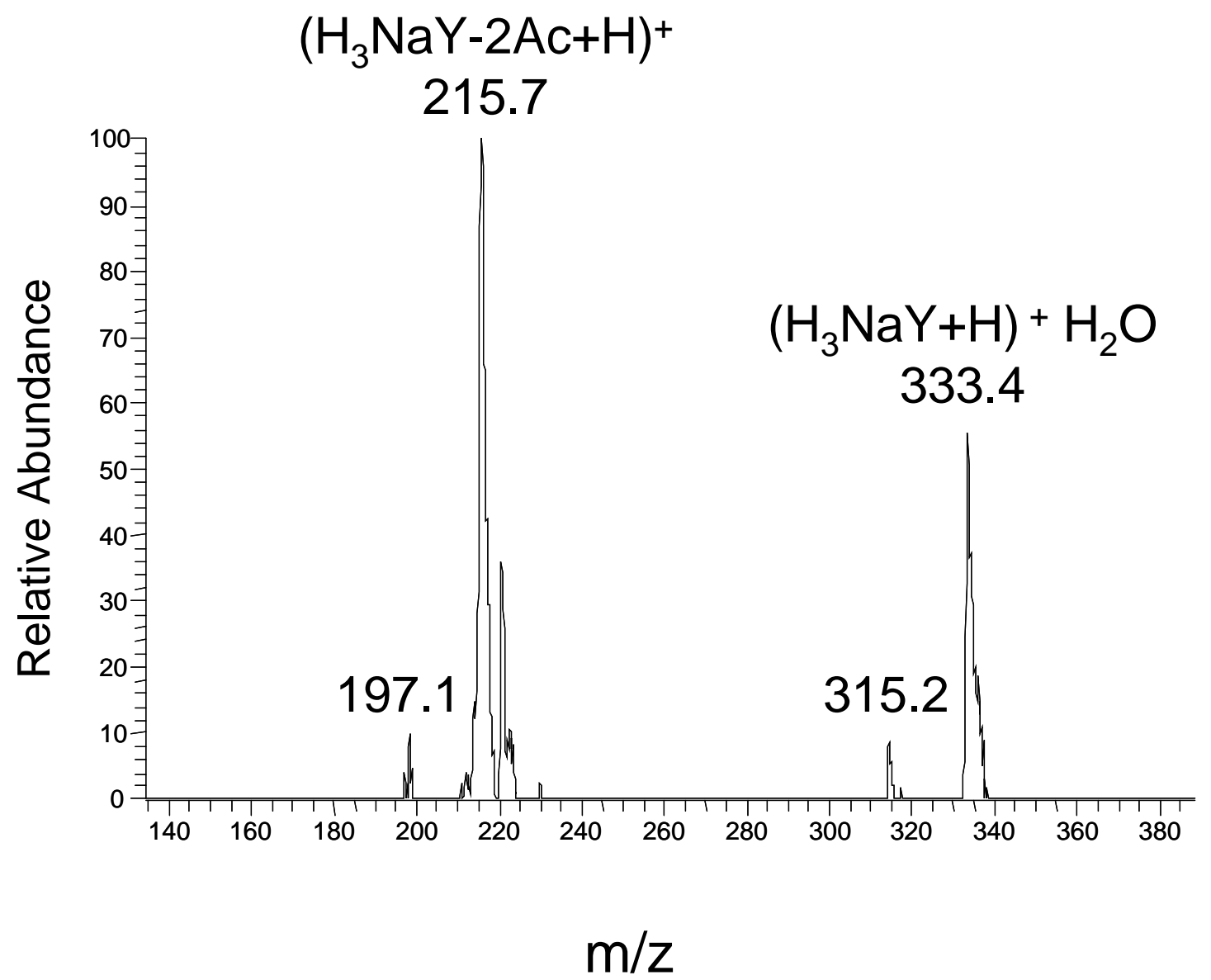

Figure 3.1 Electrospray mass spectrum of EDTA in solution of methanol at concentration of $10^{-6} \mathrm{M}$. 
The purity of the EDTA was analyzed by the electrospray ion trap mass spectrometry prior to its application in the identification of fragments released in CID-MS. A group of peaks generated by ESI-MS was shown in Figure 3.1. The EDTA was usually available in its sodium salt form, hence, the peak of $315.2 \pm 0.3$ was identified as the singly charged molecule ion. This peak always showed up in the ESI-MS of EDTA. It had to be pointed out that, some other peaks, such as the peak of $333.2 \pm 0.5$ which was recognized as the hydrated form of the molecular ion, could be produced in a relatively high abundance, as shown in Figure 3.1. Due to the high intermolecular attraction between the two electrolytes, EDTA and $\mathrm{H}_{2} \mathrm{O}$, the hydrated form could be more abundant than the molecular ion when the ions were electrosprayed from an aqueous solution. Because of the large molecule size of the EDTA, the electrostatic interaction accounting for the hydration was so weak as to be easily broken during the source Collision-Induced Dissociation. The CID-MS of the same EDTA system showed that the spectra looked similar to the one shown in Figure 3.1 except that the abundance of hydrated form of EDTA became lower than that of the molecular species. The blank experiments implied that the singly charged molecular ions of $315.2 \pm 0.3$ would be the major EDTA species in CID reactions and be ready to chelate with free metals released by metallo-protein. 
The major species present in the MS are listed in Table 3.1. For those species with $\mathrm{m} / \mathrm{z}$ values of $229.7 \pm 0.3$ and $215.4 \pm 0.3$, structural changes resulting from loss of the chelating functional group accounted for their incapability to complex with metal. This simplifies the CID-MS and lets us focus on that singly charged complex ion which was a mass marker in pairing with the EDTA ligand ion.

Table $3.1 \mathrm{~m} / \mathrm{z}$ value of EDTA in ESI-MS

Calculated $\mathrm{m} / \mathrm{z}$

$\left(\mathrm{H}_{3} \mathrm{NaY}+\mathrm{H}\right)^{+} \cdot \mathrm{H}_{2} \mathrm{O}$

333.26

315.25

$\left(\mathrm{H}_{3} \mathrm{NaY}+\mathrm{H}\right)^{+}$

$\left(\mathrm{H}_{3} \mathrm{NaY}-\mathrm{NaOH}-\mathrm{COO}+\mathrm{H}\right)^{+}$

229.95

215.26
$\left(\mathrm{H}_{3} \mathrm{NaY}-2 \mathrm{Ac} \cdot+\mathrm{H}\right)^{+} \cdot \mathrm{H}_{2} \mathrm{O}$
Observed $\mathrm{m} / \mathrm{z}$

$333.2 \pm 0.5$

$315.2 \pm 0.3$

$229.7 \pm 0.3$

$215.4 \pm 0.3$ 
Due to the large formation constant of EDTA with metal species, EDTA could be a ligand competitor as well as a mass marker during mixing and electrospraying the MT and EDTA solution. The presence of the complex peak prior to the CID leads to difficulty in identifying the route through which the metal atoms went from the MT to the EDTA complex. Only the production of Zn-EDTA after CID and no reaction of MT with EDTA before CID would indicate that the direct metal exchange reaction in the solution between EDTA and MT had been restricted or eliminated. It was indicated in the previous kinetics study of the reaction of MT with EDTA [11] that both a direct ligand substitution process and a metal-protein dissociation process could result in the metal exchange reaction.

The ligand substitution process is a pseudo first order reaction that would be affected significantly by the concentration of EDTA. According to the substitution process, when the EDTA concentration was several orders higher than that of the zinc species, EDTA acted as a ligand competitor and Zn-EDTA was detected upon the mixing of the reactants. The problem could be eliminated by lowering the EDTA concentration. The dissociation process will not be affected by the concentration of reactants, here in this case, which were Zn-MT and EDTA. Conditions could be adjusted such that it was 
implied that in the fresh mixture of EDTA and MT there was no detectable amount of ZnEDTA complex formed before the CID process. Overall, the injection of fresh mixture of MT and diluted EDTA into the ESI source would theoretically favor the usage of EDTA as a mass marker rather than a ligand competitor. This was verified when no signal for Zn-EDTA was observed in the mass spectrum when a freshly mixed solution of EDTA with MT was immediately injected into the ESI source for MS analysis.

The MS shown in Figure 3.2, a detailed view of the full scan on the fresh mixture reveals no signal indicative of Zn-EDTA complex formation withour CID. As predicted above, the most abundant species were the hydrated forms of EDTA molecular ions because no collision dissociation energy was induced. These results eliminate two questionable points regarding the proposed experiments. First, the competitive distribution of metal ions between EDTA and MT was not even noticeable if an extremely diluted solution of EDTA was involved. Second, EDTA and MT could be electrosprayed simultaneously and MS spectra acquired without any interaction between the two.

CID experiments on the freshly mixed EDTA and Zn-MT solution yielded the MS/MS results shown in Figure 3.3. The most abundant species was the singly charged molecular ion of EDTA, in agreement with the analysis made above. Comparison with Figure 3.2, 
reveals a new peak, at $\mathrm{m} / \mathrm{z} 380.0 \pm 0.2$ arising from the formation of the product species upon the CID reaction, the Zn-EDTA complex ions. The presence of the ion pair of EDTA with Zn-EDTA suggested that the chelating reagent used as a mass marker successfully made the metal ions visible by the mass analyzer whose detection window was theoretically limited due to its physical characteristics.

\section{$\left(\mathrm{H}_{3} \mathrm{NaY}+\mathrm{H}\right)+\mathrm{H}_{2} \mathrm{O}$ \\ 333.4}

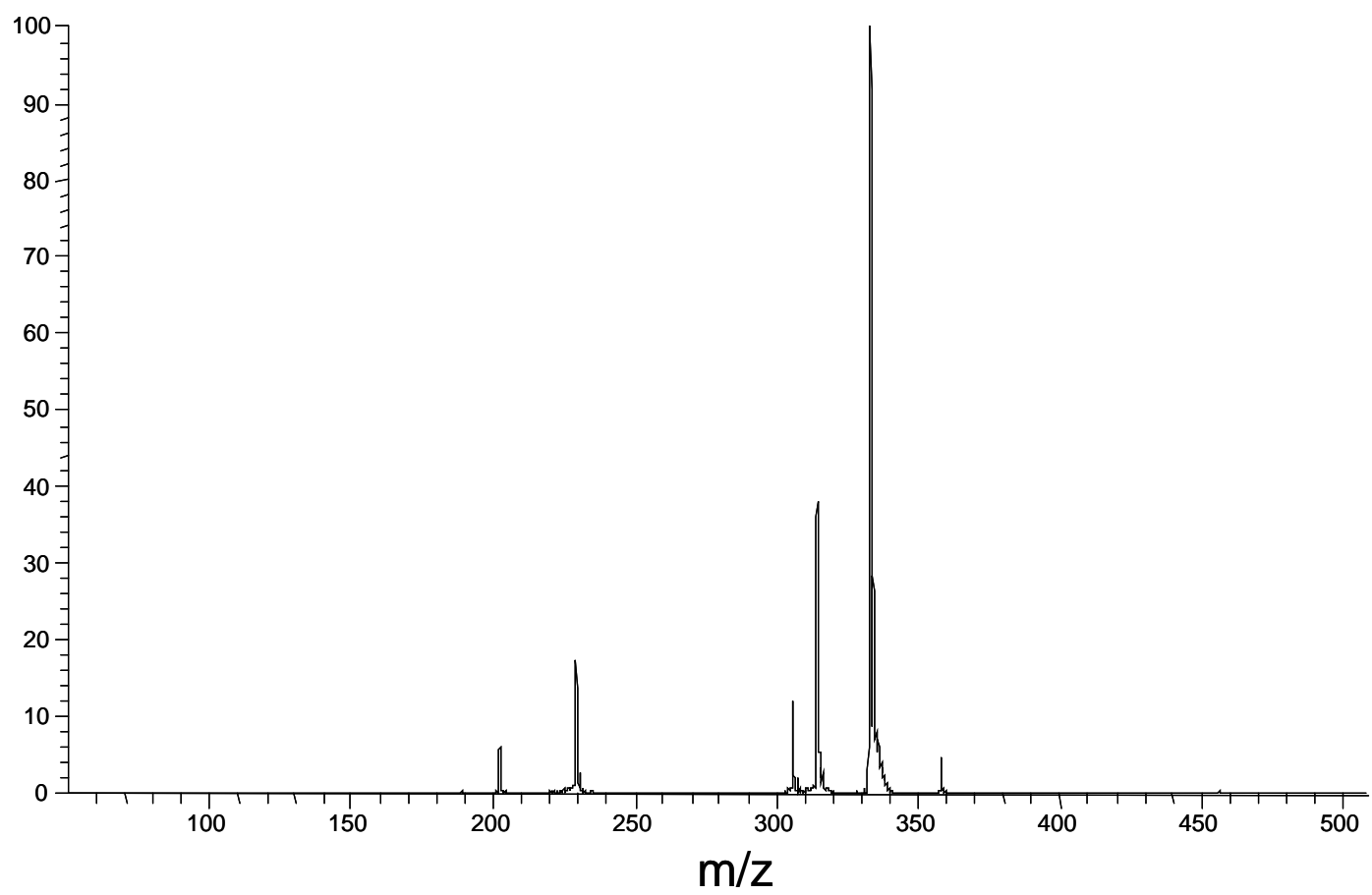

Figure 3.2 Mass spectra of EDTA freshly mixed with Zn-MT. 


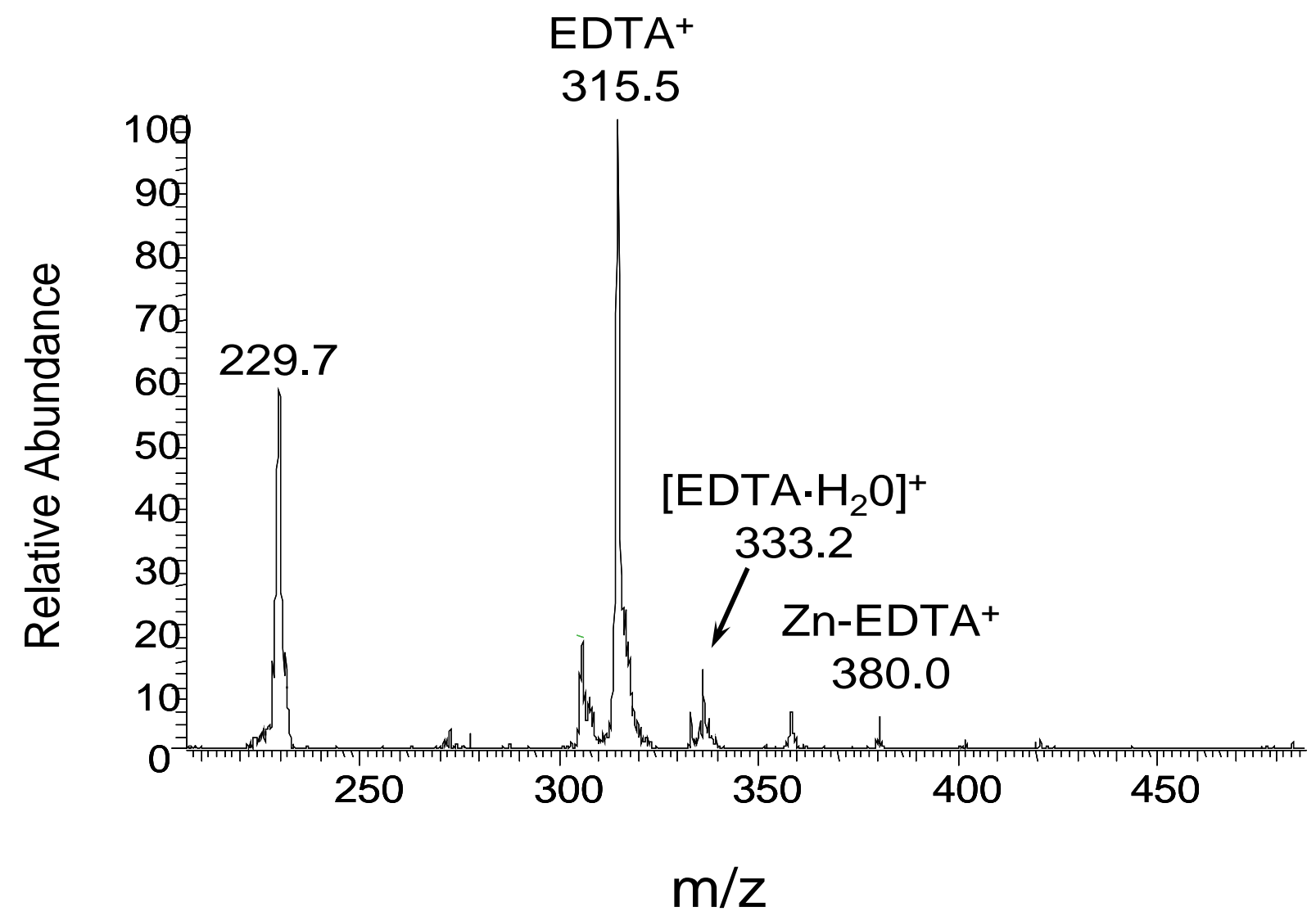

Figure 3.3 In-source CID MS on solution of EDTA and Zn-MT 
The strategy is useful to extend the limited detection window of the mass analyzer and to make the existing analyzer more versatile. It was implied that the multi-charged ions with a small $\mathrm{m} / \mathrm{z}$ value and the single-charged ions with a large $\mathrm{m} / \mathrm{z}$ value could be detected by adding net mass or net charges respectively. Even for the detectable fragments, the presence of the ions pairs of the fragment ions and their complexed form could be used for the confirmation of the production of the fragments. It also could be used to detect the neutral fragments produced in the dissociation reaction. The ionic complex of those neutral species would provide the direct evidence of their existence in MS. 


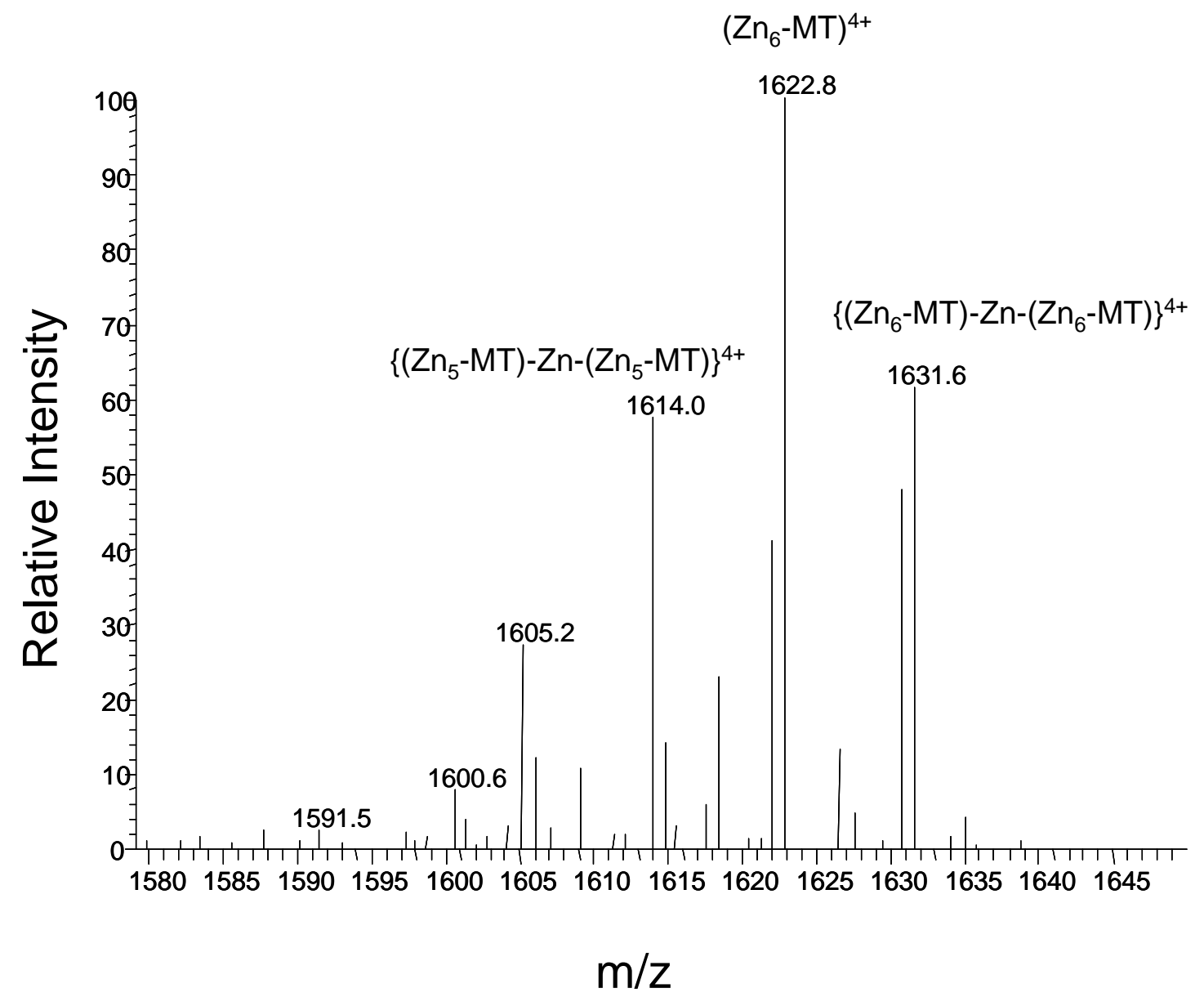

Figure 3.4 CID MS of mixture of EDTA and Zn-MT shows the dimer of metallothionein formed. 
Shown in Figure 2.3, the MS/MS scan of $\mathrm{Zn}_{7}-\mathrm{MT}$ solution at $\mathrm{pH} 7.8$ when the relative collision energy level was set as $17.5 \%$ [12] shows that the peak with the highest abundance was identified as the molecular ions with charge of $4+$ and they were set as the parent ions. The peak next to the parent ions' peak was the most abundant product ions produced in the respective condition. Varying the relative collision energy levels, the MS/MS scans on the parent ions showed the change in the product species. More parent ions were fragmented as more collision energy was introduced into the ion cloud and different products were generated, as shown in Figure 3.4 in which the energy level was set as $22.5 \%$. All of the parent ions, $\left(\mathrm{Zn}_{7}-\mathrm{MT}\right)^{4+}$, were fragmented into a series of product ions. The most abundant peak with an $\mathrm{m} / \mathrm{z}$ of $1623 \pm 0.4$ was of the expected product ions which were supposed to be generated from molecular ions by losing one zinc.

Starting from zero, the relative collision energy was increased in half unit steps and a series of mass spectra for each different energy level was examined. Increasing the energy level, the intensity of the peak of $1631.7 \pm 0.3$ increased until it reached a maximum value and then decreased to baseline. The ion with $\mathrm{m} / \mathrm{z} 1631.7 \pm 0.3$ is an intermediate ion between the parent ions and the expected product ions losing one equivalent zinc. It is interesting to note that the intermediate ions were always present in the mass spectra no matter what ions were set as parent ions. A MS/MS/MS scan on the 
peak of $1631.7 \pm 0.3$ showed similar mass spectra as the one shown in Figure 3.4. After obtaining the whole series of mass spectra, all of the fragment ions were listed as in Table 3.2.

The metallothionein ions containing different numbers of zinc atoms were sorted and listed to the left of the column. The intermediate ions between the adjacent $\mathrm{Zn}_{\mathrm{m}}-\mathrm{MT}$ $(\mathrm{m}=1,2, \cdots, 7)$ ions differing in one equivalent zinc were listed to the right of the column. All of the listed ions were in the +4 charge state, other charge states were not included in Table 3.2. 
Table 3.2 list of fragment ions and their molecular weights.

\begin{tabular}{|c|c|c|}
\hline & Calculated $\mathrm{m} / \mathrm{z}$ & Observed $\mathrm{m} / \mathrm{z}$ \\
\hline$\left(\mathrm{Zn}_{7}-\mathrm{MT}\right)^{4+}$ & 1640.1 & $1640.3 \pm 0.5$ \\
\hline$\left.\left(\mathrm{Zn}_{6}-\mathrm{MT}\right)-\mathrm{Zn}-\left(\mathrm{Zn}_{6}-\mathrm{MT}\right)\right\}^{4+}$ & 1632.2 & $1632.0 \pm 0.4$ \\
\hline$\left(\mathrm{Zn}_{6}-\mathrm{MT}\right)^{4+}$ & 1624.2 & $1623.6 \pm 0.6$ \\
\hline$\left.\left(\mathrm{Zn}_{5}-\mathrm{MT}\right)-\mathrm{Zn}-\left(\mathrm{Zn}_{5}-\mathrm{MT}\right)\right\}^{4+}$ & 1616.3 & $1615.4 \pm 0.7$ \\
\hline$\left(\mathrm{Zn}_{5}-\mathrm{MT}\right)^{4+}$ & 1600.5 & $1599.8 \pm 0.7$ \\
\hline$\left.\left(\mathrm{Zn}_{4}-\mathrm{MT}\right)-\mathrm{Zn}-\left(\mathrm{Zn}_{4}-\mathrm{MT}\right)\right\}^{4+}$ & 1592.6 & $1592.4 \pm 0.5$ \\
\hline$\left(\mathrm{Zn}_{4}-\mathrm{MT}\right)^{4+}$ & 1584.6 & $1583.9 \pm 0.9$ \\
\hline$\left.\left(\mathrm{Zn}_{3}-\mathrm{MT}\right)-\mathrm{Zn}-\left(\mathrm{Zn}_{3}-\mathrm{MT}\right)\right\}^{4+}$ & 1576.7 & $1576.0 \pm 0.7$ \\
\hline$\left(\mathrm{Zn}_{3}-\mathrm{MT}\right)^{4+}$ & 1568.8 & $1568.9 \pm 1.0$ \\
\hline$\left.\left(\mathrm{Zn}_{2}-\mathrm{MT}\right)-\mathrm{Zn}-\left(\mathrm{Zn}_{2}-\mathrm{MT}\right)\right\}^{4+}$ & 1560.9 & $1560.0 \pm 1.0$ \\
\hline$\left(\mathrm{Zn}_{2}-\mathrm{MT}\right)^{4+}$ & 1552.9 & $1552.4 \pm 0.7$ \\
\hline$\left.\left(\mathrm{Zn}_{1}-\mathrm{MT}\right)-\mathrm{Zn}-\left(\mathrm{Zn}_{1}-\mathrm{MT}\right)\right\}^{4+}$ & 1545.0 & $1545.5 \pm 1.0$ \\
\hline$\left(\mathrm{Zn}_{1}-\mathrm{MT}\right)^{4+}$ & 1537.0 & $1537.3 \pm 0.8$ \\
\hline
\end{tabular}


One of the assumptions made to explain the observations focuses on the loss of a small fragment which was either neutral or charged. If so, the difference between adjacent peaks of about 8.2 Da must be assigned to the $\mathrm{m} / \mathrm{z}$ value of a charged small fragment or to the mass of a neutral species. In addition to the assignment, the assumption also implies that the MT molecule must contain no less than seven uniform units in common with the fragment ready to be released. By checking the peptide sequence provided [2], no repeated unit had such a mass property unless the zinc atoms were charged with +8 .

Most of the ions listed in Table 3.2 had been set as target ions and scanned by MS/MS/MS, i.e. $\mathrm{MS}^{\wedge}$. Mass spectra were obtained in which the peaks were evenly separated by about $8.2 \mathrm{Da}$. Here, the same mass loss in $\mathrm{MS}^{\wedge \mathrm{n}}(\mathrm{n}=2,3) \mathrm{CID}$ implied the loss of the same species during all kinds of the CID processes. And the absence of the product peaks with larger $\mathrm{m} / \mathrm{z}$ value than that of the target ions reduced the possibility that the target ions could have been produced by a combination of a few different unit ions. Both of the observations most likely ruled out the possibility that the series of ions listed in Table 3.2 was formed by releasing an identical fragment with $\mathrm{m} / \mathrm{x}$ value of 8.2 Da form the monomeric molecule ions. Another possible explanation for the production of the series of the ions is through the formation of dimeric intermediates. 
The dissociation process for the MT molecular ions resulting in dimeric intermediate formation occurs as follows. Upon the collision with the neutral gas species, the energy was transferred to the metal complex which activated the metal species in the $\beta$-domain first [12]. The Zn-MT molecular ions freed four equivalent sulfhydryl groups by releasing one equivalent metal which then combined with those four sulfhyhryl groups tetrahedrally. The fragment ion with such free activated sulfhydryl groups undergoes interaction with other molecular ions. During such an interaction, the free sulfhydryl groups compete with the Zn-binding sulfhydryl groups belonging to the intact metallothionein ion in binding the zinc atom. A newborn zinc-sulfhydryl complex would form either within the MT ion or between the two MT ions. No interesting information would be provided by MS if the $\mathrm{Zn}-(\mathrm{SR})_{4}$ complex had reformed within the monomeric ion. However, the formation of the new-born complex between the two monomeric MT ions caused the dimerization of the MT ions in which the zinc complex worked as a metal bridge. Therefore, a metal-sulfhydryl bridge was formed to combine two involved MT ions into a dimer in which the total charges would be +8 and the mass would be the sum of the dimeric MT minus the mass of a zinc atom.

The valence bonds in the bridge complex were weaker compared to those in the regular tetrahedral metal-thiol complexes. If no more collision energy was introduced into the 
gas-phase ion, the bridge would not be broken to release the metal trapped in the bridge and the dimer intermediates would be kept intact. The consequent statement that the temporary stability of the dimers in the ion trap mass analyzer was necessary for MS scans was confirmed by the presence of the intermediates in the mass spectra. However, the dimers formed during the collision induced dissociation procedure were not isolated from the further collision. After releasing the shared zinc ions, these dimeric intermediate species were broken to form two identical product ions which apparently lost one equivalent metal ions from the MT molecule ions.

Those resultant product ions losing one equivalent metal ion could experience further CID to form other dimer intermediates with fewer metals, "descendants". As shown in Table 3.2, all of the intermediates were of the same structure except the difference in the number of the zinc atoms in the monomeric subunits. The multipeptide chains were kept intact throughout the whole experiment in this paper. The CID procedure was again applied on the product ions which was $\left(\mathrm{Zn}_{6}-\mathrm{MT}\right)^{4+}$ in this step and the metal-bridged dimer with five zinc atoms in each subunit was produced prior to the generation of the $\left(\mathrm{Zn}_{5}-\mathrm{MT}\right)^{4+}$. The process to release the zinc atoms one by one would keep going on until only the apo-protein ions were left as the primary fragment ion in the ion trap. 
The assumption of the presence of a dimeric intermediate is consistent with the CID mass spectra. The differences between any two adjacent peaks were all 8.2Da and 16.3Da was the difference between one peak and every other peak. For the monomeric ions, the charges were all +4 and the differences in number of zinc accounted for the peak differences. For the dimeric intermediate ions, the charges were all +8 and the difference of two zinc atoms suggested the same math results. 


\subsection{Conclusion}

Metal-protein bond dissociation properties were studied by the tandem mass spectrometry. Collision-induced dissociation (CID) in the quadrupole ion trap (QIT) was used to produce fragment ions softly. Only the metal-peptide bonds were broken during CID as the collision energies were set at low values. The chelating reagent EDTA was used to confirm the production of the free metal ions in the CID process by capturing them and forming complex ions which were detectable by the ion trap mass analyzer. The behavior of EDTA in the tandem MS was verified before its application in CID-MS. From the mass spectrum, it was demonstrated that the dimers could neither form in the stock solution nor in the ion trap prior to the CID process. This excluded the possibility that the dimer was the same species as the one mentioned before [1]. A novel form of the metallothionein dimer was discovered in the tandem MS studies. The series of dimers present in the tandem mass spectra appear to be an intermediate between the parent ions and the expected products. The formation of dimer is explained in sharing one metal by two MT monomers to form a tetrahedral metal-thiol complex bridge while the thiol groups were donated evenly by two monomeric MT peptide chains. Not only were the dimer intermediates produced in the CID of the molecular ions, but also the monomeric descendant ions resulting from losing one equivalent metal from the respective parent 
ions appeared in the CID mass spectra as well. The MS/MS/MS on the produced dimeric intermediates produced monomeric ions together with the descendant dimeric intermediates. The mechanism of forming the dimer intermediate was described. 


\subsection{Reference}

1. Zangger, K.; Armitage, L. M. J. Inorg. Biochem., 2002, 88(2), 135-143.

2. Kägi, J. H. R.; Schäffer, A. Biochemistry, 1988, 27, 8509-8515.

3. Margoshes, M; Vallee, B. L. J. Am. Chem. Soc., 1957, 79, 4813-4814.

4. Vašák, M.; Kägi, J. H. R.; Hill, H. A. O. Biochemistry, 1981, 20, 2852-2856.

5. Furey, W. F, Robbins, A. H.; Clancy. L. L.; Winge, D. R.; Wang, B. C.;

Stont, C. D. Science, 1986, 231, 704-710.

6. Otvos, J. D.; Engeseth, H, R.; Wehrli, S. Biochemistry, 1985, 24, 67356740.

7. Zangger, K.; Shen, G.; Öz, G.; Otovs,J. D.; armtage, I. M. Biochem. J. 2001, $359,353-360$.

8. Palumaa, P.; Mackay, E. A.; Vašák, M. Biochemistry, 1992, 31, 2181-2186.

9. Palumaa, P.; Vašák, M. Euro. J. Biochemistry, 1992, 205, 1131-1135.

10. Frankel, A.; Bredt, D. S.; Pabo, C. O. Science, 1988, 240, 70-73.

11. Hathout, Y.; Reynolds, K. J.; Szilagyi, Z.; Fenselau, C. J. Inorganic Biochemistry. 2002, 88(2), 119-122. 
12. Lu, Y.; King, F. L. submitted.

13. Asano, K. G.; Goeringer, D. E.; Butcher, D. J.; McLuckey, S. A. Int. J. Mass Spectrom. 1999, 190/191, 281-293.

14. Li, H.; Otvos, J. D. Biochemistry, 1996, 35, 13929-13936.

15. Cobine, P. A.; Jones, C. E.; Dameron, C. T. J. Inorganic Biochemistry. 2002, 88(2), 192-196.

16. Li, T. Y.; Shaw III, A. J.; Petering, D. H. Proc. Natl. Acad. Sci. U.S.A. 1980, 77, 6334-6338.

17. Hoffmann, E.; Stroobant, V. Mass Spectrometry Principles \& Applications, $2^{\text {nd }}$, John Wiley \& Sons, Chichester, 2002. 


\section{Chapter 4 Electrochemically-Induced Reactions of Hexafluorophosphate Anions with Water in Negative Ion Electrospray Ionization Mass Spectrometry of Undiluted Ionic Liquids}

The influence of water on the observed gas-phase population of negative ions in electrospray ionization mass spectrometry was studied for the undiluted ionic liquid 1,3butyl-methyl-imidazolium hexafluorophosphate $\left(\mathrm{BMIM}^{+} \mathrm{PF}_{6}^{-}\right)$. During the electrospray process, electrolytic reduction of water enhances the production of tetrafluorophosphate $\left(\mathrm{F}_{4} \mathrm{PO}^{-}\right)$which undergoes further reactions to produce difluorophosphate $\left(\mathrm{F}_{2} \mathrm{PO}_{2}^{-}\right)$and metaphosphate $\left(\mathrm{PO}_{3}{ }^{-}\right)$anions. These anions are observed in addition to the pre-existing hexafluorophosphate anion. The apparent substitution of two fluorine atoms with one oxygen is attributed to a series of reactions initiated by the hydrolysis of hexafluorophosphate. This hydrolysis reaction was enhanced by the addition of hydroxide, formed via the hydrolysis of water or through the addition of ammonium hydroxide. The formation of $\mathrm{F}_{\mathrm{x}} \mathrm{PO}_{\mathrm{y}}{ }^{-}$was studied as a function of the electrospray current and solution flow rate. The mass spectral response shows a quantitative logarithmic 
relationship between $\mathrm{F}_{\mathrm{x}} \mathrm{PO}_{\mathrm{y}}{ }^{-}$signal intensities (adjusted for mole equivalents of $\mathrm{H}_{2} \mathrm{O}$ required) and the amount of water present, against which the water content could be rapidly assessed. Results were found to be comparable to Karl Fischer titration data. 


\subsection{Introduction}

Composed entirely of organic cations and inorganic complex anions, room temperature ionic liquids (ILs) have attracted tremendous attention as novel solvents. The most commonly investigated cations are $N, N$-dialkylimidazolium, $N$-alkylpyridinium, and tetra-alkyl-ammonium. Common anions are tetrafluoroborate $\left(\mathrm{BF}_{4}^{-}\right)$, hexafluorophosphate $\left(\mathrm{PF}_{6}^{-}\right)$, bis[(trifluoromethyl)sulfonate $]$amide $\left(\mathrm{TF}_{2} \mathrm{~N}^{-}\right)$, and trifluoroethanoate $\left(\mathrm{CF}_{3} \mathrm{CO}_{2}^{-}\right)$. These salts display unique properties in addition to being liquid at room temperature. These include negligible vapor pressure, wide electrochemical windows, and high ionic conductivity. As an alternative to aqueous or

organic solvents, ILs are thought to hold much promise for green chemistry applications. As a new solvent system, ILs are being investigated in a variety of applications such as polymer synthesis $[1,2,3]$, catalytic processes $[4,5]$, electrochemical reactions [6], liquid-liquid extractions [7], and as a vacuum compatible matrix for matrix-assisted laser desorption/ionization $[8,9,10,11,12,13]$.

Impurities and their effects on the properties of the ILs have been the subject of several studies $[6,14,15,16]$. Because ILs often absorb water, the effect of water on 
electrochemical properties has been studied $[6,14]$. Research on the solubility of water in ILs is very important, particularly when the ILs are used with water sensitive materials and reactions. Depending on the choice of anions, water solubility varies [14]. For example, ILs composed of $\mathrm{PF}_{6}^{-}$anions are not water- miscible, yet $\mathrm{Cl}^{-}$based ILs are water-miscible. Despite the immiscibility of $\mathrm{PF}_{6}{ }^{-}$based ILs, water is often absorbed at concentrations as high as $16 \%(w / w)$ [14]. Studies of water-contaminated 1-butyl-3methylimidazolium hexafluorophosphate $\left(\mathrm{BMIM}^{+} \mathrm{PF}_{6}^{-}\right)$ionic liquids suggest that the water/IL system is not homogenous but is instead a 'nano-structured', bi-phasic solution [6]. The presence of water in such water-immiscible ILs was found to affect electrochemical characteristics and increase ion diffusion rates $[6,14,15,16]$.

Electrospray mass spectrometry (ES-MS) has been widely used to transfer ions from the liquid phase into the gas phase for MS analysis. It has extended the range of MS applications to high polarity, high mass, and highly labile molecules. Alfassi et al. developed a method using ES-MS to quantify the hydrophobic IL solubilities in water [17]. Acceptable ES-MS detection of minor analyte species, such as $\left[\mathrm{Ru}\left(\eta^{6}-p\right.\right.$ cymene $)\left(\eta^{2}\right.$-triphos $\left.) \mathrm{Cl}\right]^{+}$, within an IL matrix has been performed following a $10^{5}: 1$ dilution with methanol [18]. Similarly, negative ion ES-MS has proven useful for the detection of negative species such as the anionic catalyst $\left[\mathrm{Ru}(\mathrm{CO})_{2} \mathrm{I}_{2}\right]^{-}$and $\mathrm{Cl}^{-}[18]$. ES- 
MS analysis of tetrabutylammonium ions and neutral ferrocene ions in neat (undiluted) ILs has been investigated and was found to have sensitivity for these dissolved analytes comparable to the diluted ILs $[19,20]$. The nonvolatile nature of ILs has not proven to be a limitation in the generation of these ions via electrospray.

In our laboratory, negative ion ES-MS of undiluted $\mathrm{BMIM}^{+} \mathrm{PF}_{6}^{-}$ILs is observed to generate water-related product anions from $\mathrm{PF}_{6}{ }^{-}$with the general formula $\mathrm{F}_{\mathrm{x}} \mathrm{PO}_{\mathrm{y}}{ }^{-}$(i.e., $\mathrm{F}_{4} \mathrm{PO}^{-}$and $\left.\mathrm{F}_{2} \mathrm{PO}_{2}{ }^{-}\right)$. This chemistry is thought to be driven by electrochemical processes within the ES emitter. The study of this chemistry is presented here, and the correlation between water content and $\mathrm{F}_{\mathrm{x}} \mathrm{PO}_{\mathrm{y}}{ }^{-}$response is characterized. 


\subsection{Experimental}

1, 3-butyl-methyl-imidazolium hexafluorophosphate $\left(\mathrm{BMIM}^{+} \mathrm{PF}_{6}{ }^{-}\right)$and 1, 3-ethyl-methylimidazolium tetrafluoroborate $\left(\mathrm{EMIM}^{+} \mathrm{BF}_{4}{ }^{-}\right)($Sigma-Aldrich, St. Louis, $\mathrm{MO})$, were vacuum-dried for 48 hours and stored in a nitrogen filled desiccator. Biphasic water/BMIM ${ }^{+} \mathrm{PF}_{6}^{-}$mixtures formed when deionized water $\left(>18 \mathrm{M} \cdot \mathrm{cm}, \mathrm{MilliQ}^{\circledR}\right.$, Billerica, MA) was spiked into the ILs. Homogenous solutions were obtained by ultrasonication for 20 minutes. Water concentrations reported in this study were calculated as follows. Karl Fischer titration (Brinkmann KF-652, Herisan, Switzerland) was used to establish the residual percent water in samples that were vacuum dried. If water was spiked into a sample, the weight of additional water was summed with that from the Karl Fischer determined "blank" to calculate the total water content.

Electrospray mass spectra were obtained with a ThermoElectron PolarisQ ${ }^{\circledR}$ Ion-Trap mass spectrometer (Austin, TX) modified with the addition of a ThermoElectron Deca ${ }^{\circledR}$ electrospray ion source. The ion optical system between the ion source and the mass analyzer is composed of two ion guides and an ion gating lens. The ion gating lens is a disk electrode with a $0.8 \mathrm{~mm}$ orifice that is positioned between quadrupole and octopole 
ion guides. Both ion guides operate at the same rf frequency, rf amplitude, and dc floating voltage, and are driven by a custom-built RF power supply [21]. The relative ion current was measured at the ion transfer tube by an electrometer (Orteck 710, Oak Ridge, TN). It should be noted that the high voltage emitter was operated without an upstream grounding point. Due to the high conductivity of ILs, (about 1000 times larger than conventional volatile solvents), grounding the injection line through the insertion of an ammeter decreased the spray voltage at the emitter tip, and disrupted the electrospray process.

An Oxford dual track syringe pump (AH55-2122, Holliston, MA) was used to continuously inject samples from a $250 \mu \mathrm{L}$ syringe (Hamilton, Reno, NV) at a constant flow rate of $0.3 \mu / \mathrm{min}$ unless otherwise noted. A 1 meter PEEK ${ }^{\circledR}$ tube with $125 \mu \mathrm{m}$ internal diameter (i.d.) connected the syringe and the emitter. The $125 \mu \mathrm{m}$ i.d. tubing was used to maintain a low backpressure for the viscous ILs. For the same purpose, PEEK ${ }^{\circledR}$ unions (No. P-742, Upchurch Scientific) with $250 \mu \mathrm{m}$ i.d. were used. A $6 \mathrm{~cm}$ long stainless steel emitter with $100 \mu \mathrm{m}$ i.d. and $500 \mu \mathrm{m}$ o.d. was used in conjunction with a stainless steel union to which the spray voltage was applied. A Tennelec/Oxford dualpolarity 0-5 kV power supply (TC950A, Oak Ridge, TN) was used to provide the negative $3-5 \mathrm{kV}$ emitter potential. 


\subsection{Results and Discussion}

To perform the initial characterization of electrospray mass spectrometry of undiluted ion liquids containing water, $\mathrm{BMIM}^{+} \mathrm{PF}_{6}{ }^{-}$was spiked with 0 to $6 \%$ (w/w) of water, and conventional Karl Fischer titration was used to measure the water content. The samples were then studied by negative ion ES-MS as a function of voltage, flow rate, and water content.

\section{Mass Spectral Characterization}

It is known that electrochemical processes at the emitter surface can influence the abundance and identity of gas-phase ions in ES-MS [22, 23], with the degree of redox chemistry occurring being a function of both reaction time at the emitter surface and the spray current. To explore this, the emitter voltage was increased to increase spray current and the flow rate was reduced to increase redox efficiency to determine their effect of these parameters on gas-phase ion abundances of $\mathrm{F}_{\mathrm{x}} \mathrm{PO}_{\mathrm{y}}{ }^{-}$. 
Negative ion electrospray mass spectra of $\mathrm{BMIM}^{+} \mathrm{PF}_{6}{ }^{-}$containing $0.24 \% \mathrm{H}_{2} \mathrm{O}$ are shown in Figure 4.1 for different emitter voltages. Injection flow rate was held constant at 0.3 $\mu 1 /$ min. Operating at a threshold voltage for ion production (3.0 kV in Figure 4.1a), only pre-formed $\mathrm{PF}_{6}{ }^{-}$ions are observed. The relative ion current $\left(i_{R C}\right)$ measured at the transfer tube was $0.31 \mu \mathrm{A}$. When the spray voltage was increased to $3.7 \mathrm{kV}$ and $5.0 \mathrm{kV}$ (Figures $3.1 \mathrm{~b}$ and $3.1 \mathrm{c}$,$) , the i_{R C}$ increased to $0.90 \mu \mathrm{A}$ and $2.02 \mu \mathrm{A}$, respectively, with a corresponding increase in $\mathrm{F}_{\mathrm{x}} \mathrm{PO}_{\mathrm{y}}{ }^{-}$anion intensities increased and a decrease in $\mathrm{PF}_{6}{ }^{-}$ intensity. Anions $\mathrm{F}_{4} \mathrm{PO}^{-}$and $\mathrm{F}_{2} \mathrm{PO}_{2}{ }^{-}$are the primary product ions observed along with $\mathrm{HPO}^{-}$and other less abundant ions whose identity could not be confirmed.

The effect of current on product ion distribution is not surprising because the electrospray ionization process is a controlled-current electrolytic process [22, 23]. Increases in emitter potential change affect the magnitude of the redox current at the emitter surface. The extent of the reaction, and therefore $\mathrm{F}_{\mathrm{x}} \mathrm{PO}_{\mathrm{y}}{ }^{-}$abundances, increases with the magnitude of ES current. As will be shown later, higher spray voltage $V_{E S}$ (resulting in higher emitter current) can be used to improve the sensitivity of water concentration determination. 


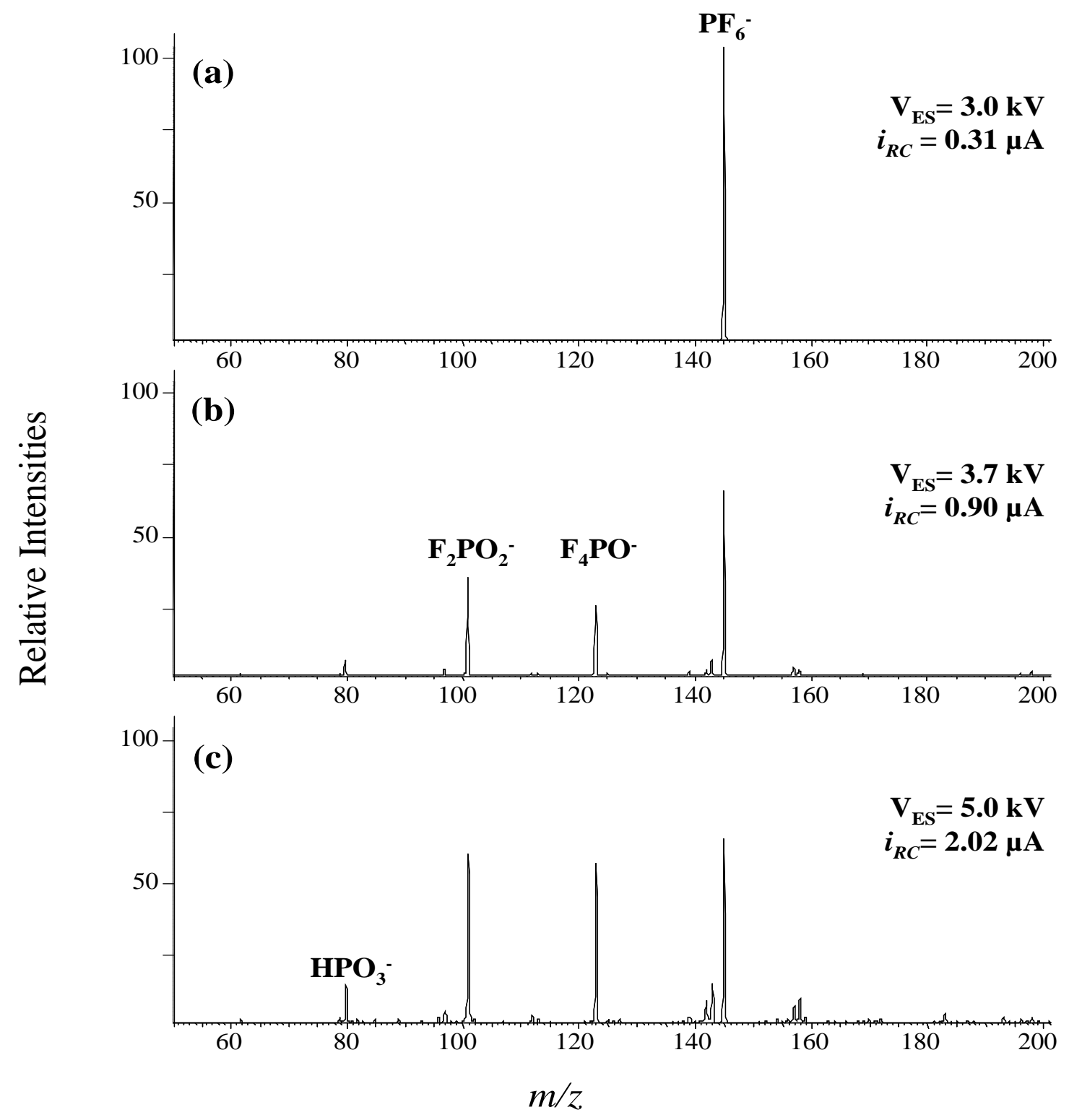

Figure 4.1. Negative ion ES-MS of $\mathrm{BMIM}^{+} \mathrm{PF}_{6}{ }^{-}$at a) $3.0 \mathrm{kV}$, b) $3.7 \mathrm{kV}$, and c) $5.0 \mathrm{kV}$, each normalized to (a). Water content and flow rate were held constant at $0.24 \%(\mathrm{w} / \mathrm{w})$ and $0.3 \mu 1 / \mathrm{min}$, respectively. 
Studies have shown that tetrafluorophosphate $\left(\mathrm{F}_{4} \mathrm{PO}^{-}\right)$, difluorophosphate $\left(\mathrm{F}_{2} \mathrm{PO}_{2}^{-}\right)$and metaphosphate $\left(\mathrm{HPO}_{3}{ }^{-}\right)$complex ions can be formed in battery cells from reactions initiated by the hydrolysis reaction of $\mathrm{PF}_{6}^{-}[24,25,26,27,28]$. The reactions are not simple consecutive processes. The decomposition of $\mathrm{PF}_{6}{ }^{-}$starts with the formation of $\mathrm{F}_{3} \mathrm{PO}$ through the reaction of $\mathrm{PF}_{6}{ }^{-}$with $\mathrm{H}_{2} \mathrm{O}$,

$$
\mathrm{PF}_{6}^{-}+\mathrm{H}_{2} \mathrm{O}-\mathrm{F}_{3} \mathrm{PO}+2 \mathrm{H}^{+}+3 \mathrm{~F}^{-}
$$

and $\mathrm{F}_{3} \mathrm{PO}$ readily adds $\mathrm{F}^{-}$to form the $\mathrm{F}_{4} \mathrm{PO}^{-}$anion [25]:

$$
\mathrm{F}_{3} \mathrm{PO}+\mathrm{F}^{-}>\mathrm{F}_{4} \mathrm{PO}^{-}
$$

Electrolytic hydrolysis of water during the electrospray process produces hydroxide ions as shown,

$$
2 \mathrm{H}_{2} \mathrm{O}+2 \mathrm{e}^{-}>\mathrm{H}_{2}+2 \mathrm{OH}^{-}
$$

which neutralize the hydrofluoric acid produced in reaction (1),

$$
2 \mathrm{OH}^{-}+2 \mathrm{HF}>2 \mathrm{H}_{2} \mathrm{O}+2 \mathrm{~F}^{-}
$$

assisting the decomposition of $\mathrm{PF}_{6}{ }^{-}$according to Le Chatelier's principle. The net reaction of the $\mathrm{PF}_{6}^{-}$with water (reactions (1) to (4)) is

$$
\mathrm{PF}_{6}^{-}+\mathrm{H}_{2} \mathrm{O}+2 \mathrm{e}^{-}>\mathrm{F}_{4} \mathrm{PO}^{-}+\mathrm{H}_{2}+2 \mathrm{~F}^{-}
$$




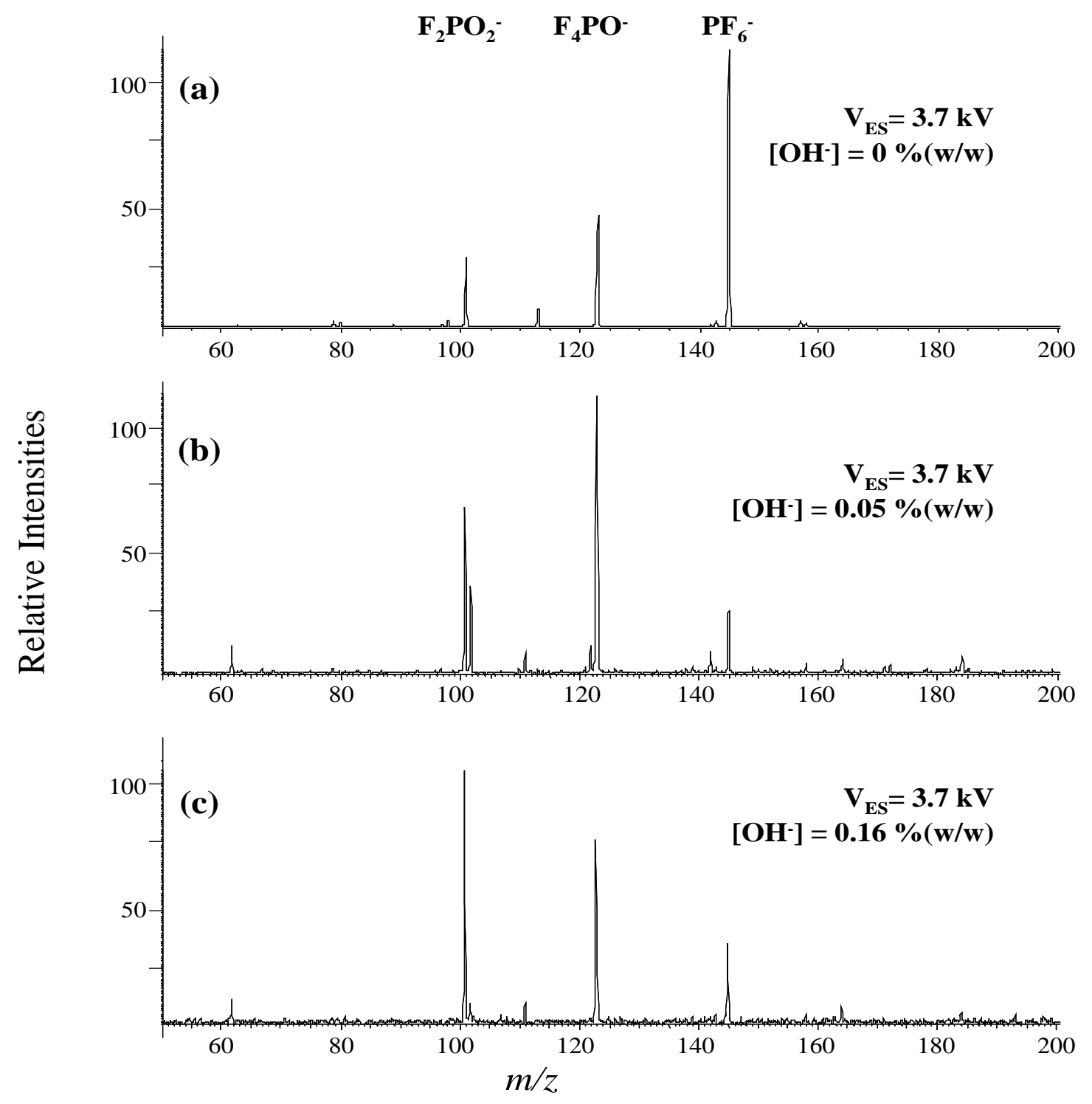

Figure 4.2. Negative ion ES-MS of $\mathrm{BMIM}^{+} \mathrm{PF}_{6}^{-}$spiked with $\mathrm{NH}_{4} \mathrm{OH}$ with $\left[\mathrm{OH}^{-}\right]$at a) $0 \%$ $(\mathrm{w} / \mathrm{w}), \mathrm{b}) 0.05 \%(\mathrm{w} / \mathrm{w})$, and c) $0.16 \%(\mathrm{w} / \mathrm{w})$, each normalized to (a). Water content, electrospray voltage, and flow rate were held constant at $2.03 \%$ (w/w), $3.7 \mathrm{KV}$, and $0.3 \mu \mathrm{l} / \mathrm{min}$, respectively. 
The role of hydroxide ions in the hydrolysis reactions was tested by ES-MS analysis of $\mathrm{BMIM}^{+} \mathrm{PF}_{6}{ }^{-}$samples that were spiked with water and ammonium hydroxide. Figure 4.2 shows the mass spectrometric response to varying concentrations of $\mathrm{OH}^{-}$. Water content $(2.03 \% \mathrm{w} / \mathrm{w})$ and the electrospray voltage $(3.7 \mathrm{kV})$ were held constant. The spectrum shown in Figure 4.2a was obtained prior to the addition of hydroxide ions. $\mathrm{PF}_{6}{ }^{-}$is the dominant species and a relatively small fraction of fluorophosphates was transformed to $\mathrm{F}_{\mathrm{x}} \mathrm{PO}_{\mathrm{y}}{ }^{-}$. As the concentration of $\mathrm{OH}^{-}$was increased (up to $0.16 \%(\mathrm{w} / \mathrm{w})$ ), $\mathrm{F}_{\mathrm{x}} \mathrm{PO}_{\mathrm{y}}{ }^{-}$products became more abundant with the dominant species in mass spectra being $\mathrm{F}_{2} \mathrm{PO}_{2}{ }^{-}$at the highest hydroxide concentration.

Difluorophosphate anion formation has been observed by Christe et al. who reported that $\mathrm{F}_{4} \mathrm{PO}^{-}$anion undergoes the exothermic disproportionation reaction $\left(\Delta \mathrm{H}=-76 \mathrm{kcal} \cdot \mathrm{mol}^{-1}\right)$ $[24,25]$,

$$
2 \mathrm{~F}_{4} \mathrm{PO}^{-}>\mathrm{PF}_{6}^{-}+\mathrm{F}_{2} \mathrm{PO}_{2}^{-}
$$

As the concentration of $\mathrm{F}_{4} \mathrm{PO}^{-}$increases, reaction (6) becomes kinetically favored. The amount of $\mathrm{F}_{4} \mathrm{PO}^{-}$anions decreases due to the disproportion reaction, and the abundance of $\mathrm{F}_{2} \mathrm{PO}_{2}{ }^{-}$increases. Other negative ions of low abundance (e.g., $\mathrm{PO}_{3}{ }^{-}, \mathrm{HPO}_{3}{ }^{-}, \mathrm{H}_{2} \mathrm{PO}_{4}^{-}$in Figures 3.1-3.4) were also observed in ES-MS, but their origin and role in $\mathrm{PF}_{6}{ }^{-}$reactions 
cannot be confirmed due to their low abundance and poor correlation with experimental variables. 


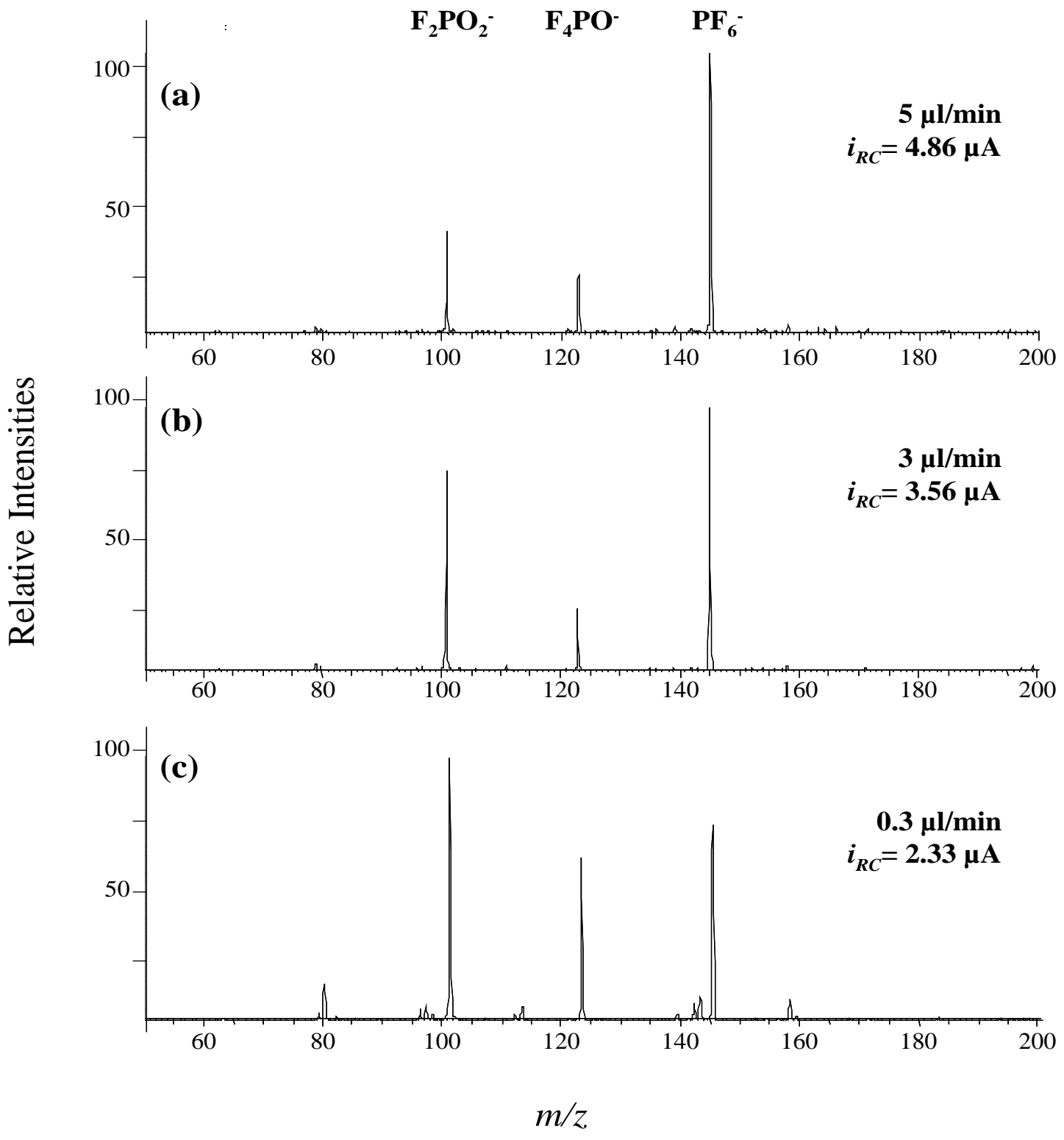

Figure 4.3. Negative ion ES-MS of $\mathrm{BMIM}^{+} \mathrm{PF}_{6}{ }^{-}$at various flow rates, a) $5 \mu \mathrm{l} / \mathrm{min}$, b) 3 $\mu \mathrm{l} / \mathrm{min}$, and c) $0.3 \mu \mathrm{l} / \mathrm{min}$, each normalized to (a). Water content and electrospray voltage were held constant at $3.43 \%(\mathrm{w} / \mathrm{w})$ and $5.0 \mathrm{kV}$, respectively. 
The mass spectra shown in Figure 4.3 demonstrate the effect of solution flow rate on multifluorophosphate anion formation. $\mathrm{BMIM}^{+} \mathrm{PF}_{6}{ }^{-}$solution was injected through the emitter at flow rates of $0.3,3$, and $5 \mu /$ min with a constant emitter voltage of $5.0 \mathrm{kV}$. The degree of $\mathrm{PF}_{6}^{-}$hydrolysis is inversely proportional to flow rate. This is consistent with an electrochemically-induced reaction at the electrospray emitter that proceeds as a function of the interaction time of water at emitter surface. The reduction in $\mathrm{i}_{R C}$ primarily reflects the lowered mass throughput at low flow rates because $\mathrm{i}_{R C}$ reflects the oxidation current for all ions arriving at the ion transfer line (including $\mathrm{PF}_{6}^{-}$) and is not a direct indication of the hydrolysis process alone. More IL and water mass is supplied at the higher flow rate, but the formation of hydrolysis products was low, presumably due to diffusion rate limitations.

\section{Effect of Water Content on $F_{x} P O_{y}^{-}$Response}

Karl Fischer titration results indicated that the 'pure' vacuum-dried $\mathrm{BMIM}^{+} \mathrm{PF}_{6}{ }^{-}$retains $0.24 \%(\mathrm{w} / \mathrm{w})$ residual water, demonstrating the difficulty in removing water from even water-immiscible ionic liquids. Incrementally increasing the electrospray voltage from 0 $\mathrm{kV}$ to $5 \mathrm{kV}$ resulted in threshold voltages $\left(\mathrm{V}_{\mathrm{T}}\right)$ - the voltage at which gas phase ions are generated - that are proportional to water content. The lowest threshold value of spray 
voltage was $3.0 \mathrm{kV}$ for the IL sample with the smallest amount of water. $\mathrm{V}_{\mathrm{T}}$ increased with water content up to $3.3 \mathrm{kV}$ for $1.4 \%$ water, reaching a plateau at $2 \%$. 

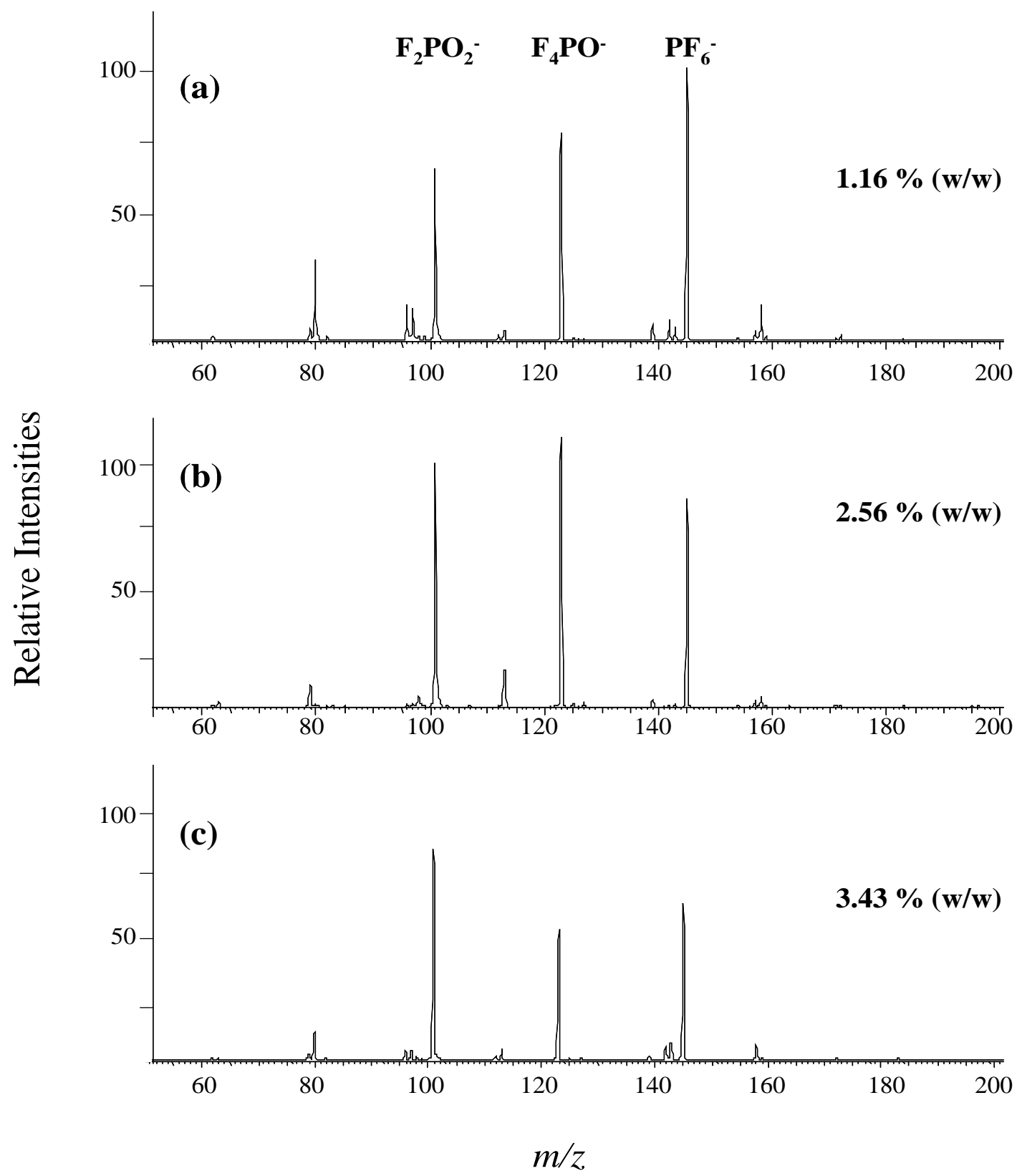

Figure 4.4. Negative ion ES-MS of $\mathrm{BMIM}^{+} \mathrm{PF}_{6}^{-}$at various water contents, a) $1.16 \%$ $(w / w), b) 2.56 \%(w / w)$, and c) $3.43 \%(w / w)$, each normalized to (a). Flow rate and electrospray voltage were held constant at $0.3 \mu 1 / \mathrm{min}$ and $5.0 \mathrm{kV}$, respectively. 
Figure 4.4 shows ES mass spectra of three $\mathrm{BMIM}^{+} \mathrm{PF}_{6}{ }^{-}$samples with different water contents electrosprayed at an emitter voltage of $5.0 \mathrm{kV}$ and a flow rate of $0.3 \mu \mathrm{l} / \mathrm{min}$. The gas-phase abundances of the $\mathrm{F}_{\mathrm{x}} \mathrm{PO}_{\mathrm{y}}{ }^{-}$ions relative to $\mathrm{PF}_{6}{ }^{-}$increase with water content. Since water content is directly related to the abundance of $\mathrm{F}_{\mathrm{x}} \mathrm{PO}_{\mathrm{y}}{ }^{-}$ions, it is possible that these can provide a convenient method to quantify the water content of undiluted ILs using electrospray mass spectrometry.

In Figure 4.5, two calibration curves are shown that were generated using emitter voltages of $3.6 \mathrm{kV}\left(R^{2}=0.96\right)$ and $4.6 \mathrm{kV}\left(R^{2}=0.98\right)$. The anions $\mathrm{F}_{4} \mathrm{PO}^{-}$and $\mathrm{F}_{2} \mathrm{PO}_{2}{ }^{-}$were plotted as function of weight concentration of water and normalized to the total ion signal measured in each scan. A weighting factor of two was used for $\mathrm{F}_{2} \mathrm{PO}_{2}{ }^{-}$to reflect the number of water equivalents involved in $\mathrm{F}_{2} \mathrm{PO}_{2}$ production. These demonstrate an empirically-determined logarithmic relationship between water content, as determined by Karl Fischer titration, and the sum $\left(\mathrm{F}_{4} \mathrm{PO}^{-}+2 \mathrm{~F}_{2} \mathrm{PO}_{2}^{-}\right)$normalized to total ion current. The nonlinear relationship with respect to water content is thought to be due to the relative and unknown rates of the pseudo-first order reaction in Equation $\mathbf{5}$ and the second-order disproportionation reaction (Equation 6). Because the reaction rate constants are not known, the use of summed intensities of the multifluorophosphate ions is thought to be more accurate and straightforward. 


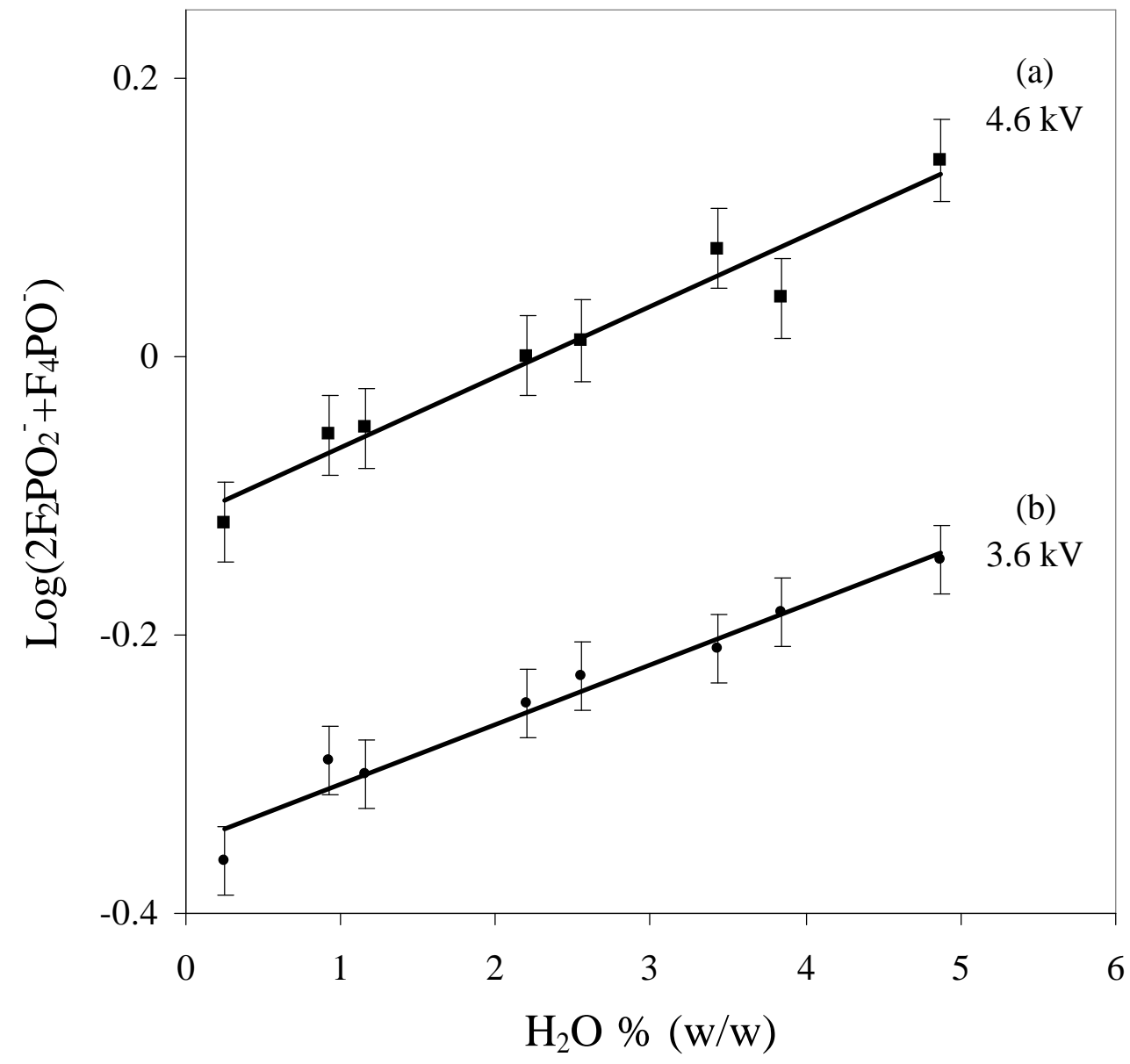

Figure 4.5. Relationship between extent of $\mathrm{PF}_{6}{ }^{-} / \mathrm{H}_{2} \mathrm{O}$ reaction and water content for $\mathrm{BMIM}^{+} \mathrm{PF}_{6}{ }^{-} \mathrm{ES}-\mathrm{MS}$ at $3.6 \mathrm{kV}$ and $4.6 \mathrm{kV}$ and at flow rate of $0.3 \mu / \mathrm{min}$. The response of the fluorophosphates were weighted for mole equivalents of water required and the sum was normalized to the total ion current in each scan. 
The results of three measurements of $\mathrm{BMIM}^{+} \mathrm{PF}_{6}{ }^{-}$were averaged for each calibrant solution, ranging from $\sim 0.24 \%(\mathrm{w} / \mathrm{w})$ to $\sim 6 \%(\mathrm{w} / \mathrm{w})$ water. Consistent with redox current considerations, analytical sensitivity was higher at the $4.6 \mathrm{kV}$ emitter voltage. The slopes of two curves are 0.063 and 0.108 , resulting in a 1.7 -fold enhancement in sensitivity at the higher emitter voltage.

The unspiked vacuum-dried sample retained a water content of $0.24 \%(\mathrm{w} / \mathrm{w})$. More vigorous cleaning procedures were not attempted. Because of the difficulty in removing the water residue from the IL sample lower water concentrations could not be evaluated and the dynamic range of the measurement was limited. The dynamic range of the method is bounded by water-solubility at the upper concentration limit and sample dehydration methods at the lower concentration limit.

The response curve shown in Figure $4.5 \mathrm{a}(4.6 \mathrm{kV})$ was used to quantify water content in two $\mathrm{BMIM}^{+} \mathrm{PF}_{6}{ }^{-}$samples. After spiking, the resulting water contents were calculated to be $0.92 \%(\mathrm{w} / \mathrm{w})$ and $1.16 \%(\mathrm{w} / \mathrm{w})$. The results based on ES-MS measurements were $0.94 \%(\mathrm{w} / \mathrm{w})$ and $1.23 \%(\mathrm{w} / \mathrm{w})$ with relative standard deviations (RSD) of $7 \%$ and $12 \%$, respectively. Karl Fischer titration results for the same samples were $0.92 \%$ and $1.04 \%$ with RSD of $13 \%$ and $8 \%$ respectively. The relative error of the measurement was less 
than $10 \%$, and accuracy and precision are comparable to the conventional Karl Fischer titration results, suggesting that negative ion ES-MS can provide an approach for the direct determination of water content for ionic liquids containing the $\mathrm{PF}_{6}{ }^{-}$anion. 


\subsection{Conclusions}

To most efficiently detect analytes or impurities within ionic liquids, electrochemical phenomenon favoring their formation must be considered. In the case of negative ion ESMS of $\mathrm{PF}_{6}^{-}$-based ILs, the reactions of water with $\mathrm{PF}_{6}{ }^{-}$results in the formation of multifluorophosphate $\left(\mathrm{F}_{\mathrm{x}} \mathrm{PO}_{\mathrm{y}}{ }^{-}\right)$ions. The substitution reaction that follows from the hydrolysis reaction of water with $\mathrm{PF}_{6}{ }^{-}$to generate $\mathrm{F}_{\mathrm{x}} \mathrm{PO}_{\mathrm{y}}{ }^{-}$species during the electrospray process is consistent with known electrochemical reactions, and parametric studies of flow rate and electrospray current support this conclusion

The $\mathrm{F}_{\mathrm{x}} \mathrm{PO}_{\mathrm{y}}{ }^{-}$products of the electrochemical reactions reported here provide an indicator of the water content in water-immiscible $\mathrm{BMIM}^{+} \mathrm{PF}_{6}^{-}$. The dependence on other residual solvents, dissolved contaminant species, and their concentrations on negative ion ES-MS will require further study, but the use of negative ion ES-MS for indirect measurement of water content in undiluted ILs can provide a rapid assessment of IL purity.

Initial studies indicate that similar product ions are obtained in ES-MS of EMIM+BF ${ }_{4}^{-}$. The electrochemically induced species $\mathrm{F}_{2} \mathrm{BO}^{-}$and $\mathrm{BO}_{2}^{-}$were observed when neat $\mathrm{BF}_{4}^{-}$ 
based ILs were electrosprayed. The hydrolysis of $\mathrm{BF}_{4}{ }^{-}$is thought to occur in an analogous manner to $\mathrm{PF}_{6}{ }^{-}$and is a matter of ongoing chemical investigations. 


\subsection{Reference}

1. H. Zhang, K. Hong and J. W. Mays, Macromolecules 35 (2002), p. 5738.

2. C. Guerrero-Sanchez, S. Ulrich, Polymer Preprints (American Chemical Society, Division of Polymer Chemistry) 45 (2004), p. 321.

3. M. J. Muldoon, C. M. Gordon, Journal of Polymer Science, Part A: Polymer Chemistry 42 (2004), p. 3865.

4. Z. Fei, D. Zhao, R. Scoelliti and P. J. Dyson, Organometallics 23 (2004), p. 1622.

5. X. Mu, J. Meng, Z. Li, Y. Kou, Journal of the American Chemical Society 127 (2005), p. 9694.

6. U. Schröder, J. Wadhawan, R. Compton, F. Marken, P. A. Z. Suarez, C. S. Consorti, R. F. de Souza and J. Dupont, New J. Chem. 24 (2000), p. 1009.

7. S. Dai, Y. Ju and C. Barnes, J. Chem. Soc. Dalton Trans. 8 (1999), p. 1201.

8. L. S. Santos, R. Haddad, N. F. Höehr, R. A. Pilli and M. N. Eberlin, Anal. Chem. 76 (2004), p. 2144. 
9. Y. Li, M. L. Gross, F. Hsu, Journal of the American Society for Mass Spectrometry 16 (2005), p. 679.

10. M. abet-Moghaddam,R. Krueger,E. Heinzle, A. Tholey, Journal of Mass Spectrometry 39 (2004), p. 1494.

11. M. Mank, B. Stahl, G. Boehm, Analytical Chemistry 76 (2004), p. 2938.

12. S. Carda-Broch, A. Berthod, D. W. Armstrong, Rapid communications in mass spectrometry : RCM 17 (2003), p. 553.

13. D. W. Armstrong, L. K. Zhang, L. He, M. L. Gross, Analytical chemistry 73 (2001), p. 3679.

14. K. R. Seddon, A. Stark and M. Torres, Pure Appl. Chem. 72 (2000), p. 2275.

15. B. D. Fitchett, T. N. Knepp and J. C. Conboy, J. Electrochem. Soc. 151 (2004), p. E219.

16. T. Welton, Chem. Rev. 99 (1999), p 2071.

17. I. Romero-Sanz, R. Bocanegra and J. Fernandez de la Mora, M. Gamero-Castaño, J. Appl. Phys. 94 (2003), p. 3599. 
18. (a) P. J. Dyson, J. S. McIndoe and D. Zhao, Chem. Comm., 4 (2003), p. 508. (b)

D. Zhao, Aust. J. Chem. 57 (2004), p. 509.

19. G. P. Jackson and D. C. Duckworth, Chem. Comm. 5 (2004), p. 522.

20. Lu Y, D. C. Duckworth, G. P. Jackson and F. L. King, 'Electrospray ionization mass spectrometry of Room Temperature Ionic Liquids', PITTCON-2005; Orlando, FL.

21. R. M. Jones, D. Gerlich and S. L. Anderson, Rev. Sci. Instrum. 68 (1997), p. 3357.

22. J. Fernandez de la Mora, G. J. Van Berkel, C. G. Enke, R. B. Cole, M. MartinezSanchez and J. B. Fenn, J. Mass Spectrom. 35 (2000), p. 939.

23. G. J. Van Berkel, J. Mass Spectrom. 35 (2000), p. 773.

24. J. W. Larson and T. B. McMahon, Inorg. Chem. 26 (1987), p. 4018.

25. K. O. Christe, D. A. Dixon, G. J. Schrobilgen and W. W. Wilson, J. Am. Chem. Soc. 119 (1997), p. 3918.

26. L. S. Kanevskii and V. S. Dubasova, Russian Journal of Electrochemistry 41 (2005), p. 3.

27. K. Nagayama, D. Kamioka, E. Iwata, H. Oka, Y. Tokunaga and T. Okada, Electrochemistry; 69 (2000), p. 6. 
28. S. E. Sloop, J. K. Pugh, S. Wang, J. B. Kerr and K. Kinoshita, Electrochemical \& Solid-State Letters 4 (2001), p. A42. 


\section{Chapter 5 Elimination in Electrospray ionization Mass Spectrometry of Imidazolium Based lonic Liquids}

\subsection{INSTRUCTION}

Room temperature ionic liquids (ILs) are low melting temperature salts composed of an organic cation paired with an inorganic anion. ${ }^{1}$ These conductive, low vapor pressure species have gained attention as novel "green chemistry" solvents for use in a range of applications including polymer synthesis, ${ }^{2}$ catalysis, ${ }^{3}$ electrochemistry, ${ }^{4}$ liquid- liquid extractions ${ }^{5}$ The most widely used organic cations in ILs are $N$ - $N$ '-dialkylimidazolium, tetraalkylammonium, or $N$-alkylpyridinium species. The chemical characterization of these species and the determination of their purity are topics of great interest to the chemical community but present a significant challenge to the analyst because of their unique characteristics.

Electrospray ionization mass spectrometry (ES/MS) allows gas-phase ions to be generated from liquid-phase samples for mass spectrometric analysis. Analytes dissolved 
in ionic liquids will be chemical products, catalysts, redox reaction products, or extractants. ES/MS is being routinely used for the analysis of ILs and their solutes. It provides a rapid method for mass identification and structure characterization. ${ }^{6}$ Due to the viscosity of ILs themselves, sample preparation for electrospray usually involves large dilution of the IL in an organic solvent. ${ }^{7}$ This approach is derived from conventional ESMS sample preparation. However, dilution may cause concerns for analysts that may be sensitive to the solvent when concentration are low. Additionally, when diluted with organic solvents some aggregation of ionic liquids molecules are observed ${ }^{7}$ making the mass spectrum complicated relative to MS of sample dissolved in neat ionic liquids. Prior to investigating analytes in ILs, fully understanding ESMS of ILs characterization themselves will help us extend their usage. Recently, ES/MS studies of undiluted ILs have shown that comparable performance can be achieved without the addition of organic solvents. ${ }^{8}$ Once the problem of high viscosity during electrspray is resolved, directly mass analysis of ILs solution provides necessary information and shows small interface due to less aggregation.

Some species not related to ionic liquids molecular peaks or dissolved solutes are identified as fragments of constituent organic cation. They have been observed in both

diluted or undiluted IL samples. ${ }^{7,8,9}$ Previous mass spectrometric research has confirmed 
that the major product ion is of 1-H-3-methyl-imidazolium, formed via fragmentation of 1-alkyl-3-methyl-imidazolium cations. It was also found that the relative gas-phase IL ion abundance of the fragment is related to the length of substituted alkyl chain on the parent organic cation. The studies presented here focus on the mechanism of neutral loss of substituted alkyl group from imidazolium ring.

ES/MS of dialkylimidazolium-based ILs has routinely been noted to yield mass spectra that indicate a generally facile fragmentation process occurs, either during the electrospray ionization process or during ion extraction into the mass spectrometer. Consistent with previous literature reports, ${ }^{6}$ tandem mass spectrometry experiments in this laboratory demonstrate that collision-induced dissociation (CID) 1-butyl-3-methyl imidazolium cations $\left([\mathrm{BMIM}]^{+}\right)$fragment yielding $N$-methyl-imidazolium cations $\left([\mathrm{MIM}]^{+}\right)$. Although this result indicates release of the butyl groups from the imidazolium ring, the origination of proton and the mechanism of this fragmentation have not been clearly established.

Carl Duerassi's group performed a mass spectrometric research on alkyl substituted pyrrole. ${ }^{10}$ In explanation of the migration of proton from a carbohydrate side chain to imidazolium ring during the fragmentation, a six-member cyclic transition state was 
proposed and examined. The hydrogen rearrangement assures that the charge resides on the imidazolium ring and neutral alkyl species are released during the electron impact ionization. Recent research ${ }^{9}$ on fragmentation of dialkylimidazolium cations shows evidence that origination of proton-charged imidazolium ring depended on the length of released sided chain. The formation of six-member transition state can not completely address the influence of the size of side chain.

In this paper, a series of dialkylimidazolium based ILs were investigated to determine both the role of beta hydrogens and the alkyl chain length on the fragmentation process. 


\subsection{Experimental}

\subsubsection{Reagents}

The ILs 1, 3-hexyl-methyl-imidazolium bis[(trifluoromethyl)sulfonyl)]amide (HMIM ${ }^{+}$ $\mathrm{TF}_{2} \mathrm{~N}^{-}$) was synthesized in house and 1, 3-butyl-methyl-imidazolium hexafluorophosphate $\left(\mathrm{BMIM}^{+} \mathrm{PF}_{6}^{-}\right), 1,3$-ethyl-methyl-imidazolium tetrafluoroborate $\left(\mathrm{EMIM}^{+} \mathrm{BF}_{4}^{-}\right)$, and 1, 3-dimethyl-imidazolium tetrafluoroborate $\left(\mathrm{MMIM}^{+} \mathrm{BF}_{4}^{-}\right)$were purchased from Sigmal-Aldrich (St. Louis, MO). All of the chemicals were vacuum-dried for 48 hours and stored in a nitrogen filled desiccator.

\subsubsection{Instrumentation}

Electrospray ionization mass spectra were obtained with a Thermo-Electron PolarisQ ${ }^{\circledR}$ Ion-Trap mass spectrometer (Austin, TX) modified with the addition of a Thermo- 
Electron Deca ${ }^{\circledR}$ electrospray ion source. The ion optical system between the ion source and the mass analyzer is composed of two ion guides and an ion gating lens. The ion gating lens is a disk electrode with a 0.03 inch orifice, and is positioned between quadrupole and octopole ion guides. The two ion guides are operating at the same RF frequency, RF amplitude, and DC floating voltage. A Tennelec/Oxford dual-polarity 0 - 5 $\mathrm{kV}$ power supply (TC950A, Oak Ridge, TN) was used to provide the negative 3 - $5 \mathrm{kV}$ emitter potential. Samples were introduced through a 1 meter PEEK ${ }^{\circledR}$ tube (CAT\#1535, Upchurch Scientific, Oak Harbor, WA) with a $125 \mu \mathrm{m}$ internal diameter (i.d.) connected a $250 \mu \mathrm{L}$ syringe (Hamilton, Reno, NV) syringe and a $6 \mathrm{~cm}$ long stainless steel emitter with $100 \mu \mathrm{m}$ i.d.. The $125 \mu \mathrm{m}$ i.d. was used to lower the high backpressure caused by the viscosity of the ILs. For the same purpose, PEEK ${ }^{\circledR}$ unions (CAT\# P-742, Upchurch Scientific) with $250 \mu \mathrm{m}$ i.d. were used. An Oxford dual track syringe pump (AH55-2122, Holliston, MA) was used to continuously inject the at a constant flow rate of $0.3 \mu \mathrm{d} / \mathrm{min}$. 


\subsection{RESULTS AND DISCUSSION}

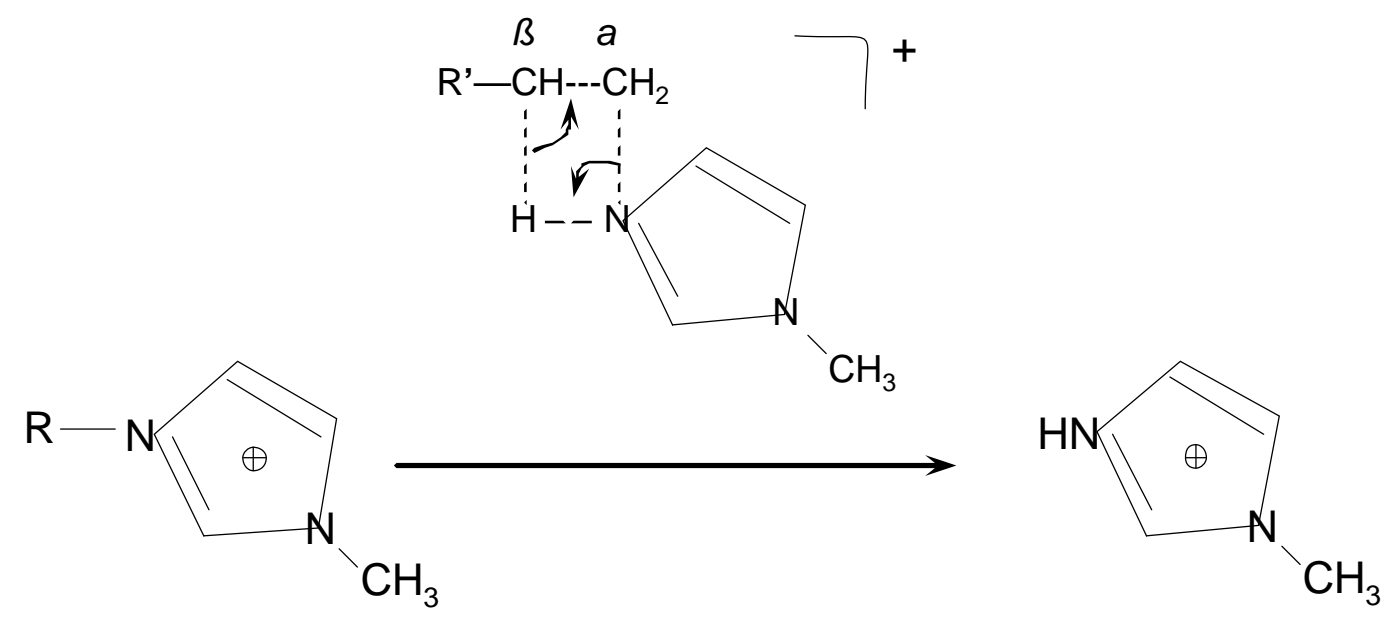

R: $\mathrm{C}_{2} \mathrm{H}_{5}, \mathrm{n}-\mathrm{C}_{4} \mathrm{H}_{9}$, or $\mathrm{n}-\mathrm{C}_{6} \mathrm{H}_{13}$.

\section{Scheme 1}

The chemical structures of dialkylimidazolium cation, proposed reaction intermediate, and the resultant fragment cations are shown in Scheme 1. It is helpful to consider how these species are synthesized to better understand the chemistry responsible for the observed fragment ions. In Scheme $\mathbf{2}$ is shown the two step synthetic process for dialkylimidazolium cations. In the first of two synthesis steps, the imidazole nitrogen 
hydrogen is substituted by a methyl carbocation to form a neutral $N$-methylimidazole.

The dialkylimidazolium cation is then obtained during the second step when a

corresponding alkyl carbocation is attached to the unsubstituted nitrogen of the neutral $\mathrm{N}$ -

methylimidazole. ${ }^{11}$ Note, prior to formation of the dialkylimidazolium product, the ring was neutral.

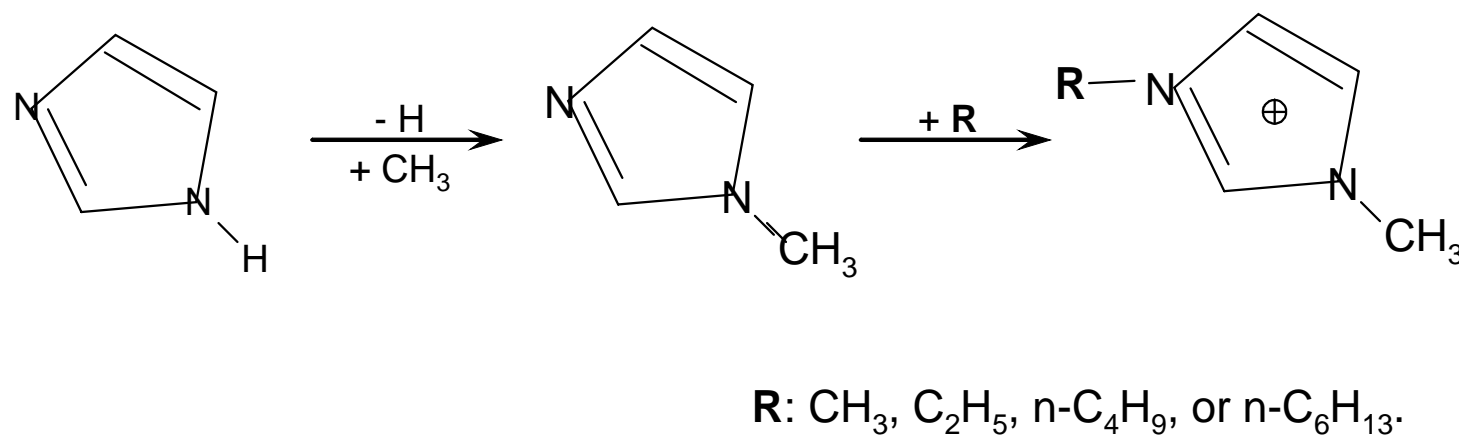

\section{Scheme 2}

The mass spectra shown in Figure 5.1 indicate that the dominant fragment ion for the 3alkyl-1-methyl-imidazolium cations is 3-H-1-methyl-imidazolium cation, the protonated 
analogue of the synthetic precursor $N$-methylimidazole. The parent and fragment ion mass difference corresponds with the molecular weight of the alkene that would result from deprotonation of the departing alkyl group. Simple retrosynthesis would lead one to believe that the alkyl carbocation is released from the ring and then a subsequent proton transfer from the alkyl carbocation to the $N$-methylimidazole occurs to yield the imidazolium carbocation and the neutral alkene. The absence of an alkyl carbocation signal during ES/MS and during CID of the parent ion suggests that the mechanism is not a bimolecular reaction. 
Figure 1
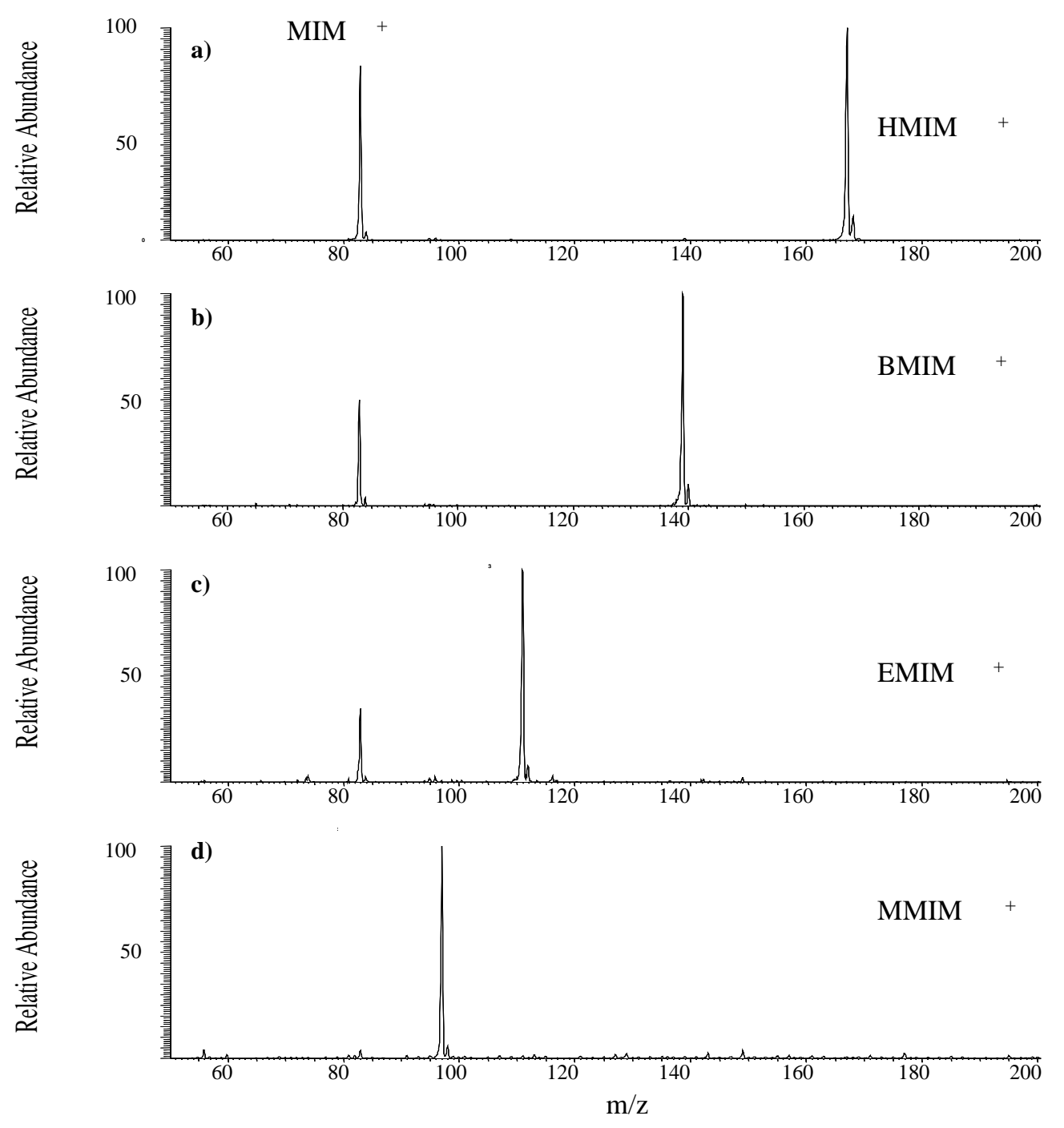

Figure. 5. 1 Positive ion ES/MS of dialkylimidazolium cation a) 1-hexyl-3-methylimidazolium, b) 1-butyl-3-methyl-imidazolium, c) 1-ethyl-3-methylimidazolium, and d) 1, 3-dimethyl-imidazolium. 
The unimolecular $\beta$-elimination reaction (Scheme 1) was considered as a possible fragmentation mechanism. To examine this mechanism, ES/MS spectra were obtained for four dialkylimidazolium species, a) 1-hexyl-3-methyl-imidazolium ([HMIM $\left.]^{+}\right)$, b) 1butyl-3-methyl-imidazolium $\left([\mathrm{BMIM}]^{+}\right)$, c) 1-ethyl-3- methyl-imidazolium ([EMIM $\left.]^{+}\right)$, and d) 1, 3-dimethyl-imidazolium $\left([\mathrm{MMIM}]^{+}\right)$. The resulting normalized mass spectra of the cationic species are presented in Figure 5.1. The base peak in each spectrum corresponds to IL cation: $\mathrm{m} / \mathrm{z}=167$ for $[\mathrm{HMIM}]^{+}, \mathrm{m} / \mathrm{z}=139$ for $[\mathrm{BMIM}]^{+}, \mathrm{m} / \mathrm{z}=111$ for $[\mathrm{EMIM}]^{+}$, and $\mathrm{m} / \mathrm{z}=97$ for $[\mathrm{MMIM}]^{+}$. The fragment ion, $\mathrm{m} / \mathrm{z}=83$ for $[\mathrm{MIM}]^{+}$, is observed as the second most abundant peak in each of these spectra except in the case of $[\mathrm{MMIM}]^{+}$. In the $[\mathrm{MMIM}]^{+}$spectrum the signal at $\mathrm{m} / \mathrm{z}=83$ is less than $5 \%$ relative abundance. The observed fragmentation for species containing alkyl groups with more than one carbon and the extent of fragmentation increases with the length of the alkyl group. The neutral fragment masses, as calculated from peak values obtained from Figure 5.1a-c, are equal to molecular weight of respective alkenes, i.e. a) 84 (hexene), b) 56 (butene), and c) 28 (ethylene). 
The differences in the relative extent of fragmentation between the cations, as shown in Figure 5.1, arise from the resonance stabilization effect of the alkyl group. The $N$-methylimidazolium ring, as a leaving group, has electron-withdrawing effects. The electron cloud in $\mathrm{C}-\mathrm{N}$ bond between the $\alpha$-carbon and the imidazole nitrogen localizes closer to the nitrogen. Although they are cleaved at the same time, $\mathrm{C}-\mathrm{N}$ bond and $\mathrm{C}-\mathrm{H}$ bond are not broken to the same extent in the transition state (scheme 1). Hence, the $\alpha$-carbon retains its carbocation character. Being an electron-donator, the alkyl tail can compensate for the positive charge on the $\alpha$-carbon and thus stabilize the transition state, assisting the elimination process. The larger alkyl chain has larger donation effects. Therefore, the fragmentation of imidazolium cation with larger alkyl substitution is more facile. 
Figure 2
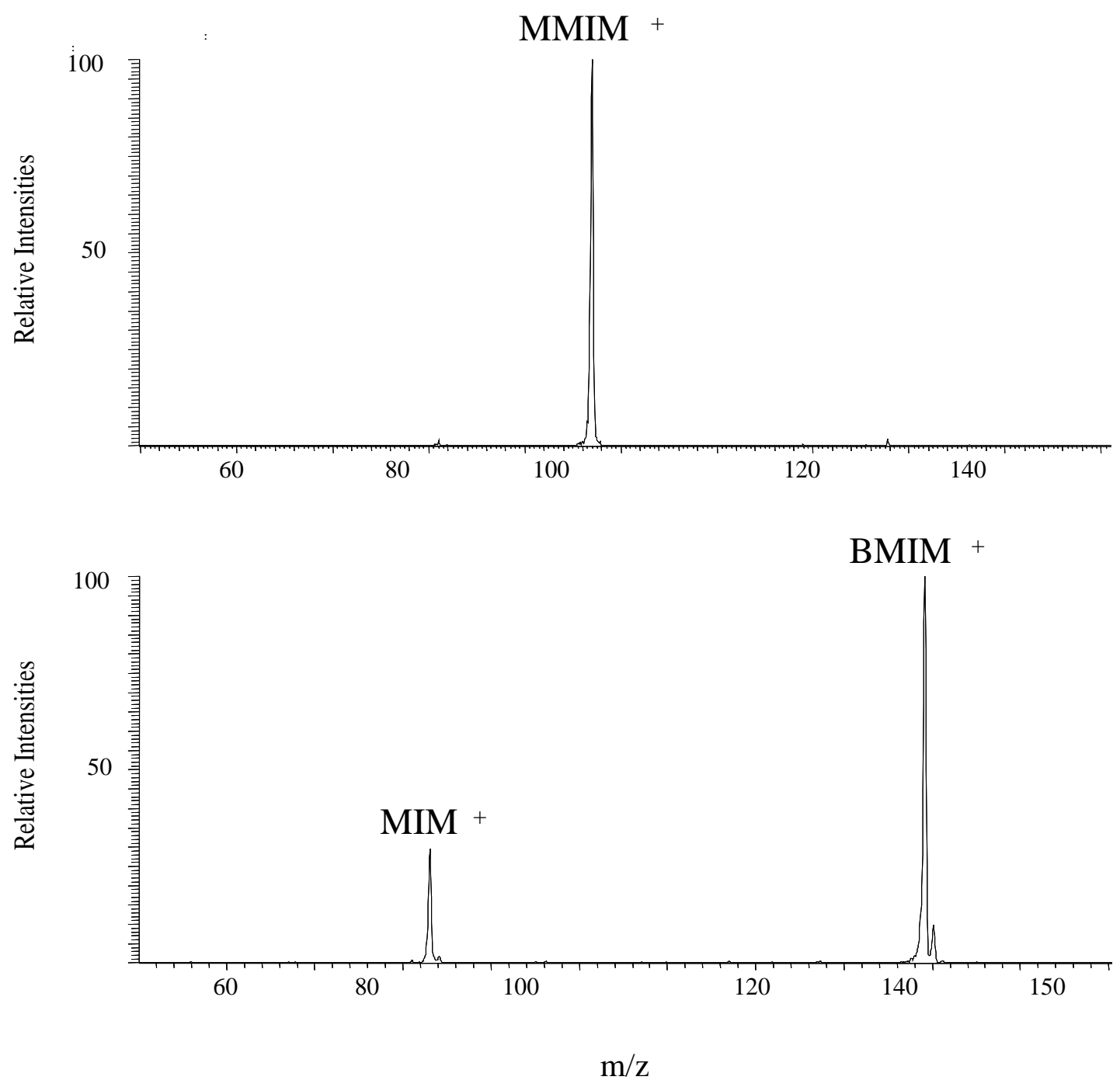

Figure. 5.2 Collision-induced dissociation mass spectra of $\mathrm{MMIM}^{+}$(upper) and $\mathrm{BMIM}^{+}$(bottom) at the same applied resonance excitation potentials. 
Similar fragmentation is observed in tandem mass spectrometry experiments in which the precursor dialkylimidazolium ion undergoes CID. Mass spectra of the products from $\mathrm{CID}$ of $[\mathrm{BMIM}]^{+}$and $[\mathrm{MMIM}]^{+}$are shown in Figure 5.2. These spectra were obtained under similar conditions with the constant collision energy and below the dissociation threshold for the imidzaole ring. Under these conditions, the $[\mathrm{MMIM}]^{+}$ions did not go fragment, whereas the $[\mathrm{BMIM}]^{+}$ions fragmented to yield $[\mathrm{MIM}]^{+}$ions. These results support the unimolecular elimination process such that alkyl group elimination from the imidazolium ring occurs when the alkyl chain possesses a $\beta$-, or $\gamma$-hydrogen through which a four-, five-, or six-membered cyclic transition state could be formed.

The fact that alkyl groups having no $\beta$-carbon can not be cleaved from imidazole nitrogen suggests an elimination mechanism in which groups leaving hydrocarbon chain are both an $N$-methylimidazole and a $\beta$-hydrogen. The elimination is a unimolecular process that yields two products: the methylimidazolium ion which is charged by transferring the hydrogen from the alkyl group, and the neutral alkene. The mechanism is considered as a hydride-elimination which can operate in gas phase with no other reagent present. ${ }^{12}$ In fragmentation of a 1-ethyl-3-methyl-imidazolium cation, a coplanar four-membered cyclic transition state is proposed. The bond between the $\alpha$-carbon and the imidazole (C$\mathrm{N})$ and the bond between the $\beta$-carbon and its hydrogen $(\mathrm{C}-\mathrm{H})$ are broken simultaneously. 
A new bond between the hydrogen and imidazole nitrogen is formed at the same time. For the cases involve the larger side chains, like propyl, butyl, or hexyl group, five- and six-membered cyclic transition state are proposed and they have less ring tension.

This model explains the observation in ES/MS of dialkylimidazolium cations quite well. The hydrogen transfer to the imidazole nitrogen is basically a protonation process that yields the $N$-methylimidazolium cation observed in the mass spectra and results in the loss of the neutral alkene. No mass spectrometric evidence of the formation of alkyl cations is observed. The benefit of existence of a hydrogen for this elimination process to occur is consistent with the observation that the dimethyl species undergoes virtually no fragmentation - the methyl group can not be cleaved off because of its inability to donate a $\beta$-hydrogen. In fact CID experiments show that as collision energy is increased the imidazole ring is opened prior to cleavage of the methyl group.

The difference in peak intensity of fragment ions, as shown in Figure 5.1, can also be contributed to the changes in stability of the cyclic transition state. In fragmentation of 1hexyl-3-methyl-imidazolium cation, a six-membered transition state is formed and it has the least ring tension comparing to the transition state with four or five centers. 
The model proposed in reference paper ${ }^{10}$ involves a six-member cyclic transition state exists in fragmentation of 1-alkyl-3-methyl-imidazolium cation. The model does not explain fragmentation of 1-ethyl-3-methyl-imidazolium ions due to insufficient carbon available for formation of large cyclic intermediates. For those imidazolium substituted with butyl of larger group, the possible origination of proton can be from $\beta$ or $\gamma$-carbon or even more distant when cyclic intermediates with larger alkyl chains are present. Our experimental design did not exclude one possibility for another. 


\subsection{Conclusion}

Fragmentation of dialkylimidazolium cations during electrospray ionization mass spectrometric analysis of room temperature ionic liquids is found to result from a $\beta$ elimination reaction that yields an $N$-methylimidazolium cation and a neutral alkene. This unimolecular dissociation reaction requires the formation of a four-membered cyclic transition state involving the $\beta$-hydrogen. Due to the absence of a $\beta$-hydrogen in methylmethyl-imidazolium, no fragmentation is observed while $\beta$-elimination is possible for ethyl-, butyl-, and hexyl-methyl-imidazolium cations. The degree of fragmentation reflects the stability of the four-membered cyclic transition state. The same process is observed in low energy collision-induced dissociation reactions of the isolated precursor ion in tandem mass spectrometry experiments. 


\subsection{REFEENCES}

1. Scammells P. J., Scott J. L., Singer, R. D. Aust. J. Chem. 2005; 58: 155.

2. Zhang H., Hong K., Mays J. W. Macromolecules 2002; 35: 5738.

3. Fei Z., Zhao D., Scoelliti R., Dyson P. J. Organometallics 2004; 23: 1622.

4. Schröder U., Wadhawan J., Compton R., Marken F., Suarez P. A. Z., Consorti C. S., de Souza R. F., Dupont J. New J. Chem. 2000; 24: 1009.

5. Dai S., Ju Y., Barnes C. J. Chem Soc. Dalton Trans. 1999; 8: 1201.

6. Milman B. L., Alfassi Z. B. Eur. J. Mass Spectrom. 2005; 11: 35.

7. Dyson P., McIndoe J., Zhao D. Chem. Comm. 2003; 4: 508.

8. Jackson G. P., Duckworth D. C. Chem. Comm. 2004; 5: 522.

9. Lesimple A., Mamer O., Miao W., Chan T. H. J. of Am. Soc. for Mass Spec. 2006; 17: 85

10. Duffield A. M., Beugelmans R., Budzikiewicz H., lightner D. A., Williams D. H., Djerassi C. J of Am. Chem. Soc. 1965, 87: 805.

11. Holbrey J. D., Matthew Reichert W., Swatloski R. P., Broker G. A., Pitner W. R., Seddon K. R., Rogers R. D. Green Chemistry 2002; 4: 407.

12. March J. Advanced Organic Chemistry, 3rd edition; John Wiley \& Sons: New York, 1985; p. 873-943. 


\section{Chapter 6 Electrospray Mass Spectrometry of Ferrocene and Ferrocenium(III) Dissolved in Undiluted Ionic Liquids}

\subsection{Introduction}

Ionic liquids are room temperature melting salts composed entirely of large cationic organic species, such as tetra-alkyl-ammonium, $N, N$-dialkylimidazolium, or $N$ alkylpyridinium, combined with small anionic inorganic species, such as tetrafluoroborate $\left(\mathrm{BF}_{4}^{-}\right)$, hexafluorophosphate $\left(\mathrm{PF}_{6}^{-}\right)$, bis [(trifluoromethyl)sulfonate]amide $\left(\mathrm{TF}_{2} \mathrm{~N}^{-}\right)$, or trifluoroethanoate $\left(\mathrm{CF}_{3} \mathrm{CO}_{2}{ }^{-}\right)$. The asymmetry of these complexes reduces the lattice energy yielding a melting point salt for the salt below room temperature. The interesting composition of ionic liquids provides them with unique properties in addition to a low melting point, including a negligible vapor pressure, a low flammability, a wide electrochemical window, and a high ionic conductivity [1]. These properties make ionic liquids interesting as suitable replacement for aqueous or organic solvents in green chemistry applications. Ionic liquids now find use as solvents in myriad applications such as polymer synthesis, [2, 3] catalysis, [4, 5] 
electrochemistry, [6] liquid-liquid extractions, [7] and matrix-assisted laser desorption/ionization $[8,9,10,11,12,13]$.

As the use of ionic liquids has grown, so have the needs for verification of their composition and characterization of their solutes. In analytical applications, the effects of the ionic liquid solvents and their composition on the analysis of species dissolved therein are of particular interest. $[6,14,15,16]$ Somewhat surprisingly, the relatively low vapor pressure of pure ionic liquids has not been observed to limit their utility in electrospray ionization. Mass spectrometry employing electrospray ionization, ESI-MS, appears to be a possible technique for the study of these unique solvents and the characterization of the analytes dissolved therein. For example, ESI-MS detection of analyte species, such as $\left[\mathrm{Ru}\left(\eta^{6}-p \text {-cymene }\right)\left(\eta^{2} \text {-triphos }\right) \mathrm{Cl}\right]^{+}$, was readily accomplished in an ionic liquid matrix [18]. Negative ion ESI-MS employing ionic liquid solvents has proven useful for the detection of anionic species such as the catalyst component $\left[\mathrm{Ru}(\mathrm{CO})_{2} \mathrm{I}_{2}\right]^{-}$and the chloride anion, $\mathrm{Cl}^{-}[18]$.

It is important to note that unlike the conventional ESI solvents, composed completely of neutral species such as water or methanol, ionic liquids (ILs), although charge neutral as the complex, are composed entirely of ions - akin to a liquid phase plasma. In spite of 
the abundance of preformed ions that constitute the ionic liquid, it does not appear that a significant portion the electrospray current is carried by these preformed ions. Mass spectra obtained from both diluted [18] and pure [19, 20, 21] ionic liquid solutions reflect this. The signal arising from the solvent is of the same order of magnitude as that from the analytes dissolved in the liquids. Simply put the ionic liquids can serve as applicable solvents for the determination of analytes by ESI-MS.

In our previous work, ESI-MS was employed successfully in the analysis of ionic additives in pure ionic liquids with results comparable to those observed for ESI-MS of ionic liquids diluted with a more traditional ESI solvent. The research regards the electrospray behavior of ferrocene and ferrocenium salt dissolved in ionic liquids. In the course of conducting these studies, a method was also developed to record the upstream ground current for the system and to control the current in ESI of ionic liquids. 


\subsection{Experimental}

The ionic liquids 1, 3-ethyl-methyl-imidazolium tetrafluoroborate $\left(\mathrm{EMIM}^{+} \mathrm{BF}_{4}^{-}\right)$and 1, 3buthyl-methyl-imidazolium hexafluorophosphate $\left(\mathrm{BMIM}^{+} \mathrm{PF}_{6}{ }^{-}\right)$, as well as ferrocene (Fc), ferrocenium tetrafluoroborate $\left(\mathrm{Fc}^{+} \mathrm{BF}_{4}^{-}\right)$, and ferrocenium hexafluorophosphate $\left(\mathrm{Fc}^{+} \mathrm{PF}_{6}^{-}\right)$were used as purchased (Sigma-Aldrich, St. Louis, MO) without further purification although the ionic liquids were vacuum-dried for 48 hours and stored in a nitrogen filled desiccator. Biphasic $\mathrm{Fc} / \mathrm{EMIM}^{+} \mathrm{BF}_{4}^{-}, 3.48 \mathrm{mM}$, was obtained by adding $0.0214 \mathrm{~g}$ ferrocene to $0.0330 \mathrm{~L}$ of the ionic liquid. Homogenous solutions were obtained by ultra-sonication of the mixture for 20 minutes. The same process was employed in the preparation of $\mathrm{Fc}^{+} \mathrm{BF}_{4}^{-} / \mathrm{EMIM}^{+} \mathrm{BF}_{4}^{-}, 3.18 \mathrm{mM}$, mixture when $0.0182 \mathrm{~g} \mathrm{Fc}^{+} \mathrm{BF}_{4}^{-}$was dissolved in $0.0210 \mathrm{~L}$ of the ionic liquid. A solution of $\mathrm{Fc}^{+} \mathrm{PF}_{6}{ }^{-} / \mathrm{EMIM}^{+} \mathrm{PF}_{6}{ }^{-}$with concentration of about $3 \mathrm{mM}$ was also prepared using the same process. All of the prepared samples were stored in a desiccator.

Mass spectra were acquired from a quadrupole ion trap mass spectrometer (Polaris $\mathrm{Q}^{\circledR}$, Thermo-Electron, Austin, TX) equipped with an electrospray ionization source (Deca ${ }^{\circledR}$, Thermo-Electron, Austin, TX). This instrument was modified via the insertion of an ion 
optical system and an ion gating lens as described previously. [21] A dual track syringe pump (AH55-2122, Oxford, Holliston, MA) was used to inject samples from a $250 \mu \mathrm{L}$ syringe (Hamilton, Reno, NV) at variable flow rates. The syringe was connected to the emitter through a 1 meter PEEK ${ }^{\circledR}$ tube with $125 \mu$ internal diameter (i.d.). The tubing was used to maintain a low backpressure for the viscous ionic liquids. A $6 \mathrm{~cm}$ long stainless steel emitter with $100 \mu \mathrm{m}$ i.d. and $500 \mu \mathrm{m}$ o.d. was used in conjunction with a stainless steel union to which the spray voltage was applied. A coated silicon capillary ( TSP075375, Phoenix, AZ) with $75 \mu \mathrm{m}$ i.d. replaced the conductive emitter in experiments requiring a nonconductive emitter. The length of the nonconductive emitter was varied between $3 \mathrm{~cm}$ and $6 \mathrm{~cm}$. A dual-polarity $0-5 \mathrm{kV}$ power supply (Model TC950A, Tennelec/Oxford, Oak Ridge, TN) was used to provide the positive 3 - $5 \mathrm{kV}$ emitter potential.

A picoammeter was connected through variable resistances, from $1 \mathrm{G}$ to $10 \mathrm{G}$, to a conductive point in the upstream line of the transferring tubing. Figure 1 shows the scheme of the upstream set-up. It should be noted that the high voltage emitter could not be operated with direct grounding through the ammeter. Because of the high conductivity of the ionic liquid (about 1000 times larger than conventional volatile solvents), grounding the injection line through the insertion of a nonresistant ammeter draws too 
much current from the power supply and then decreases the spray voltage at the emitter tip, and eventually disrupts the spray process. The resistor inserted into the upstream grounding line limits the current drawn from the power supply and keeps the electrospray ionization process stable during measurement of the upstream grounding current. By varying the resistance to ground, the upstream grounding current can be regulated enabling study of the impact of this current on the electrospray process. Ammeter, $A_{1}$, is connected on the inlet of mass analyzer to measure the spray current $\left(I_{E S}\right)$. Ammeter $\mathrm{A}_{2}$ is placed behind the resistor array to measure the upstream grounding current $\left(I_{G}\right)$. 


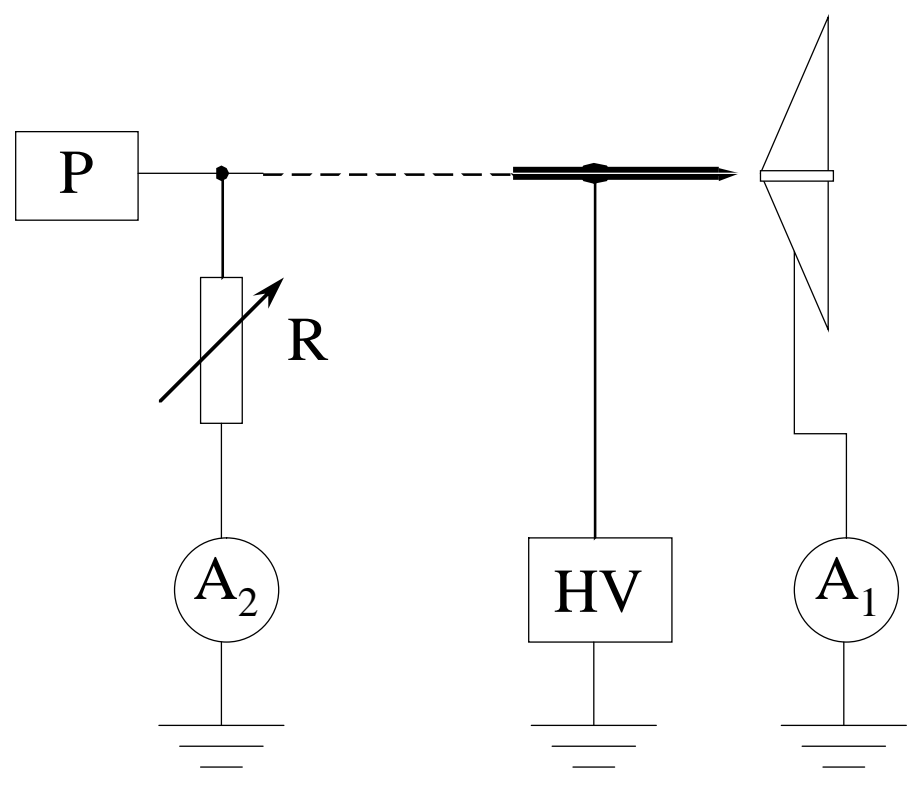

$\mathrm{P}$ is of injection pump.

$A$ is of ammeter.

$\mathrm{HV}$ is of high voltage power supply

Figure. 6.1. Scheme of the set-up of the electrospray source with upstream ground current measurement. Two picoammeters $A_{1}$ and $A_{2}$ were used to record the electrospray currents. $\mathrm{R}$ is of an array of resistors. $\mathrm{P}$ is of injection pump. $\mathrm{HV}$ is of high voltage power supply. Picoammeter A2 is attached to the ion transfer tubing on the mass spectrometer. 


\subsection{Results and Discussion}

\subsubsection{MS Response of Pre-existing Ions in Ion Liquids}

Figure 2 shows the positive ion mode electrospray mass spectrum of pure $\mathrm{EMIM}^{+} \mathrm{BF}_{4}{ }^{-}$ containing $3 \times 10^{-3} \mathrm{M} \mathrm{Fc}^{+} \mathrm{BF}_{4}^{-}$. The three most abundant peaks appear at $\mathrm{m} / \mathrm{z}$ values of 83,111 , and 186 respectively. The smaller signals at $\mathrm{m} / \mathrm{z} 186$ and 111 correlate with the pre-existing $\mathrm{Fc}^{+}$and $\mathrm{EMIM}^{+}$cations. The most abundant signal, at $\mathrm{m} / \mathrm{z} 83$, arises from the methylimidazolium $\left(\mathrm{MIM}^{+}\right)$ions. Previous work indicates that this species is a product of the dissociation of the $\mathrm{EMIM}^{+}$ion to yield the neutral ethylene molecule and $\mathrm{MIM}^{+}$ during the electrospray ionization process. [22] At the concentration of the solution employed, the relative ratio of liquid phase ion abundances of $\mathrm{Fc}^{+}$and $\mathrm{EMIM}^{+}$is nearly 1/2000. In spite of the small ratio, the mass spectrometric signal intensity of $\mathrm{Fc}^{+}$is about one third of that of $\mathrm{EMIM}^{+}$, reflecting their relative gas-phase ion abundances. It appears that the concentration of gas-phase $\mathrm{Fc}^{+}$was enhanced relative to that of the solvent ions during the electrospray ionization process. 


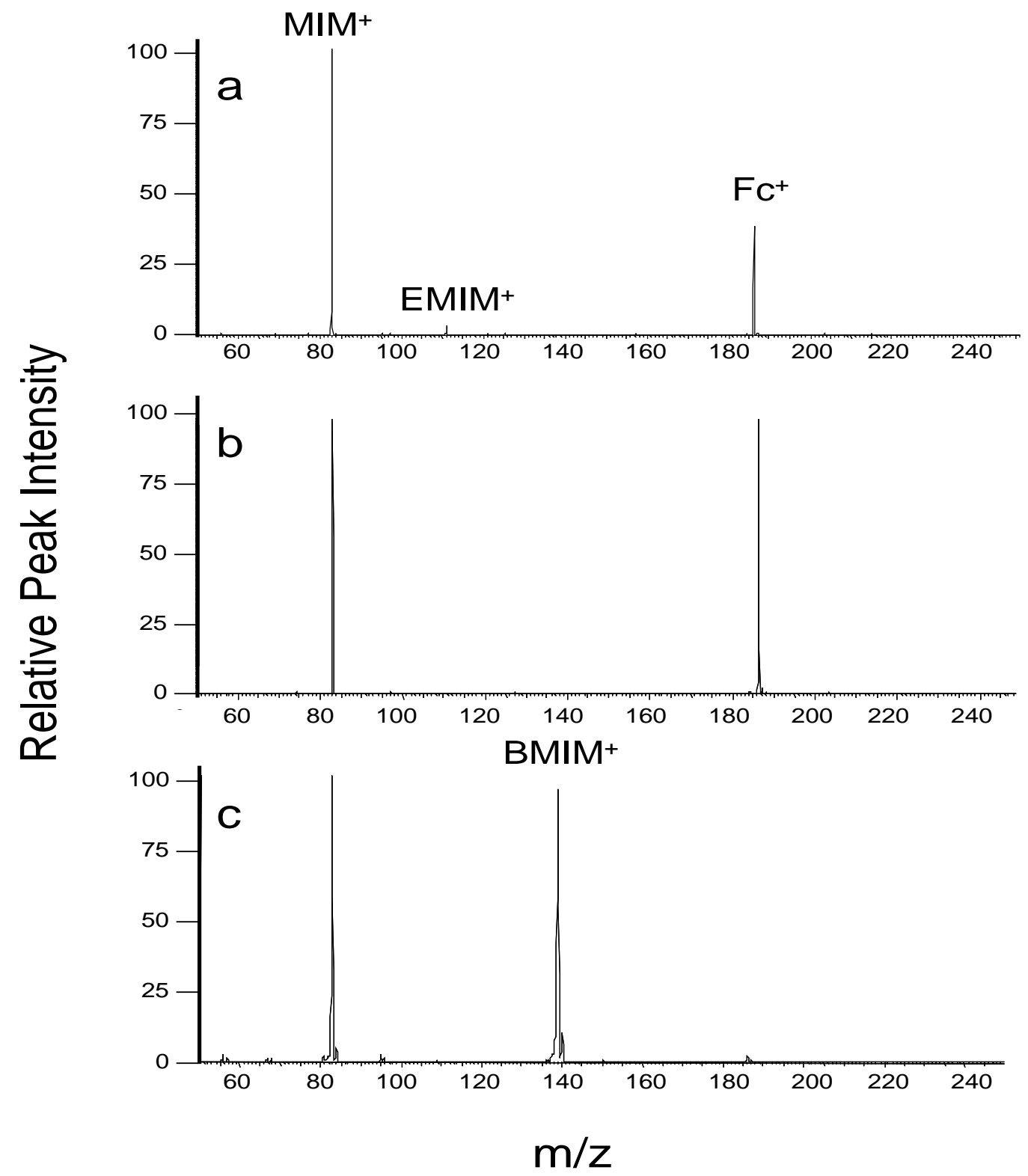

Figure. 6.2. Positive ion ESI-MS of undiluted ILs solution at spray voltage of $4.0 \mathrm{kV}$, injection flow rate of $3.0 \mu \mathrm{l} / \mathrm{min}$, and upstream grounding resistance of 10 $\mathrm{G}$. The measured total electrospray current is $1.2 \mu \mathrm{A}$. (a) ESI-MS of $\mathrm{Fc}^{+} \mathrm{BF}_{4}^{-}$in $\mathrm{BMIM}^{+} \mathrm{BF}_{4}^{-}$(b) ESI-MS of ferrocene in $\mathrm{BMIM}^{+} \mathrm{BF}_{4}^{-}$. (c) ESI$\mathrm{MS}$ of $\mathrm{Fc}^{+} \mathrm{BF}_{4}^{-}$in $\mathrm{BMIM}^{+} \mathrm{PF}_{6}^{-}$. 
Tang and Kebarle [23] proposed dependence of gas-phase ion concentrations on the corresponding liquid phase ion concentrations. The observed variation between solution and gas-phase was ascribed to differences in ion-pairing effects. During the electrospray process, ions in the surface layer of Taylor cone are transferred into gas-phase. Replenishment of these surface ions depends on their ion mobility in the solution. Within the ionic solvent, the movement of electrolyte ions is controlled by the spray field and the Coulombic force between the ions and their counter ions. Ionic species with stronger ionpairing will move slower resulting in a lower concentration in surface layer.

Consequently, the gas-phase concentration of these ions will be limited by their lower concentration at the surface of the Taylor cone. As they are composed of entirely charged species, ionic liquids show negligible vapor pressure due to the strong Coulombic force between their component ions. Thus the preformed ions composing the ionic liquid are constrained both from evaporation off the surface and movement to replenish the surface layer from the bulk solution. However, dissolved analyte species that have weak ionpairing forces with the solvent ions can be present in a large population on the surface layer and will experience higher evaporation rates resulting in their enrichment in the vapor phase. Therefore, analyte ions can yield stronger mass spectrometric signal than the ionic liquid species even if their liquid phase concentration is small relative to that of the 
ionic liquid ions. Our MS observations, Figure 2(a), are consistent with the above in that the ferrocenium cation exhibits a strong signal relative to that of the ionic liquid cation.

Dependence of ion evaporation on ion-pairing effects arises when ionic groups are capable of binding with analyte ions through a strong Coulombic interaction. To test this, $\mathrm{Fc}^{+} \mathrm{PF}_{6}^{-}$, ferrocenium hexafluorophosphate, which has larger ionic bond strength between $\mathrm{Fc}^{+}$and $\mathrm{PF}_{6}^{-}$comparing to that between $\mathrm{Fc}^{+}$and $\mathrm{BF}_{4}^{-}$, was dissolved in undiluted 1-butyl3-methyl-imidazolium hexafluorophosphate $\left(\mathrm{BMIM}^{+} \mathrm{PF}^{-}\right)$ionic liquids and was electrosprayed. The resulting mass spectrum, shown in Figure 2(c), yielded no signal corresponding to the ferrocenium ions, as would be expected for the more strongly bound species. 


\subsubsection{MS Response of Neutral Species in Ion Liquids}

Mass spectra were obtained for ferrocene dissolved in undiluted ionic liquids under various experimental conditions. Ferrocenium cations resulting from the oxidation of ferrocene are observed in ESI-MS of these ionic liquid mixtures. Similar to the mass spectral observations for the ferrocenium ions dissolved in ionic liquids described above, the two most abundant species observed in the mass spectrum are $\mathrm{Fc}^{+}$and $\mathrm{MIM}^{+}$, as shown in Figure 2(b). The evaporated species are identical and their concentrations are about the same if an assumption of complete oxidation of neutral ferrocene to ferrocenium is proposed, one would expect to observe similar ESI MS spectra. However, comparison of the relative $\mathrm{Fc}^{+}$peak intensity in the mass spectrum of $\mathrm{Fc} / \mathrm{ILs}$, Figure 2(b), with that in the mass spectrum of $\mathrm{Fc}^{+} / \mathrm{ILs}$, Figure 2(a), reveals that electrospray of neutral Fc/ILs yields more gas-phase ions than that of ionic $\mathrm{Fc}^{+} / \mathrm{ILs}$. Again, the ion relative signal intensities in ESI mass spectra obtained from ionic liquids are thought to correlate more closely with the concentration of ions on the surface of the Taylor cone than the concentration of the corresponding ions in the bulk solution. [23] 
The observation of $\mathrm{Fc}^{+}$in ESI-MS of Fc/ILs indicates that $\mathrm{Fe}$ (II) is oxidized to Fe (III) during the ESI process. This electrochemical reaction occurs in the interface between the surface layer of the electrolytic solution and the conductive emitter. Although the produced ferrocenium ions can diffuse into the bulk solution resulting in a decrease in their surface concentration, the ion diffusion rate is limited by the viscosity of the ionic liquid and the electrostatic constriction on the charged particles. Because of the higher viscosity of ILs compared to conventional electrospray solvents, diffusion of produced $\mathrm{Fc}^{+}$will be relatively slow as compared to the case in a conventional solvent. On the other hand, ion-pairing effect of ionic matrix on the charged solute analyte constrains diffusion of electrochemically produced $\mathrm{Fc}^{+}$from interface of electrode and solution into the bulk solution. This means that the $\mathrm{Fc}^{+}$will accumulate in the interface layer. The interface layer enriched by $\mathrm{Fc}^{+}$becomes the surface layer of the Taylor cone and the ions are readily available for the evaporation process. Hence, the observed increase in signal compared to the situation for the preformed ionic species.

This hypothesis was tested further by electrospraying Fc/ILs under identical conditions but through non-conductive emitters with varied lengths. A T-adaptor with a platinum wire was inserted into the transportation line for the application of the electrospray voltage. Electrochemical reactions take place only around the platinum wire tip. Silicon 
capillary emitters with increasing lengths are used to provide longer diffusion time for produced $\mathrm{Fc}^{+}$and stronger flow turbulence. The resulting mass spectra show that $\mathrm{Fc}^{+}$ signal decreases as the length of the nonconductive portion of the emitter was increased. As no further oxidation of ferrocene was carried out in the non-conductive emitter, concentration of $\mathrm{Fc}^{+}$in surface layer is lowered because diffusion of produced $\mathrm{Fc}^{+}$and subsequent pairing were assisted by the flow turbulence and the available time. As a result, fewer ions are electrosprayed into gas-phase.

\subsubsection{Controlling the electrolytic current independent of the electrospray current}

The efficiency of electrospray ionization for ferrocene dissolved in an ionic liquid depends on an underlying electrolytic process. The idea that the electrolytic process inherent in electrospray ionization is akin to a controlled current electrolysis in an electrochemical cell has been proposed and tested. [23, 24, 25] The degree of oxidation occurring in positive ion mode electrospray ionization increases with the electrospray ionization (ESI) current and varies with the injection flow rate due to the change in reaction time. In order to increase the current without changing the electrospray process, 
an upstream grounding circuit is applied. Extra current, termed here the upstream current, flows through the electrolyte solution via this route resulting in enhanced electrospray ionization.

Three different resistances, of $1 \mathrm{G}, 5 \mathrm{G}$, and 10G , were inserted into upstream grounding circuit. For each hardware set-up, both upstream currents $\left(I_{G}\right)$ and electrospray currents $\left(I_{E S}\right)$ were measured for flow rates of $0.5 \mu \mathrm{l} / \mathrm{min}, 3 \mu \mathrm{l} / \mathrm{min}$, and $5 \mu \mathrm{l} / \mathrm{min}$ of ionic liquids containing ferrocene. The results of these measurements are shown in Table 1. For a constant electrospray voltage of $4.0 \mathrm{kV}$, the measured upstream currents, $I_{G}$, do not change with the flow rate. However, the $I_{G}$ is affected by the resistance inserted into the upstream ground circuit in a proportional manner, suggesting the possibility of controlling the electrolytic current during the electrospray process. 
Table 6.1 Measured currents are listed

\begin{tabular}{|c|c|c|c|}
\hline $\begin{array}{l}\text { Resistance } \\
R(\mathrm{G})\end{array}$ & $\begin{array}{l}\text { Injection Flow Rate } \\
\quad F . R .(\mu 1 / \mathrm{min})\end{array}$ & $\begin{array}{l}\text { Upstream Ground Current } \\
\qquad I_{G}(\mu \mathrm{A})\end{array}$ & $\begin{array}{c}\text { Electrospray Current } \\
I_{E S}(\mu \mathrm{A})\end{array}$ \\
\hline \multirow{3}{*}{1} & 0.5 & 4.2 & 0.79 \\
\hline & 3 & 4.2 & 0.79 \\
\hline & 5 & 4.2 & 0.79 \\
\hline \multirow{3}{*}{5} & 0.5 & 0.82 & 0.80 \\
\hline & 3 & 0.82 & 0.80 \\
\hline & 5 & 0.82 & 0.77 \\
\hline \multirow{3}{*}{10} & 0.5 & 0.46 & 0.81 \\
\hline & 3 & 0.46 & 0.83 \\
\hline & 5 & 0.45 & 0.75 \\
\hline
\end{tabular}

Apparently, the total current is not changed with the flow rate as indicated in Table 1, which is inconstant with the observation described in previous paper. [21] In that work, the effect of flow rate on the redox reaction was about the time permitted for chemicals interacting with the electrodes, that is, the oxidation would be carried out more 
completely as the reaction time being longer, therefore, more current was required for oxidization of analytes. It is always the current that controls the electrochemical reaction. Moreover, the experiment [21] was done while the sample transportation line and emitter were floating at spray voltage and no upstream grounding circuit was set- up. Only $I_{E S}$ was recorded and was considered. [21] Here in this case, set-up of upstream ground circuit addresses more significant effects on total current than flow rate does.

\subsubsection{Effect of Flow Rate on the MS intensity of electrochemical-induced ferrocenium ions}

The effect of injection flow rate on the electrospray ionization was evaluated under conditions of constant current. In Figure 6.3, total ion current (TIC) is plotted vs. the flow rates. Total ion current (TIC) stands for the charges carried by the emitted ions detected by the mass spectrometer. It is proportional to but not equal to the electrospray current which consists of both the TIC collected by the detector and other charged droplets that are not collected by the mass spectrometer. Here we use TIC to express electrospray efficiency. Three different currents are applied and mass spectra are recorded independently. Each of three curves describes the effect of flow rate on the TIC when the 
current is fixed. There is no influence of current upon the TIC because three curves showing the same pattern stay close and cross with each other. 


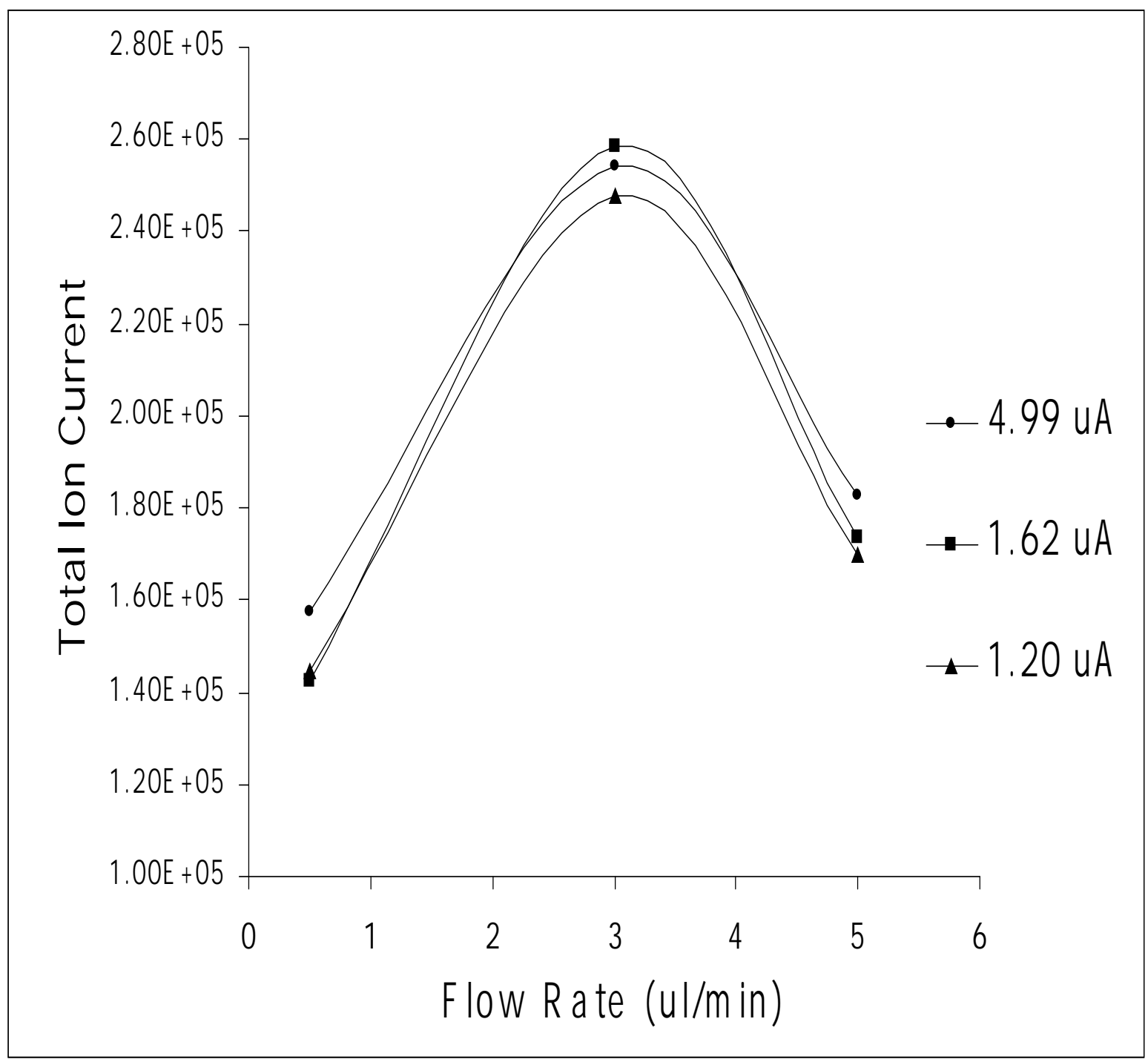

Figure. 6.3. Plots of total ion current (TIC) against the injection flow rate. Three curves are ploted at a) $4.99 \mu \mathrm{A}$, b) $1.62 \mu \mathrm{A}$, c) $1.20 \mu \mathrm{A}$. 
Each of curves shows that TIC reaches a maximum point when the injection flow rate of $3 \mu / \mathrm{min}$ is applied. The change in TIC reflects the effect of flow rate on electrospray of $\mathrm{Fc}^{+}$and ILs ions. The charges leaving the emitter tip are carried out as molecular ions and charged droplets. The charged droplets are screened by the ion transfer capillary, skimmer, and/or quadrupole ion guides so that they are not collected by the ion trap mass analyzer. Only the molecular ions are detectable and total ion current reflectes the intensity of these ions multipled by an unknown gain factor. At the smallest flow rate, ions of ferrocenium and ILs are evaporated off the surface layer accompanied by very few charged nano-droplets. These molecular ions dominate the emitted mass flow and contribute to the TIC. Increasing with the flow rate, more ions and droplets are transferred into gas-phase due to mass transport effect. Therefore, TIC increases with the amount of emitted ions. As flow rate keeps going up, however, the amount of mass spectral detectable ions drops and the emitted droplets become the dominant charge carriers where the drop emission increases with mass flow [25]. Using time-of-flight mass analyzer, it is practical to monitor both types of charge carrier, but it is not the case in ion-trap analyzer. [25] Overall, the plots of TIC against increasing flow rate show smaller gain of ions at either low or high mass flow and better TIC at mass flow around 3 $\mu / \min$. 


\subsubsection{Effect of Spray Current on the MS intensity of electrochemical- induced ferrocenium ions}

The effect of spray current on the yield of gas-phase ions was examined under controlled ground current conditions. Three curves are plotted in Figure 4, and each curve reflects change in ion intensity of $\mathrm{Fc}^{+}$with total recorded current while the injection flow rate is

fixed. $\mathrm{Fc}^{+}$ion intensity increases with the current. At the smallest flow rate, the effect of current on analyte ion production is balanced off by the diffusion of produced ferrocenium. Large current imposed on the electrolyte assists the oxidation of ferrocene. However, the small injection flow gives longer time period to allow produced ions to diffuse into bulk solution completely.

As the flow rate increases to $3 \mu \mathrm{l} / \mathrm{min}$, more $\mathrm{Fc}^{+}$ions are produced as the oxidation current increases. Curve starts at total recorded current of about $0.8 \mu \mathrm{A}$ and the change in amount of produced $\mathrm{Fc}^{+}$did not reflect the change in flow rate. It is proposed that the production of ferrocenium ions is limited by the current and the $\mathrm{Fc}^{+}$still have time to diffuse away from the surface layer. Situation is not significantly changed when the current increases to about $1.2 \mu \mathrm{A}$. The fact that a big jump in $\mathrm{Fc}+$ intensity is observed with the current changeing to $1.6 \mu \mathrm{A}$ implies the power of current. However, again, the 
reason that why signal does not increase linearly with the current is not clear and is under investigation.

The plot of $\mathrm{Fc}^{+}$intensity at $5 \mu \mathrm{l} / \mathrm{min}$ shows a nearly linear relationship. It increases with the spray current as we expected. Higher current assists production of $\mathrm{Fc}^{+}$and the ions accumulating in the surface layer are ready for evaporation. Short injection time will not allow the ions to diffuse efficiently. During the experiment, the effect of mass flow on the size of emitted charged particles is observed and large droplets of ionic liquids are present as waste outside of the mass spectrometer inlet. Comparing to that of flow rate at $0.5 \mu / \mathrm{min}$, electrospray at $5 \mu / \mathrm{min}$ consumes 10 times more sample but the improvement in yield is not that much, only about 2 times or less. 


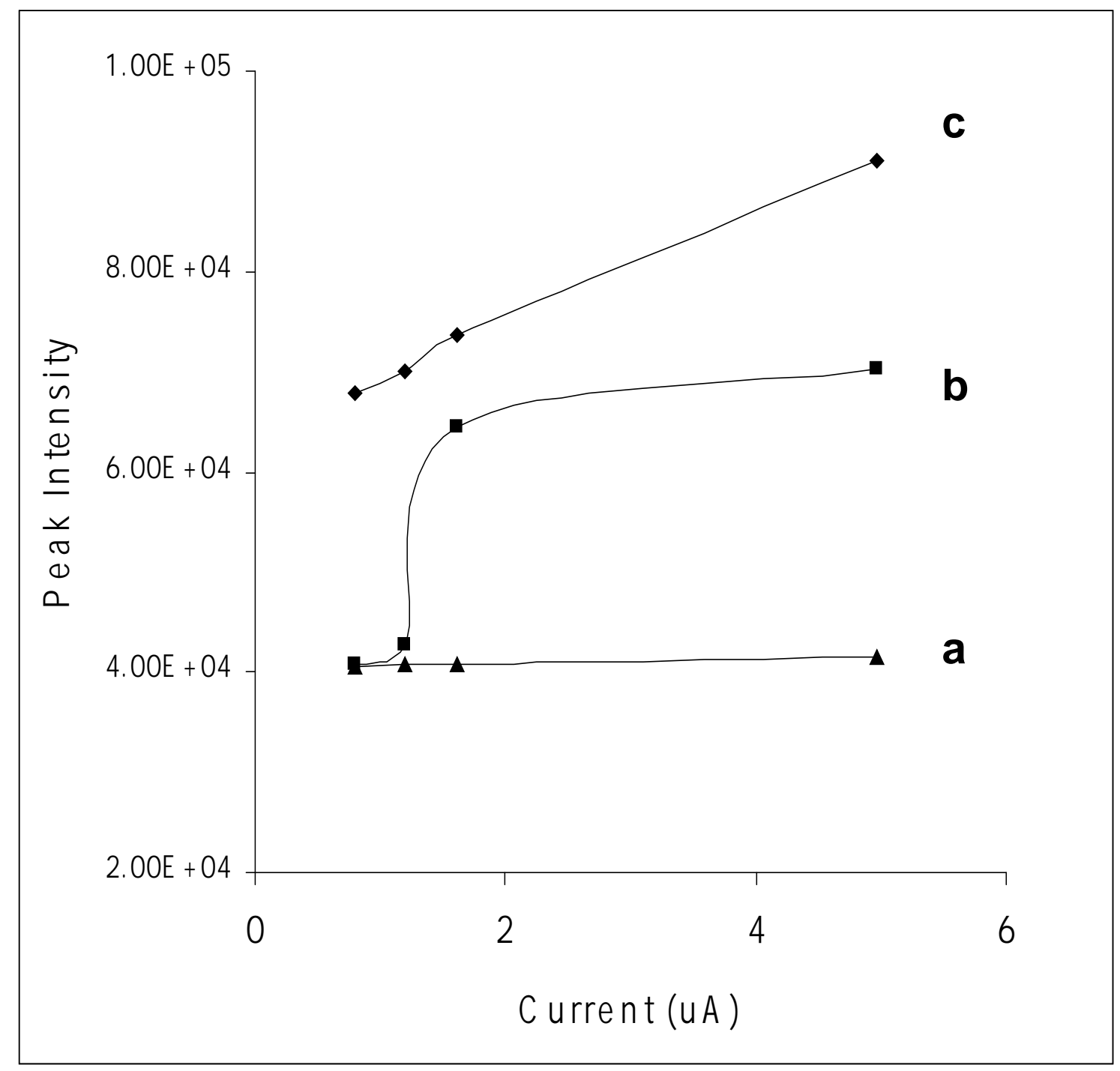

Figure. 6.4. Plots of ferrocenium ion current against the total current. Three curves are ploted at a) $0.5 \mu / \mathrm{min}$, b) $3 \mu / \mathrm{min}$, c) $5 \mu / \mathrm{min}$. 


\subsection{Conclusion}

Analytes dissolved in undiluted ionic liquids are initially studied by electrospray mass spectrometry. Mass spectra show the capability of electrospray to generate practical ion signals from the pure ionic liquids matrix. Electrospray behaviors of both oxidizable neutral species and their preformed ions are compared parallel. Mass spectra of preformed ferrocenium cations show that their signals are not suppressed by the concentrated solvent ions. The ratio of gas-phase ion intensities of the analyte to matrix ion is enhanced comparing to the solution concentration. It is due to the ion-pairing effects between the analyte ions and the solvent ions. Solvent ions with strong columbic forces with their counter ions are constrained to escape into gas-phase while the analyte ions with weak electrostatic force show enhanced signal. Electrospray of neutral ferrocene molecules produces strong mass spectrometric signal even better than that of preformed species due to the surface accumulation effect when the ionization is only taken place in the interface between electrode and sample solution. Insertion of resistance to upstream grounding circuit during electrospray of highly conductive sample will provide an approach to control the redox current and supply extra current to the electrochemical reaction. 


\subsection{Reference}

1. Hiroyuki Ohno Electrochemistry Aspects of Ionic Liquids, A John Wiley \& Sons: New York, 2005; p. 2.

2. C. Guerrero-Sanchez, S. Ulrich, Polymer Preprints (American Chemical Society, Division of Polymer Chemistry) 45 (2004), p. 321.

3. M. J. Muldoon, C. M. Gordon, Journal of Polymer Science, Part A: Polymer Chemistry 42 (2004), p. 3865.

4. Z. Fei, D. Zhao, R. Scoelliti and P. J. Dyson, Organometallics 23 (2004), p. 1622.

5. X. Mu, J. Meng, Z. Li, Y. Kou, Journal of the American Chemical Society 127 (2005), p. 9694.

6. U. Schröder, J. Wadhawan, R. Compton, F. Marken, P. A. Z. Suarez, C. S. Consorti, R. F. de Souza and J. Dupont, New J. Chem. 24 (2000), p. 1009.

7. S. Dai, Y. Ju and C. Barnes, J. Chem. Soc. Dalton Trans. 8 (1999), p. 1201.

8. L. S. Santos, R. Haddad, N. F. Höehr, R. A. Pilli and M. N. Eberlin, Anal. Chem. 76 (2004), p. 2144.

9. Y. Li, M. L. Gross, F. Hsu, Journal of the American Society for Mass Spectrometry 16 (2005), p. 679. 
10. M. abet-Moghaddam,R. Krueger,E. Heinzle, A. Tholey, Journal of Mass Spectrometry 39 (2004), p. 1494.

11. M. Mank, B. Stahl, G. Boehm, Analytical Chemistry 76 (2004), p. 2938.

12. S. Carda-Broch, A. Berthod, D. W. Armstrong, Rapid communications in mass spectrometry: RCM 17 (2003), p. 553.

13. D. W. Armstrong, L. K. Zhang, L. He, M. L. Gross, Analytical chemistry 73 (2001), p. 3679.

14. K. R. Seddon, A. Stark and M. Torres, Pure Appl. Chem. 72 (2000), p. 2275.

15. B. D. Fitchett, T. N. Knepp and J. C. Conboy, J. Electrochem. Soc. 151 (2004), p. E219.

16. T. Welton, Chem. Rev. 99 (1999), p 2071.

17. I. Romero-Sanz, R. Bocanegra and J. Fernandez de la Mora, M. GameroCastaño, J. Appl. Phys. 94 (2003), p. 3599.

18. (a) P. J. Dyson, J. S. McIndoe and D. Zhao, Chem. Comm., 4 (2003), p. 508. (b) D. Zhao, Aust. J. Chem. 57 (2004), p. 509.

19. Jackson, G. P.; Duckworth, D. C. Electrospray Mass Spectrometry of Undiluted Ionic Liquids. Chem. Comm. 2004, 5, 522-523. 
20. Lu Y, D. C. Duckworth, G. P. Jackson and F. L. King, 'Electrospray Mass Spectrometry of Room Temperature Ionic Liquids', PITTCON-2005; Orlando, FL.

21. Lu Y.; Duckworth D. C.; King F. L. manuscript submitted to J. Am. Soc. Mass Spec.

22. Lu Y.; Duckworth D. C.; King F. L. manuscript in preparation.

23. Tang, L.; Kebarle, P. Dependence of Ion Intensity in Electrospray Mass Spectrometry on the Concentration of the Aanalytes in the Electrosprayed Solution. Analytical Chemistry, 1993, 65(24), 3654-3668.

24. Van, G. J.; Zhou, F. Electrospray as a Controlled-Current Electrolytic Cell: Electrochemical Ionization of Neutral Analytes for Detection by Electrospray Mass Spectrometry. Analytical Chemistry, 1995, 67, 3958-3964.

25. Romero-Sanz, I., Bocanegra, R., Fermandez de la Mora Source of Heavy Molecular Ions Based on Taylor Cones of Ionic Liquids Operating in the Pure Ion Evaporation Regime. J. of Applied Physics, 2003, 94, 3599-3603. 